\title{
The world starts with me : promoting sexual and reproductive health and rights of adolescents in Uganda
}

Citation for published version (APA):

Rijsdijk, L. E. (2013). The world starts with me : promoting sexual and reproductive health and rights of adolescents in Uganda. [Doctoral Thesis, Maastricht University]. Datawyse / Universitaire Pers Maastricht. https://doi.org/10.26481/dis.20130905lr

Document status and date:

Published: 01/01/2013

DOI:

10.26481/dis.20130905Ir

Document Version:

Publisher's PDF, also known as Version of record

Please check the document version of this publication:

- A submitted manuscript is the version of the article upon submission and before peer-review. There can be important differences between the submitted version and the official published version of record.

People interested in the research are advised to contact the author for the final version of the publication, or visit the DOI to the publisher's website.

- The final author version and the galley proof are versions of the publication after peer review.

- The final published version features the final layout of the paper including the volume, issue and page numbers.

Link to publication

\footnotetext{
General rights rights.

- You may freely distribute the URL identifying the publication in the public portal. please follow below link for the End User Agreement:

www.umlib.nl/taverne-license

Take down policy

If you believe that this document breaches copyright please contact us at:

repository@maastrichtuniversity.nl

providing details and we will investigate your claim.
}

Copyright and moral rights for the publications made accessible in the public portal are retained by the authors and/or other copyright owners and it is a condition of accessing publications that users recognise and abide by the legal requirements associated with these

- Users may download and print one copy of any publication from the public portal for the purpose of private study or research.

- You may not further distribute the material or use it for any profit-making activity or commercial gain

If the publication is distributed under the terms of Article 25fa of the Dutch Copyright Act, indicated by the "Taverne" license above, 
Liesbeth

Rijsdijk

The World Starts

With Me

Promoting sexual and

reproductive health and

rights of adolescents

in Uganda 


\section{Colophon}

(C) 2013, Liesbeth E. Rijsdijk, Diepenveen, the Netherlands Lay-out Liesbeth Rijsdijk

Cover design Coen Temminck

Printing MultiCopy Apeldoorn

Universitaire Pers Maastricht 


\section{The World Starts}

With Me

Promoting sexual and

reproductive health and

rights of adolescents

in Uganda

Proefschrift

ter verkrijging van de graad van doctor aan de Universiteit Maastricht, op gezag van de Rector Magnificus, Prof. Dr. L.L.G. Soete volgens het besluit van het College van Decanen, in het openbaar te verdedigen op

donderdag 5 september 2013 om 12.00 uur door

Liesbeth Rijsdijk 


\section{Promotor}

Prof. dr. R.A.C. Ruiter

\section{Copromotores}

Dr. A.E.R. Bos (Open Universiteit, Heerlen)

Dr. R. Lie (Universiteit Wageningen, Wageningen)

\section{Beoordelingscommissie}

Prof. dr. H. Hospers (voorzitter)

Prof. dr. H.W. van den Borne

Dr. S. Cardey (University of Reading, United Kingdom)

Prof. dr. M.A. Koelen (Wageningen University \& Research centre Health and Society, Wageningen)

Dr. F.E.F. Mevissen

The The World Starts With Me study presented in this dissertation was funded by Rutgers WPF and the Westberg Foundation. 
"Mti hukunjwa wakati ungali mchanga" (Swahili)

(A stick is straightened while still young)

Ugandan proverb 



\section{Contents}

Chapter $1 \quad$ Introduction

Chapter 2 Correlates of delayed sexual intercourse and condom use among adolescents in Uganda: A cross-sectional study

Chapter 3 Sexual and Reproductive Health and Rights: Implications for comprehensive sex education among adolescents in Uganda

Chapter 4 Implementation of The World Starts With Me, a comprehensive rights-based sex education programme in Uganda

Chapter 5 The World Starts With Me: A multilevel evaluation of a comprehensive sex education programme targeting adolescents in Uganda

Chapter 6

General Discussion

References

Summary

Samenvatting

Dankwoord\Acknowledgements 



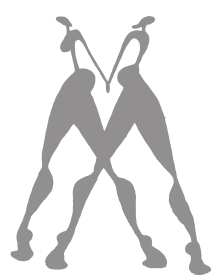

Chapter 1
Introduction 
As elsewhere, adolescents in Uganda are vulnerable when it comes to securing their sexual and reproductive health and rights (SRHR). Although universally declared, SRHR is a difficult and controversial issue in international contexts, especially when it concerns adolescents (Oronje, Crichton, Theobald, Lithur, \& Ibisomi, 2011). Both sexual and reproductive rights are based on human rights that are already recognized in national laws, international human rights documents and other relevant UN documents. One of the key strategies in the Plan of Action on Sexual and Reproductive Health and Rights (The Maputo Plan of Action) is addressing the sexual and reproductive health needs of adolescents and youth as a key SRH component (African Union Commission, 2006).

Sexual rights protect all people's rights to fulfil and express their sexuality and enjoy sexual health, respecting the rights of others and within a framework of protection against discrimination (WHO, 2010a). SRHR refer to the rights of all persons to the highest attainable standard of health in relation to sexuality. These rights include the right to seek, receive and impart information in relation to sexuality; the right to sex education; the right of respect for the bodily integrity; the right to decide to be sexually active or not and to marry or not and with whom; the right to decide whether or not and when to have children; and the right to pursue a satisfying, safe and pleasurable sexual life free of coercion, discrimination and violence (WHO, 2002).

A number of factors contribute to adolescents' SRHR vulnerability, both at the individual level (e.g., lack of awareness, insufficient knowledge about SRHR, negative attitudes, norms and low self-efficacy towards (safe) sexual behaviours) and at the contextual level (e.g. socio-cultural norms towards gender issues, low socio-economic status, legal framework). As a result, Ugandan adolescents, and in particular girls, are exposed to risks of early initiation of sexual intercourse, HIV/AIDS and STI infections, unintended pregnancies, and coercive sex (Neema, Musisi, \& Kibombo, 2004; Neema, Ahmed, Kibombo, \& Bankole, 2006; Lloyd, 2010; Cowan \& Pettifor, 2009).

Comprehensive rights-based sex education (CRSE) can play a major role in promoting SRHR for young people, by ensuring that they receive the necessary information and education to take their own well-informed decisions on sexuality and sexual behaviour (Kirby, 2007; Kirby, Obasi, \& Laris, 2006; Paul-Ebhohimhen, Poobalan, \& van Teijlingen, 2008; Gallant \& Maticka-Tyndale, 2004). The rights-based approach focuses 
on the attainment of rights within local cultural and power dynamics, emphasising social inclusion, equality, and empowerment (Braeken \& Cardinal, 2008). According to the International Planned Parenthood Federation (IPPF), a rights-based approach to comprehensive sex education, "[ . . . ] seeks to equip young people with the knowledge, skills, attitudes and values they need to determine and enjoy their sexuality physically and emotionally, individually and in relationships." (2010, p. 6).

CRSE is likely to be most effective when it is based upon theory- and evidence based needs assessments and intervention strategies (Kok, Schaalma, Ruiter, van Empelen, \& Brug, 2004; Schaalma et al., 2009; Bartholomew, Parcel, Kok, Gottlieb, \& Fernandez, 2011). Understanding the socio-cognitive determinants of safe sex behaviour helps to specify which behaviour and determinants should be addressed to obtain the desired health outcomes (e.g. delaying (first) sexual intercourse and using condoms when sexually active based on own well-informed decision making), to prioritize age-, gender- or other segments, and to select behaviour change methods that are tailored to the needs of the target population and fit the intervention context (Bartholomew et al., 2011). Chalmers, Aggleton, Ingham, \& Stone (2006) distinguish different contexts that should be considered when exploring young people's sexual health and the factors that may affect it: (1) political context including legal and policy issues; (2) socio-economic context including demographic patterns, patterns of employment and unemployment, and educational opportunities; (3) community context including cultural, religious and traditional influences on young people; (4) interpersonal context in which young people live their lives and negotiate their relationships; and (5) programmatic context in which responses to young people's sexual health needs take place. Both interpersonal and programmatic contexts are embedded in and influenced by the other three context levels: the political, socio-economic and community contexts. SRHR are considered universal, but if not connected to the local context in which they have to take form, CRSE runs the risk of remaining a 'paper reality' (Thomas, 2007). Understanding the socio-cultural, economic and political context in which sexual behaviour takes place helps to determine which multi-sectoral approach should be taken and which supporting environments should be promoted (Bartholomew et al., 2011, Chapter 3; Parker, 2001; Ingham, 2006). 
Although often portrayed as competing approaches (Parker \& Aggleton, 2003; Ingham, 2006), in the current dissertation the author takes the stand that both contextual and individualistic approaches towards understanding sexual behaviour and SRHR are valuable and can be used complementing to each other. Individuals do not behave in a vacuum (Ingham, 2006); their (sexual) behaviour takes place and is formed within a specific socio-cultural, economic and political context (i.e. social and structural determinants of SRHR). Gaining more understanding of both the socio-cognitive individual factors (e.g. intention, self-efficacy, risk perception, attitudes and norms) is therefore as important as understanding how the structural socio-cultural, economic and political context influences and impacts upon the individual behaviour and the choices a person makes and is able to make. Together these insights will give valuable input for theory- and evidence based intervention development. The other way around, that is the influence of individual behaviour, especially of important environmental decision makers like parents, religious leaders and policy makers, on the environment, i.e. in forming social norms (Bartholomew et al., 2011; Kok et al., 2012), is also of importance, but not the focus in this dissertation.

This dissertation reports on the results of different studies conducted to increase our insight in socio-cognitive determinants of safe sex behaviour among Ugandan adolescents, to explore the views of Ugandan adolescents on SRHR in their own daily socio-cultural, economic and political context, and to assess the effectiveness and implementation context of the comprehensive rights-based sex education programme The World Starts With Me implemented in Uganda among secondary school students.

\section{Sexual and reproductive behaviour and health of Ugandan adolescents}

Adolescents (age 13-19) are generally curious. They want to experiment and explore life, including their sexuality and sexual life, which is often accompanied by risk taking behaviour. This is a universal and completely normal process in human development. However, early sexual debut, especially among girls, is associated with coerced sex (Pettifor, O’Brien, MacPhail, Miller, \& Rees, 2009; Koenig et al., 2004a; Koenig et al., 2004b) and with a higher likelihood of sex with high-risk (multiple) partners without 
using condoms (WHO, 2010b; Koenig et al., 2004a; Pettifor, van der Straten, Dunbar, Shiboski, \& Padian, 2004). In predominantly low and middle-income countries, coerced sexual initiation is also associated with HIV/STIs (Stockman, Lucea, \& Campbell, 2012). As such, early sexual debut increases the risks of unintended pregnancies, HIV and other sexually transmitted infections (STIS).

Based on Ugandan DHS data, Slaymaker et al. (2009) show that women born after the 1980s are delaying sexual debut compared with earlier cohorts (born before 1980), although the trend is less clear in men. This finding is confirmed by a cross-sectional study by Biraro et al. (2009), suggesting a clear delay in age at first sex in Ugandan women but less clear changes in Ugandan men. Despite an increased delay of sexual intercourse, still more than one tenth (12\%) of young Ugandan women and almost one fifth (18\%) of young men between the age of 15 and 19, had their first sexual intercourse before the age of 15 (UBOS, 2012). Among the age group 20-24 years, the vast majority (58\%) of women and $43 \%$ of the men had become sexually active by age 18 (UBOS, 2012). A comparison of the percentages of women (aged 20-24), who started sexual intercourse by the age of 18 years in the period 1994-2003 shows that Uganda was among the highest in Sub-Sahara Africa (SSA): $73.5 \%$ of this group had their first sexual intercourse before the age of 18 (Mensch, Grant, \& Blanc, 2006).

When sexually active, most Ugandan adolescents do not use a condom. The Demographic Health Survey conducted in 2005 among a national sample of 4.643 Ugandan adolescents aged 15-24 years (3.646 female and 997 male), showed that only $28 \%$ who ever had sex $(N=2.970)$, used a condom at first sex, with a slight difference between boys (29\%) and girls (27\%) (UBOS and Macro International, 2007). Consequently, teenage pregnancies are a major concern, estimated at 25\% in 2006 (UBOS and Macro International, 2007) and at 24\% in 2011 (UBOS, 2012). The Uganda percentage is as high as that of the UK $(26.7 \%)$, where teenage pregnancy rates are among the highest of Europe, but lower than the US, that scores highest in the world with a $41.9 \%$ teenage pregnancy rate (UN, 2006). Despite declining fertility rates among teenagers aged 1519 years old from 178 (per 1000 women) in the 2000-01 Ugandan Demographic Health Survey (UDHS) to 134 (per 1000 women) in the 2011 UDHS (UBOS, 2012), these rates are still among the highest in SSA (WHO, 2010b). More than one-third (39\%) of women 
age $20-49$ gave birth by age 18 , and almost two-third (63\%) by age 20 . In $2011,24 \%$ of Ugandan women age 15-19 were mother or pregnant with their first child (UBOS, 2012).

In general, teenage pregnancy has huge social and reproductive health consequences, such as negative effects on the socio-economic status and higher morbidity and mortality rate for both mother and child (Singh, 1998; UNFPA, 2007). Since the introduction of universal primary education instituted by the Ugandan government, girls who get pregnant are allowed to return to school after delivery (Neema et al., 2004). However, many pregnant girls are still expelled from school because current school policy is to have pregnant girls terminate their education (UBOS, 2012). Furthermore, abortion in Uganda is highly restricted by law (Neema et al., 2004), and consequently access to safe abortion is extremely limited, especially for unmarried girls. Of the approximately 117,000 unsafe abortions that occur annually, $55 \%$ are done among $17-20$ years old girls, with serious complications (23\%) even leading to death (2\%).

Unprotected sexual intercourse also comes with the risk of getting HIV infected. Uganda is often mentioned as the success story when it comes to responding to the HIV/AIDS epidemic in the late nineties and the beginning of 2000 (Green, Halperin, Nantulya, \& Hogle, 2006; UNAIDS, 2004; Kirby \& Halperin, 2008). The national prevalence rate of $18 \%$ in 1993 dropped to $6 \%$ in 2000 and is now at a 6.7\% (UAC, 2012). HIV prevalence among young people aged 15-24 years has decreased to levels under national figures (UNAIDS, 2012). Gender plays a prominent role, as girls are at much higher risk than boys: the HIV prevalence among girls is four times higher compared to boys ( $4.3 \%$ and $1.1 \%$ respectively; UAC, 2010$)$.

The success of Uganda's early response to the HIV/AIDS epidemic is generally ascribed to a strong political leadership in mobilising a broad-based response to the epidemic, a strong multi-sectoral, decentralised and community response, and open dialogue right at the start of the epidemic (PANOS, 2003; UAC, 2012). However, there are indications that HIV prevalence in Uganda may be increasing again. Recent research and trend analyses show an increase in risk-taking behaviours, particularly in multiple sexual partnership and non-spousal sex (Opio et al., 2008), a general decrease in condom use (UNAIDS, 2012), specifically in non-spousal sex among men (Wabwire-Mangen, Odiit, Kirungi, Kisitu, \& Wanyama, 2009). 
In conclusion, Ugandan adolescents, especially girls, face severe sexual and reproductive health problems. They run the risk of unwanted pregnancy and STI/HIV infection by having (coerced) unprotected sexual intercourse at a young age. Knowing the socio-cognitive determinants of safe sex behaviour, i.e. delaying sexual intercourse or using condoms when sexually active, is important to inform CRSE on which aspects to focus.

\section{Socio-cognitive determinants of safe sex behaviour}

Choices relating to safe sex behavioural options, such as delaying sexual intercourse for the first (primary delay) or second time (secondary delay) and using condoms when having sex, requires some form of planning and forethought. Therefore, socio-cognitive theories and models are often used to determine factors that can explain and predict safe sex behaviour. The Theory of Planned Behaviour (TPB; Ajzen, 1991) is such a theory that is often used in informing objectives for sexual and reproductive health interventions.

The TPB (Ajzen, 1991) and its recent successor the Reasoned Action Approach (RAA) (Fishbein and Ajzen, 2010) both contend that the intention to perform a certain behaviour is the most important immediate antecedent of behaviour, although control performance of the behaviour has to be taken into account as well (Albarraci'n, Johnson, Fishbein, \& Muellerleile, 2001). Both TPB and RAA state that behavioural intention is a function of attitudes, norms and perceived behavioural control towards the behaviour. Attitude is defined as "a latent disposition or tendency to respond with some degree of favorableness or un-favorableness to a psychological object" (Fishbein \& Ajzen, 2010, p. 76). The RAA differs from the TPB in the way norms are defined. The TPB refers to subjective norms as a person's perception that important others prescribe, desire or expect the performance or non-performance of a specific behaviour. The RAA has expanded the concept to perceived social norms, which is considered a function of beliefs that specific, important individuals or groups (e.g. friends, parents, one's girlfriend, one's husband) approve or disapprove of a certain behaviour (injunctive norms) as well as beliefs that these referents themselves perform or do not perform that specific behaviour (descriptive norms). Self-efficacy, also termed per- 
ceived behavioural control, refers to "the extent to which people believe that they are capable of, or have control over, performing a given behaviour" (Fishbein \& Ajzen, 2010, p. 155).

In the United States and Western Europe, research on the adoption of many health-related behaviour has been conducted that supports the TPB (Godin \& Kok, 1996; Armitage \& Conner, 2001), including condom use (Sheeran, Abraham, \& Orbell, 1999; Sheeran \& Taylor, 1999; Bennet \& Bozionelos, 2000; Schaalma, Kok, \& Peters, 1993; Jemmott \& Jemmott, 2000; Gredig, Nideroest, \& Parpan-Blaser, 2006) and delay of sexual intercourse (Carjaval et al., 1999; Santelli et al., 2004; Buhi, Goodson, Neilands, \& Blunt, 2011).

As unsafe sexual behaviour is also an important health risk among adolescents in SSA (Kaaya et al., 2002; Neema et al., 2004), studies on the socio-cognitive determinants of (the intention of) delaying sexual intercourse and (the intention of) condom use in an African setting can give major insights on which elements to target in an educational intervention.

\section{Determinants of initiating and delaying sexual intercourse in a Sub-Saharan Africa context}

Only a few studies can be found on (socio-cognitive) predictors of initiating sexual intercourse or on delaying sexual intercourse among adolescents in a SSA context. A study based on the Information-Motivation-Behavioural Skills framework (Fisher \& Fisher, 1992) conducted among young Kenyans showed that the likelihood of initiating sexual intercourse correlated with the inability to reject common local myths about HIV transmission and prevention, with experiencing more pressure to engage in sex and with knowing someone who had died of AIDS. Furthermore, boys with a lower self-efficacy to abstain were also more likely to initiate sexual intercourse.

Results from a survey among in- and out-of-school urban youth $(N=561)$ in Ethiopia showed that being out-of-school, male, aged 20-24, and using alcohol and khat (an amphetamine-like substance) predicted the likelihood of sexual activity (Taffa, Klepp, Sundby, \& Bjune, 2002). Using alcohol was also found to correlate positively with sexual intercourse among Rwandan adolescents, as well as high self-esteem 
(for boys) and the perceived sexual activity of peers (both boys and girls). Perceived self-efficacy to refuse sex with someone truly loved, perceived self-efficacy to refuse sex with someone known for more than three months, and negative attitudes towards premarital sex were negatively correlated with sexual intercourse (Babalola, Awasum, \& Quenum-Renaud, 2002).

A study among sexually active unmarried Ugandans aged 15 to 24 showed that, after initiating sexual intercourse, some adolescents decided to abstain from sex until they are older, married, or have a paid job (Tumwesigye, Ingham, \& Holmes, 2008). Nearly two thirds of the sexually active respondents abstained for three months, slightly less than half abstained for six months and $18 \%$ abstained for twelve months. Whether they abstained purposively with a sexual partner, or because they did not have a sexual partner, is not known. Taking alcohol, going to parties and talking to parents about sex, were found as associating factors with discontinuation of secondary abstinence. Secondary abstinence is more common in SSA than in other regions of the world (Khan \& Mishra, 2008), because of fear of getting pregnant (females), not having a partner (males), and fear of HIV and other STIs (both males and females).

\section{Determinants of condom use in a Sub-Saharan Africa context}

In African countries, more studies can be found on socio-cognitive determinants of the intention to use condoms than on (secondary) delay. These studies largely support TPB, which is in line with research conducted in western contexts (Sheeran et al.,1999; Bennet \& Bozionelos, 2000; Albarracı'n et al., 2001). Attitudes, social norms, and the perceived behaviour control or self-efficacy towards condom use are found to be significant predictors of the (intention) to use condoms (Lugoe \& Rise, 1999; Bryan, Kagee, \& Broaddus, 2006; Schaalma et al., 2009; Gilles, Liddell, \& Bydawell, 2005; Bosompra, 2001; Taffa et al., 2002). In their study on predicting condom use among high-school students in South Africa, Eggers, Aarø, Bos, Mathews, \& de Vries (2013) showed that self-efficacy did not predict condom use directly but indirectly via intention.

A comparative study conducted among university students in South Africa and the US shows that subjective norm and attitudes explain more variance in intention to 
use condoms in the American sample than the South African sample, but self-efficacy was found to be a stronger predictor to intention of condom use in the South African sample (Heeren, Jemmott, Mandeya, \& Tyler, 2007).

What these studies show in general, is that the social cognition models, such as the TPB, are useful in different geographical contexts for identifying determinants of condom use intentions, including a SSA context (see also Albarracín et al., 2001). What these studies also show is that the relative importance and the content of the TPB variables do differ across context, behaviour and population concerned (Fishbein, 2000). For instance, using condoms could be primarily determined by attitudes in one culture or specific population, and normatively driven in another culture or population. Also the content of the determinant could differ across context: perceived social norms in an African context seem to be more related to what the family thinks, whereas in an European context peers play a more important role (Giles, Liddell, \& Bydawell, 2005). In addition to measures of attitude, subjective norm and perceived behavioural control/self-efficacy, variables from other social cognition models, like the Health Belief Model (e.g. perceived risk), but also knowledge of risks of unprotected sex, HIV and ways of transmission seem to be important factors in explaining condom use in SSA (Ukwuani, Tsui, \& Suchindran, 2003). A study among South African adolescents showed that for girls, the level of correct information they had about HIV transmission and the use of condoms to prevent HIV, was significantly correlated with attitudes towards condom use. Also, in the same study, positive outlook, being a combination of a measurement of self-esteem and positive future orientation, was included as a precursor of self-efficacy and seemed to be significantly correlated with self-efficacy, positive attitudes towards condom use and perceptions regarding norms of condom use (Bryan et al., 2006). In a study among non-spousal partnerships in four cities in SSA (i.e. Yaoundé, Cameroon; Cotonou, Benin; Ndola, Zambia; and Kisumu, Kenya), educational level was found to be the primary determinant of condom use; the higher the educational level, the higher the chance that a condom was used during sexual intercourse (Lagarde et al., 2001). 


\section{Socio-cultural, economic and political context of sexual behaviour}

Individualistic socio-cognitive theories have limitations when it comes to gaining an in-depth understanding of (reasons for unsafe) sexual behaviour. They emphasize individual cognitive processes and the subjective aspects of social influences and are in essence based on the assumption that individuals take rational decisions related to (sexual) health behaviour whereas in reality many factors influence young people's (non-volitional) sexual behaviour and decision making (Aarø, Schaalma, \& Åstrøm, 2008). As such, these theories ignore the wider and diverse social, cultural, economic and political structural factors that influence or even shape sexual behaviour and decision making, such as lack of access to condoms, power differences between genders, poverty, stigma and taboo (Parker \& Aggleton, 2003; Ingham, 2006). The debate transcends the boundaries between Psychology, Sociology and Anthropology. In general, psychologists emphasize the individualistic socio-cognitive approach towards understanding human behaviour, whereas sociologists and cultural anthropologists take a more holistic contextual approach (Ingham, 2006).

In the 1990's researchers began to focus on the interpretation of cultural meanings, rather than on calculating behavioural frequencies such as how many adolescents use a condom at first sex, in order to better understand risky sexual behaviour in different socio-cultural settings in the context of the HIV and AIDS epidemic (Parker, 2001). Also, more and more attention was being given to structural factors influencing risky sexual behaviour, such as economic situation. The critique is not so much on the use of the health-behavioural models to explain human behaviour per se, but more specifically on the assumption that “(...) more broad-based prevention programs could be developed in order to persuade individuals to change their behaviours in ways that would ultimately reduce the risk of HIV infection." (Parker, 2001, p. 165).

Contextual factors are also important determinants of sexual behaviour in SSA. A review of the analysis of sexual behaviour data from 59 countries, including Uganda, shows a huge diversity in sexual behaviour by region and sex, indicating mainly social and economic determinants of sexual behaviour (Wellings et al., 2006). The authors conclude that although individual behaviour change is central to improving sexual health, efforts are also needed to address these structural determinants. 


\section{Contextual factors of sexual behaviour among Ugandan adolescents}

In the Ugandan socio-cultural context, talking about sexual matters among young people and adults is often considered taboo. When adolescents ask questions on sexuality issues, they will be suspected of being sexual active. This is considered to be one of the reasons why young people do not often consult medical personnel at local clinic-based health centres (Nobelius et al., 2010). Although the operation of an effective decentralised health service delivery system with a focus on strengthening district health systems is one of the priority areas of the Ugandan government, the actual access for young people to sexual and reproductive health services is limited, due to fear, embarrassment and shyness, not knowing where to obtain the required services, and costs and distance (Darabi et al., 2008).

In Uganda, socio-cultural and religious norms promote abstinence until marriage. However, as in many other societies, a double standard concerning sexuality is prevalent, whereby girls are expected to be modest, tender, submissive and passive, while boys are "encouraged to engage in behaviours that assert their masculinity, autonomy, assertiveness, activity and ambition " (Muhanguzi, 2011, p.714). Such sexual double standards constrain girls' sexual authority and self-determination (Wolff, Blanc, \& Gage, 2000), while reinforcing boys' view of being in control of sexual relationships (Muhanguzi, 2011).

The economic disadvantaged position most Ugandan adolescents are in also has implications for sexual self-determination. Compared to other SSA countries, the prevalence of exchanging money and gifts in return for sex, referred to as "transactional sex", is high in Uganda (Luke \& Kurz, 2002; Nyanzi, Pool, \& Kinsman, 2010). Three-quarters of adolescent unmarried women said they had received gifts or money in exchange for sex from their sexual partner, and one-third of adolescent males reported having received gifts or money for sex from their sexual partner (Neema, Musisi, \& Kibombo, 2004). Also, cross-generational relationships between older men and younger women or, less commonly, between older women and younger men are prevalent in Uganda. Approximately 30\% of 15-24 years old Ugandan females are involved in (transactional) relationships with men who are at least 10 years older (Darabi et al., 2008). This enhances risky sexual behaviour - such as non-use of condoms, and 
having concurrent multiple sex partners (Kelly et al., 2003). A growing number of studies address this issue, whereby it is often assumed that poverty and power inequality force girls to have (unprotected) sex with older men (Amuyunzu-Nyamongo, Biddlecom, Ouedraogo, \& Woog, 2005).

In general, the Ugandan political context is not supportive of promoting sexual rights for young people. The defilement law prohibits sexual intercourse under 18 , and the Ugandan Government also does not support the promotion of condom use among adolescents. In such a socio-cultural, economic and political context, the right to complete and accurate information on SRHR and the right to sexual self-determination of young people are hard to exert.

\section{Comprehensive rights-based sex education}

SRHR for young people include the right to make their own well informed choices on when to start having sex (at what age), how often, with whom (e.g. same sex or opposite sex), and how (e.g. using condoms, contraceptives or nothing) (IPPF, 2003). To make a well informed choice to delay sexual intercourse until one feels ready to have sex, and to use condoms to protect oneself from unwanted pregnancy and infections, is therefore part of the sexual and reproductive health rights of young people. 'Being ready' varies for each person and hence the decision to have sex should be a consensual decision between the sexual partners. Also the choice not to have sex, to delay sexual intercourse or to abstain due to for instance limited access to (good quality) condoms, even when someone is ready for it, is the right of the individual. This right to self-determination is formulated as follows by The Swedish Association for Sexuality Education: "Young people are in their right to have sexual relations because they are in love and have sexual desire. They have the right to feel lust and joy in their sexuality, and the right to say 'Yes' or 'No' to sex on the basis of their own will and desire. Thus, they also have a right to the knowledge they require to take wise decisions." (Sjödahl, 2004, p. 5).

School-based sex education can play an important role in enabling young people to make these well-informed choices relating to their sexual and reproductive health. Worldwide, more and more youth are enrolled in school before and when they initiate 
sex and schools are mostly the one institution in a country that is regularly attended by many young people. As such, school-based sex education programmes have the potential to address young peoples' SRHR, reduce adolescents' sexual risk taking behaviour and promote consensual safe sexual behaviour (Kirby, 2011).

Given the high rates of school enrolment in Uganda ( $96 \%$ of females and $98 \%$ of males ever attending school), comprehensive rights-based sex education at schools is an important strategy to address young peoples' SRHR. Almost half (42\%) of the adolescents (aged 12 to 14 years) who attended school $(N=2556)$ said that their school offered sex education classes or talks, increasing to $60 \%$ of the adolescents aged 15-19 years $(N=2615)$. An additional $10 \%$ had attended schools where they were offered classes on sex education, but they did not attend. Of those who had attended classes in sex education, the majority ( $87 \%$ of young women and $74 \%$ of young men) reported attending prior to their first sex (Neema et al., 2006).

Internationally, there is a wide diversity of definitions and framing of sex education. In the US, comprehensive sex education is opposed to abstinence only programmes (Kirby et al., 2006; Kirby, 2008; Bleakly, Hennessy, \& Fishbein, 2006; Collins, Alagiri \& Summers, 2002). As such, comprehensive sex education is defined as "abstinence-plus" programmes that "emphasize abstinence as the safest behaviour but also promote the use of condoms or other forms of contraception for those who do have sex." (Kirby, 2008, p.18). However, since 1994, when reproductive health and gender equality were specifically placed in a human rights-based framework in the Cairo Programme of Action (UN, 1995), the so-called rights-based approach towards sex education has emerged and has gained more and more popularity, especially among Western-based, non-US, donors.

According to UNESCO (2009), comprehensive sex education is more than abstinence-plus; it aims at "providing clear, well informed, and scientifically-grounded sexuality education based in the universal values of respect and human rights." (UNESCO, 2009 , p. iii). In this definition of comprehensive sex education, the notion that young people, whether they are girls or boys, hetero-, homo-, or bisexual, regardless their socio-economic or cultural background, have sexual and reproductive rights is central. Braeken and Cardinal (2008) argue that the rights-based approach is one of three main 
approaches combined in comprehensive sex education. The other two are (1) a morality approach (enabling young people to develop their own values and to make their own personal choices, while appreciating the impact their choices can have on others) and (2) a health promotion approach (focusing on sexual and reproductive health outcomes from a medical and technical perspective). The rights-based approach focuses on human rights issues and power dynamics within (intimate) relationships, and aims at empowering young people, improving personal expression and self-respect, and increasing satisfaction, communication, safety and health (UNFPA, 2010).

\section{Sex education in Uganda}

As early as 1987, Uganda introduced AIDS education in primary schools, being one of the first countries in the world to do so (Baldo \& Uzamugunda, 2000). The Ugandan Ministry of Education and Sports (MoES) aims to provide all students with life-skills and age appropriate, accurate, complete and scientifically factual information on HIV/ AIDS (MoES, 2006). Biology and Religion classes (Christian and Muslim), as part of the Uganda Ordinary Certificate of Education, address reproductive health and marriage. In some schools, classes on Social Etiquette and Moral Education are being taught aiming at developing moral values and norms related to sexuality matters (Muhanguzi \& Ninsiima, 2011). A number of sex education programmes have been implemented in schools at different levels, including programmes from the Straight Talk Foundation and anti-cross generational sex campaigns.

The main sex education programme implemented at primary and secondary schools in Uganda, however, is PIASCY, the President's Initiative on HIV/AIDS Strategy on Communication to Youth (Government of Uganda, 2010). Since November 2004, in line with the US President's Emergency Plan for AIDS Relief (PEPFAR) strategy at that time, the Ugandan Ministry of Education decided not to promote condoms in schools any longer. Consequently, PIASCY, co-funded by PEPFAR, focuses mainly on promoting delay of sexual intercourse until marriage and abstinence only (Cohen \& Tate, 2006; Iyer \& Aggleton, 2012). Similar trends were observed in other SSA countries, like Kenya (Njue, Nzioka, Ahlberg, Pertet, \& Voeten, 2009). The resistance against condom use and also against comprehensive sex education is based on the fear that condom pro- 
motion and sex education evoke earlier sexual initiation, a fear which is not supported by research evidence (Kirby, 2007; Yeboah \& Maticka-Tyndale, 2008).

The focus on abstinence only is also not in line with the international recognition that young people are sexual human beings with a right to self-determination, education and information, youth-friendly services, protection and participation as declared at the International Conference on Population and Development (ICPD) Programme of Action (UN, 1995). This Programme of Action included several formulations highlighting the link between young people and SRHR. An example of this link is the obligation of states to protect and promote young people's right to sex education, information and health services and to establish, in cooperation with non-governmental organisations (NGOs) appropriate programmes, including education and counselling of adolescents in the areas of gender relations and equality, violence against adolescents, responsible sexual behaviour and family-planning practice and reproductive health (PoA7.45-46).

\section{The effectiveness of school-based sex education}

Several reviews (Kirby et al., 2006; Ross, Dick, \& Ferguson, 2006; Kirby, 2011) show that curriculum- and group-based sex education programmes in both developed as developing countries can be effective in promoting safe sex behaviour among adolescents (i.e. delay sex, reduce the frequency of sex, reduce the number of partners, increase condom use, increase overall contraceptive use and reduce unprotected sex). These reviews also show that comprehensive school-based sex education programmes that promote condom use among young people do not evoke earlier sexual initiation, nor an increase in sexual activity, as many of the critiques of comprehensive sex education fear. To the contrary, several studies show that comprehensive sex education leads to responsible safer sexual behaviour among young people (Kirby, 2002b, 2007, 2008), also in a SSA setting (Yeobah \& Maticka-Tyndale, 2008; Fitzgerald et al., 1999).

Different authors and organisations (Kirby, 2006; Kirby, 2009; Alford, 2003; Alford, 2008; UNAIDS, 1997) have identified critical characteristics of effective (curriculum-based) sex education and HIV/STI prevention education programmes. These characteristics relate to the development, the content and the implementation of these 
programmes. Effective programmes are based on a logic model approach, involving members of the target community, especially adolescents, and people with different backgrounds in theory, research, and sex and STD/HIV education. Important in the development stage is that activities are designed that are consistent with community values and available resources (e.g., staff time, staff skills, facility space, supplies).

Looking at content, effective programmes have clear goals for preventing HIV, other STIs, and/or teen pregnancy, and contain clear messages about specific health behaviours related to these goals. Activities and teaching methodologies should be used that create a safe social environment for youth to participate, that are appropriate to the youths' culture, developmental age and sexual experience, and help them to personalize the information. Effective sex-education programmes cover topics in a logical sequence, addressing psychosocial risk and protective factors with evidence-based change techniques. Apart from providing medically accurate information about both abstinence and contraception, including condoms, effective programmes assist youth in clarifying their individual, family, and community values as well as in developing skills in communication, refusal, and negotiation.

For the implementation of sex education programmes, it is important to secure support from appropriate authorities such as departments of health or education, school districts, or community organizations and to select and train teachers, providing them with continuous supervision and support. Also, to successfully implement the program it might be necessary to implement activities to recruit and retain youth and overcome barriers to their involvement. Finally, effective programmes implement virtually all activities with reasonable fidelity.

Review studies focusing specifically on the effectiveness of school-based sex education programmes implemented in a Sub-Saharan context (Gallant \& Matycka-Tyndale, 2004; Paul-Ebhohimhen et al., 2008) show a greater impact on knowledge and attitudes than on reported safe sexual behaviours. Pre-intervention sexual history of the target group greatly influences behaviour change in favour of abstinence (virgins at baseline) and condom use (non-virgins at baseline) (Paul-Ebhohimhen et al., 2008). In a review of a wide variety of HIV prevention interventions in South Africa, Harrison, Newell, Imrie, \& Hoddinott (2010) concluded that the effects of most interventions on 
sexual risk behaviour or biological outcomes were limited. However, the following factors seem to enhance intervention effects: (1) focus on at least one social or structural risk factor (e.g., poverty or alcohol abuse), (2) using group-based delivery to change social norms, (3) relieving the burden on teachers by using additional personnel, e.g., from outside the school-setting, when intervention is school-based, and (4) directing intervention efforts at the school as well as individual level. Of the five school-based interventions reviewed, four experienced serious implementation problems, challenging fidelity of implementation, which lead to the recommendation to give top priority to improve the implementation process of school-based intervention models in a Sub-Saharan context (Harrison et al., 2010).

\section{The World Starts With Me}

In 2002 and 2003, the World Population Foundation (WPF) and Butterfly Works (both Dutch NGO's), together with SchoolNet Uganda (SNU; Ugandan NGO), developed the comprehensive rights-based sex education programme The World Starts With Me (WSWM). It is one of the 18 curricula underlying UNESCO's technical guidance on sexuality education (UNESCO, 2009), and addresses the SRHR needs of adolescents.

WSWM is a low-tech, computer-based interactive sex education programme aimed at secondary school students (age 12-19) and developed by drawing from a combination of (evidence-based) approaches in sex education (e.g. rights-based, health promotion, behaviour change, and adolescent developmental approaches), aiming to empower and support young people in making their own, informed decisions about sex.

The theoretical foundation of WSWM stems largely from two social-psychological theories focusing on determinants of behaviour: the theory of planned behaviour (TPB) (Ajzen, 1999, 2002; Fishbein \& Ajzen, 2010) and the Health Belief Model (HBM) (Becker, 1974). Extensive use was made of the experience of the Dutch evidence-based programme "Long Live Love" (Schaalma et al., 1994), and of materials of existing sex education programmes of Rutgers WPF Vietnam, United Nations Children's Fund (UNICEF) Namibia and Straight Talk Uganda.

The experiences with the implementation of past programmes indicated that young people need programmes that are accessible, non-judgemental, and responsive 
to what young people want (McCauley, Salter, Kiragu, \& Senderowitz, 1995; Hughes \& McCauley, 1998). WSWM is based on the same principles, combining the need of young people to develop computer skills and creative expression, and at the same time focusing on SRHR.

The programme aims to empower young people to make their own responsible choices and perceive young people as the actors and social agents of change instead of mere recipients of messages. Therefore, WSWM adheres to the following five rights-based principles: (1) openness and acceptance of young people's sexuality, not on taboos; (2) a positive, non-judgmental approach towards sexuality, not on fear or control; (3) equity in gender and sexual orientation; (4) the right of young people to complete and accurate information, to self-determination and protection; and (5) active participation of young people in all stages of programme planning and implementation (Leerlooijer et al., 2011). The main behavioural goals of WSWM are to delay sexual intercourse; increase other sexual activities than sexual intercourse; increase use of condoms if sexually active and decrease coercive sex among young people.

To ensure that relevant stakeholders participated in the development of WSWM, a Goals and Development Group was established, consisting of IT-experts, artists, youth workers, reproductive health trainers, teachers and secondary school students from Uganda. As a group, they provided insight in and input on for instance the feasibility of the proposed intervention strategy (computer-based; extra-curricular) and vehicles through which to deliver the programme (e.g. making use of (digital) peer educators, role play, interactive games and quizzes) (Leerlooijer et al. 2011). The main reasons for the Goals and Development Group to opt for computer-based intervention was the extra motivational power this would give students in learning how to work with a computer, which would be of great added value at the labour market. In addition, computer-based assignments and interactive lessons unburdens the workload for teachers, which is quite an important implementation factor in a context where teachers and curricula are overloaded and the programme is extra to the existing curriculum. Also, computer-based lessons unburden teachers from initiating discussions about sensitive issues such as sexuality. SchoolNet Uganda is the implementing partner, which mission is "(...) to support the introduction of Information Communication Technology (ICT) in 
Ugandan schools and to build the schools' and teachers' pedagogical capacity to optimally use the ICT resources in the schools (...)" (SchoolNet Uganda, n.d.).

A meta-review of studies testing computer-based interventions in a Western (US) context aiming at increasing condom use among a variety of at-risk populations showed similar efficacy as human-delivered sexual education interventions (Noar, Black, \& Pierce, 2009). The use of computers in sex education programmes not only enables adolescents to learn healthy and responsible behaviour and life skills, but also to develop their creative and IT skills in preparation for job opportunities.

WSWM uses virtual peer educators, David and Rose, who are the main sources of knowledge and who guide secondary school students in their learning process. The lessons usually start with a theme-based warming up activity, followed by a presentation by Rose and David. The next step is often a game (such as the 'body change game', the 'personality game', the 'who is responsible' game or the 'safe sex quiz'), which serves to help students internalize information and explore opinions. The main part of most lessons is the assignment, for example creating a storyboard, an art work or conduct a role-play addressing the topic of that specific lesson. WSWM was designed for a setting, like in Uganda, where the computers used in schools tend to be basic and where four to five students have to share one computer. However, as many schools do not have (enough) computers WSWM also allows students to read the information and to do the assignments and exercises without the computer, using hard copy manuals. This way the same learning objectives can be met as when WSWM is followed using a computer, although the extra incentive of developing computer skills is lost. WSWM is carried out in English, which is the official language of Uganda. The role of the teachers is to facilitate the process of learning, coach students to explore opinions, and practise skills by using role play, creating story boards, art work, and other (digital) means. Teachers are required to guide students in a non-judgmental way, acknowledging the rights of young people to gain information and make their own decisions when it comes to their sexuality. To facilitate teachers in this new role, they receive a training lasting 5 to 6 days prior to implementing WSWM in their schools. 
The programme consists of 14 lessons, divided into four sections (see Table 1.1 for an overview of the WSWM lessons). The first section aims to build self-esteem and personal decision-making, gaining insights into a person's identity and sexual development. Personal values and norms are addressed as they form a basis for learning to make personal decisions. In the second section, the role of the social environment (e.g. peers, family, close friends, teachers, and media), gender equity and sexual and reproductive rights are addressed, in order to teach young people to cope with social influences on their own decision making. The third section addresses sexuality as something beautiful, as a vital source for life, but also addresses sexual health problems and the life skills necessary to know how to avoid or deal with them. The fourth section focuses on applying lessons learned about goal setting regarding the students' future and on making booklets for use in peer education. The curriculum closes with an exhibition at which young people show their parents and the community the results of the class efforts, such as slogans, posters, and action plans.

WSWM was first introduced in 30 secondary schools in Uganda in September 2003 as a club-based, extra-curricular programme. In subsequent years, the programme has been introduced in more than 150 schools throughout the country, reaching approximately 15.500 secondary school students in 2009 . Since the start, 422 secondary school teachers and 120 peer educators have been trained (WPF, 2010). 
Table 1.1 Overview of "The World Starts With Me" Curriculum

Lesson Topic
Section 1: Self-esteem and decision making

1 The World Starts With Me

2 Emotional Ups and Downs

3 Is Your Body Changing Too?
Building self-esteem, insight into own sexual development

Exploring processes of autonomy and own norms \& values

Body changes

Section 2: The social environment

$4 \quad$ Friends and Relationships

5 Boys and Girls, Men and Women

$6 \quad$ Fight for your Rights!
Focus on social environment: Own social relationships, own value system, cultural \& political influences, reorienting gender roles $\&$ human rights

\section{Section 3: Sexuality}

7 Sexuality and Love

8 Pregnancy: 4 Girls and 4 Boys!

9 Protect Yourself: STI's; HIV/AIDS

10 HIV/AIDS: $U$ have a role 2 play 2

11 Love Shouldn't Hurt
Addressing potential of sexuality

Pregnancy and the impact for girls and boys Strengthening personal decision making Learning to respect decisions of a partner Addressing stigma, sexual harassment/ abuse

Section 4: Goal setting

12 Your Future, Dreams and Plans

13 My Top Tips Peer Book

14 The Exhibition
Goal setting and planning for the future Learning how to share goals \& plans with peers and community 


\section{Outline of the dissertation}

As comprehensive rights-based sex education programmes are most likely to be effective when they are theory- and evidence-based (Bartholomew et al., 2011), intervention development and improvement should be rooted in a context-specific needs assessment that assesses determinants of individual (safe) sexual behavioural choices and specific socio-cultural, economic and political contextual factors that may influence these choices. This dissertation reports on four studies that together have the objective to give input to the intervention development, objectives, target group segmentation, content, form and implementation context of comprehensive rights-based sex education in Uganda.

The first study (reported in Chapter 2) aimed to gain insight in socio-cognitive determinants of safe sex behaviour (i.e. intention to delay and intention to use condoms), assessing differences in predictors between adolescents with and without previous sexual experience. A school-based sample was drawn from 48 secondary schools throughout Uganda. Participants $(N=1978)$ completed a questionnaire measuring beliefs regarding pregnancy, STIs and HIV and AIDS, attitudes, social norms and self-efficacy towards condom use and abstinence/delay, and intentions to use condoms and delay sexual intercourse. As secondary sexual abstinence is one of the recommended ways for the prevention of STI/HIV and unplanned pregnancies, participants with and without previous sexual experience were compared.

The second study (Chapter 3) explored how the right to complete and accurate information on SRHR and the right to sexual self-determination can be made relevant in the political, socio-economic and community context in which Ugandan adolescents grow up. Based on the findings drawn from seven focus group discussions (FGDs) among 56 Ugandan adolescents at schools in Lira (Northern Uganda) and Kasese (Western Uganda) implications for content, form and context of CRSE were formulated.

The third study (Chapter 4) focused on the extent to which the World Starts With Me programme was implemented successfully and to examine the socio-cognitive factors associated with successful implementation such as teachers' attitudes towards and self-efficacy of teaching WSWM. This study also aimed to explore the 
main perceived barriers and supportive factors of implementation according to the teachers. Sixty-five teachers participated in a pre- and post-test survey, responding to questions on implementation of the programme (i.e., dose delivered and fidelity of implementation), their attitudes, towards sex education in general and WSWM in particular, their self-efficacy towards teaching and discussing sexuality issues in class, and the perceived barriers, support and subjective norms encountered with regard to implementing WSWM at their schools. Results gave a better understanding of reasons for not completing the whole programme and for not strictly following the WSWM manual when implementing the programme.

The fourth study, which is reported in Chapter 5, aimed to assess the effects of WSWM on socio-cognitive determinants of safe sex behaviour, including non-coercive sex among Ugandan secondary school students. This study was based on a quasi-experimental design, involving intervention $(N=853)$ and comparison groups $(N=$ 1011). A survey was conducted both before and immediately after the intervention was implemented. A post-hoc comparison was made between schools based on dose delivered and fidelity of implementation of WSWM, assessed through the process evaluation.

The empirical chapters have been submitted as separate articles to peer-reviewed scientific journals. As a result, the chapters might provide overlap of information. The final chapter 6 summarizes the most significant findings of the studies reported in this dissertation and discusses them in the context of current literature and reflects on methodological limitations of the studies. It outlines implications of the research findings for the development, implementation and evaluation of comprehensive rights-based sex education programs. This chapter closes with recommendations for future research on sex education for adolescents in a Sub-Saharan context.

Finally, the subtitle of this dissertation, Mti hukunjwa wakati ungali mchanga (Swahili for "A stick is straightened while still young"), refers to the importance of focusing on young people (children and adolescents) when it comes to promoting safe sexual behaviour, even though they are sexually not active yet. Young people have the right to know about the pleasures and possible dangers of sexuality and how to protect themselves from STIs, HIV infection and unwanted pregnancy, they have the right 
to learn the skills to make their own decisions relating to their sexual life, and to do so free from any form of violence or pressure and economic, socio-cultural or political and institutional constraints. I do realize this is a lot to wish for, but as a Dutch proverb says: Alle kleine beetjes helpen ("Every little bit helps"). 


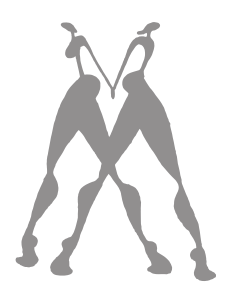

\section{Correlates of delayed sexual intercourse and condom use among adolescents in Uganda: A cross-sectional study}

This chapter has been published in similar form as:

Rijsdijk, E.L., Bos, A.E.R., Lie, R., Ruiter, R.A.C., Leerlooijer, J.N., \& Kok, G. (2012). Correlates of delayed sexual intercourse and condom use among adolescents in Uganda: a cross-sectional study. BMC Public Health, 12, 817. 


\begin{abstract}
Comprehensive sex education, including the promotion of consistent condom use, is still an important intervention strategy in tackling unplanned pregnancies, HIV/AIDS and sexually transmitted infections (STIS) among Ugandan adolescents. This study examines predictors of the intention to use a condom and the intention to delay sexual intercourse among secondary school students (aged 12-20) in Uganda. A schoolbased sample was drawn from 48 secondary schools throughout Uganda. Participants $(N=1978)$ completed a survey in English measuring beliefs regarding pregnancy, STIs and HIV and AIDS, attitudes, social norms and self-efficacy towards condom use and abstinence/delay, intention to use a condom and intention to delay sexual intercourse. As secondary sexual abstinence is one of the recommended ways for preventing HIV, STDs and unplanned pregnancies among the sexually experienced, participants with and without previous sexual experience were compared. Results show that for adolescents without sexual experience (virgins), self-efficacy, perceived social norms and attitude towards condom use predicted the intention to use condoms. Among those with sexual experience (non-virgins), only perceived social norm was a significant predictor. The intention to delay sexual intercourse was, however, predicted similarly for both groups, with attitudes, perceived social norm and self-efficacy being significant predictors. This study has established relevant predictors of intentions of safe sex among young Ugandans and has shown that the intention to use condoms is motivated by different factors depending on previous sexual experience. A segmented approach to intervention development and implementation is thus recommended.
\end{abstract}




\section{Introduction}

In contrast to most SSA countries, Uganda reported a dramatic decline in HIV prevalence, from about 18\% in 1992 (Wabwire-Mangen, Odiit, Kirungi, Kisitu, \& Wanyama, 2009) to about 4.1\% in 2003 (UNAIDS, 2004). However, HIV prevalence has since risen and is now stabilized at around $7.0 \%$ (UNAIDS, 2010). Recent research and trend analyses show an increase in risk-taking behaviours, particularly in multiple sexual partnership and non-spousal sex (Opio et al., 2008). A decrease in condom use in non-spousal sex among men has also been noted (Wabwire-Mangen et al., 2009).

Almost $14 \%$ of Ugandan adolescents is sexually active by age 15 (15.5\% of the girls and $12.2 \%$ of the boys) (UNAIDS, 2010) and over $50 \%$ by age 18 (UBOS and Macro International, 2007). However, in a study among sexually active unmarried Ugandans aged 15 to 24 , it was concluded that after initiating sexual intercourse, some adolescents decide to abstain from sex until they are older, married, or have a paid job (Tumwesigye, Ingham, \& Holmes, 2008). Nearly two thirds of the sexually active respondents abstained for three months, slightly less than half abstained for six months and $18 \%$ abstained for twelve months. Taking alcohol, going to parties and talking to parents about sex, were found as associating factors with discontinuation of secondary abstinence. Secondary abstinence is more common in SSA than in other regions of the world (Khan \& Mishra, 2008).

When sexually active, around $15 \%$ of the young Ugandans aged $15-19$ years, ever used a condom. Of those aged 15-24 years who ever had sex, $28 \%$ used a condom at first sex, with a slight difference between boys (29\%) and girls (27\%). By the age of 19 , approximately $50 \%$ of all Ugandan women have had their first child (UBOS and Macro International, 2007). Moreover, $36 \%$ of the births among Ugandan adolescents mothers younger than 20 years are unintended (Biddlecom, Hessburg, Singh, Bankole, \& Darabi, 2007).

These figures show that comprehensive sex education, including the promotion of consistent condom use, is still an important intervention strategy in tackling unplanned pregnancies, HIV/AIDS and sexually transmitted infections (STIs) among Ugandan adolescents. This is also recognised by the Ugandan government, as young people are included as one of the main target groups for prevention efforts in Uganda (Government of Uganda, 2010). 
Comprehensive sex education programmes are likely to be most effective when they are based upon theory- and evidence- based needs assessments and intervention strategies (Kok, Schaalma, Ruiter, van Empelen, \& Brug, 2004; Schaalma et al., 2009; Bartholomew et al., 2011). Hence it is important to know which factors determine safe sexual behaviour, i.e., condom use and (secondary) delay of sexual intercourse.

\section{Determinants of condom use and delay of sexual intercourse}

As safe sex behaviour requires (individual) planning and forethought, socio-cognitive theories like the Theory of Planned Behaviour (TPB) (Ajzen, 1991; Ajzen, 2002), and, more recently, its successor the Reasoned Action Approach (RAA) (Fishbein \& Ajzen, 2010), are often used to design interventions that promote safe sex behaviour. According to the RAA, the most important determinant of planned behaviour is the intention to perform the behaviour. This is supported by a meta-analysis of 47 experimental tests of intention-behaviour relations which showed that a medium to large sized change in intention leads to a small to medium sized change in behaviour (Webb \& Sheeran, 2006). Behavioural intention, in turn, is the result of a combination of attitudes towards the behaviour, the perceived norm (e.g. descriptive and injunctive norms, social encouragement, pressure) and self-efficacy (Ajzen, 2002; Ajzen \& Fishbein, 2010; Fishbein, 1998). Attitude is defined as a person's disposition to respond favourably or unfavourably towards a certain behaviour. The perceived norm is a function of beliefs that specific, important individuals or groups (e.g. friends, parents, one's girlfriend, one's husband) approve or disapprove of a certain behaviour as well as beliefs that these referents themselves perform or do not perform that specific behaviour. Self-efficacy, also termed perceived behavioural control, refers to "the extent to which people believe that they are capable of, or have control over, performing a given behaviour" (Fishbein \& Ajzen, 2010, p. 155).

The RAA has been supported by research, mainly conducted in the USA and Western Europe, on the adoption of many health-related behaviours (Godin \& Kok, 1996; Armitage \& Conner, 2001), including condom use (Sheeran, Abraham, \& Orbell, 1999; Bennet \& Bozionelos, 2000; Albarracín, Johnson, Fishbein, \& Muellerleile, 2001; Schaalma, Kok, \& Peters, 1993; Jemmott \& Jemmott, 2000; Aarø et al., 2006; Gredig, Nideroest, \& 
Parpan-Blaser, 2006) and sexual intercourse delay (Ajzen, 1991; Carjaval et al., 1999). Although unsafe sexual behaviour is an important health risk among SSA adolescents (Kaaya et al., 2002), there have only been a few recent studies on the socio-cognitive determinants of (the intention of) delaying sexual intercourse and (the intention of) condom use in an African setting that meet international criteria concerning sample size and the use of multivariate statistical methods. Nonetheless, despite the paucity of research, the studies that have been conducted appear to support RAA; notably on correlates and determinants of condom use (Schaalma et al., 2009; Heeren, Jemmott, Mandeya, \& Tyler, 2007; Giles, Liddell, \& Bydawell, 2005; Bryan, Kagee, \& Broaddus, 2006; Lugoe \& Rise, 1999; Meekers \& Klein, 2002); on both primary abstinence and condom use (Babalola, Awasum, \& Quenum-Renaud, 2002) and on sexual activity and condom use intentions (Taffa, Klepp, Sundby, \& Bjune, 2002). To the best of our knowledge, there is only one study on secondary abstinence and its determinants (Tumwesigye et al., 2008) but this study does not consider socio-cognitive determinants.

Studies combining primary delay, secondary abstinence and condom use are, to the best of our knowledge, non-existent. When researching the correlates and predictors of these three main preventive safe sex behaviours among Sub-Saharan adolescents, the previous sexual experience of participants should be considered. In fact, on the basis of their systematic review of school-based sexual health interventions to prevent STI and HIV in SSA, Paul-Ebhohimhen, Poobalan and van Teijlingen (2008) concluded that behaviour change related to either abstinence or condom use is greatly influenced by participants' pre-intervention sexual history (i.e. having previously been sexually active or not). This clearly suggests that the determinants of, and explained variance for, (secondary) sexual intercourse delay and condom use could differ between adolescents who, at baseline, have already engaged in (anal or vaginal) sexual intercourse and adolescents who have not.

This study sets out to determine the socio-cognitive correlates and key predictors of the intention to use a condom the next time one has sex and the intention to (primary or secondary) delay sexual intercourse among young people in Uganda. Furthermore, it sought to assess differences in predictors between adolescents with and without previous sexual experience. 


\section{Methods}

\section{Participants and procedure}

Data were derived from a cross-sectional survey conducted with secondary school students $(N=1986)$, aged 12-20 years, in Uganda. A total of 48 schools were selected throughout Uganda. Some schools were segregated by gender, others were not. Also, some schools were day schools while others were boarding schools. At all schools, the principal or a teacher approached 50 students to participate in the study. To ensure an equal distribution of gender and age, the principals/teachers were asked to select a group of 50 students on the basis of gender (if possible) and age. Participation in the study was on a voluntary basis. In total, 887 boys and 1099 girls participated, yielding a response rate of $83 \%$. The mean age of the participants was 16.1 years $(S D=1.87)$. Eight participants $(0.4 \% ; 2$ boys and 6 girls) were subsequently excluded from analyses as they specifically indicated they were raped. The final sample was $N=1978$ (885 boys and 1093 girls).

Data collection took place in March 2008. The participants completed a self-administered questionnaire in English in their classroom under the supervision of two research assistants who ensured that the room was quiet and that participants did not discuss their answers with others. They also provided clarification on questionnaire items if necessary. The research assistants were first year undergraduate students at the Makerere University in Kampala, Uganda and were, prior to data collection, trained for three days by two researchers, one Ugandan and one Dutch, on the objectives of the study, the structure of and rationale for the questionnaire, how to best respond to participants' questions about the questionnaire (e.g., What is meant by anal sexual intercourse?), and how to go about creating and maintaining a safe, quiet environment in which participants could anonymously complete their questionnaire. After completing the questionnaire, participants were given a soft drink and a snack as well as a Health Referral List with information on counselling services in their district, if available. All participants provided informed consent and the Ethics Committee at Maastricht University's Faculty of Psychology and Neuroscience in the Netherlands approved this study prior to initiation. 
The questionnaire was derived from a questionnaire previously used in Tanzania and South Africa (Mũkoma et al., 2009a) and pre-tested among adolescents from a school in Kampala. The pre-test yielded minor adaptations to the questionnaire. Two versions of the questionnaire were developed: one for boys and one for girls. Both contained the same questions but different wording (e.g., girlfriend versus boyfriend).

\section{Variables and measurements}

The dependent variables were the intention to delay sexual intercourse and the intention to use a condom the next time one engages in sexual intercourse. The independent variables were derived from the RAA and included attitudes, perceived social norms and self-efficacy towards delaying sexual intercourse and towards condom use. Additionally, items relating to age, gender, beliefs about pregnancy, HIV/AIDS and STI and sexual experience (having had sexual intercourse or not) were included. Pearson's correlations were assessed for constructs consisting of two variables at a $p<.01$ level. Mean scores for items measuring a similar underlying construct (scales) were employed. For some constructs, the correlation was not significant, in which case we used separate items. Most items were measured using 5-point Likert scales. If measured otherwise, it will be indicated in the text.

Intention to delay sexual intercourse was measured by the following item: "Do you think you will wait to have sexual intercourse until you are older?" Attitude towards delayed sexual intercourse was measured by two items $(r=.31 ; p<.01)$ : "It is better that young people my age who are in a steady relationship postpone sexual intercourse until they are older" and "Young people my age should not engage in sex until they are older". Perceived social norm for delayed sexual intercourse was measured by two items $(r=.22 ; p<.01)$ : "My friends believe that it is acceptable for people my age to have sexual intercourse with a steady boyfriend/girlfriend" and "My friends believe that people my age should postpone sexual intercourse until they are older.". Self-efficacy to delay sexual intercourse was measured by two items $(r=.45 ; p<.01)$.: "For me, waiting to have sexual intercourse until I am older is difficult" and "I am confident that I can wait to have sexual intercourse until I am older.". 
Intention to use a condom was measured by the following item: "Do you think you and your (future) lover will use a condom when you have sexual intercourse?". Attitude towards condom use was measured by two separate items: "It is wise to use a condom during sexual intercourse" and "It is pleasant to use a condom". Perceived social norm for condom use was measured by one item: "My friends think that people my age should use a condom when having sexual intercourse". Self-efficacy for condom use was measured by two items $(r=.32 ; p<.01)$ : "For me, using a condom every time I have sexual intercourse is difficult" and "I am sure I can use a condom every time I have sexual intercourse".

Beliefs about pregnancy were measured by two items $(r=.44 ; p<.01)$ : "A girl cannot get pregnant the first time she has sex" and "If a girl washes herself thoroughly immediately after sexual intercourse, she cannot get pregnant". Beliefs about HIV/ AIDS were measured by the following two statements $(r=.16 ; p<.01) .:$ "HIV can be transmitted through mosquito bites" and "When someone is HIV-infected, this can always be seen in their appearance". Beliefs about STI were measured by two statements $(r=.22 ; p<.01)$ : "Biologically, boys have a higher risk of contracting sexually transmitted infections than girls" and "Anal sexual intercourse is a safe way to protect oneself from sexually transmitted infections".

To assess whether respondents were sexually experienced or not, they were asked two questions: "With how many different people have you had sexual intercourse in your life?" (None; with ... people; I don't want to talk about this; I don't know), and: "Have you ever practised anal sexual intercourse? (No; Yes; I don't want to talk about this). Those who indicated they had sexual intercourse (including 'anal' sexual intercourse) before had to answer a third set of questions, relating to their first and last sexual experience (e.g. age at first sex, how long ago they last had sexual intercourse and their experience at first and last sex (e.g. forced; tricked; consensual). Those respondents who answered "None" and "no" to the first two questions, and skipped the questions meant for those who had had sexual intercourse before, were defined as "without sexual experience". All remaining respondents who answered the questions meant for those who had had sexual intercourse before, were defined as "sexual experienced", unless they answered these questions inconsistently. Those participants were defined as "unknown". 


\section{Data analysis}

Means, standard deviations, frequencies and percentages were calculated to provide a description of the sexual history of the sample. Bivariate correlations between the intention to use condoms and the intention to delay sexual intercourse, on the one hand, and the relevant determinants, on the other, were then assessed. Subsequently, linear regression was employed to determine the relative importance of the correlates of the intention to use condoms and the intention to delay sexual intercourse. A p-value of .01 was used at a $95 \%$ confidence interval. All variables in our model for sexual intercourse delay and in our model for condom use had low levels of collinearity. For delayed sexual intercourse, the variance inflation factor [VIF] was 1.19 and 1.15 among participants with and without previous sexual experience, respectively. For condom use, the VIF was 1.15 and 1.12. The tolerance level for all models was > .2. Data were analysed using SPSS 17.0.

\section{Results}

\section{Socio-demographic and sexual experience of the respondents}

Table 2.1 shows the demographic (age, gender) and sexual experience of the respondents. The mean age of the respondents was 16.1 years $(S D=1.86)$. Of the total sample, $55.3 \%$ (885) were boys and $44.7 \%$ (1093) were girls. More than a quarter $(27.4 \%)$ of the respondents indicated they had engaged in sexual intercourse: $37.2 \%$ of the boys $(N=885)$, and $19.4 \%$ of the girls $(N=1093)$, of which $10.5 \%$ reported having had anal sexual intercourse ( 96 boys and 62 girls). Girls indicated more often than boys that they did not have any sexual experience (i.e. vaginal or anal intercourse): $58.4 \%$ of the girls against $36.6 \%$ of the boys. The previous sexual experience of the remaining participants (24\%) is unknown as these participants did not answer the items measuring past sexual behaviour or answered these questions inconsistently.

\section{Delayed sexual intercourse: correlations with socio-cognitive factors}

Table 2.2 shows means, standard deviations and inter-correlations between the intention to delay sexual intercourse and the various socio-cognitive factors. The mean scores of intention to delay intercourse, beliefs about pregnancy, beliefs about HIV, 
attitude towards delayed sexual intercourse, self-efficacy to delay intercourse and the perceived social norm were just below or just over 4 (e.g. agree), which is relatively high. The intention to delay sexual intercourse was positively correlated with beliefs about pregnancy $(r=.14 ; p<.01)$, beliefs about STI $(r=.09 ; p<.01)$, beliefs about HIV $(r=.09 ; p<.01)$, attitude towards delayed sexual intercourse $(r=.36 ; p<.01)$, self-efficacy to delay sexual intercourse $(r=.46 ; p<.01)$ and the perceived social norm for delayed sexual intercourse $(r=.07 ; p<.01)$.

\section{Condom use: correlations with socio-cognitive factors}

Table 2.3 shows means, standard deviations and inter-correlations between the intention to use a condom and the various socio-cognitive factors. Intention to use a condom, beliefs about pregnancy, beliefs about HIV, attitude towards condom use (both it is wise to use a condom and it is pleasant to use a condom) and the perceived social norm scored relatively high (> 3.5). The intention to use condoms was positively correlated with both attitude items, namely 'it is wise to use a condom' ( $r=.15 ; p<.01)$, and 'it is pleasant to use a condom' $(r=.08 ; p<.01)$. Intention to use condoms was also positively correlated with self-efficacy for condom use $(r=.29 ; p<.01)$ and the perceived social norm towards condom use $(r=.18 ; p<.01)$.

\section{Predictors of intention to delay sexual intercourse and secondary delay}

To assess the relative importance of the predictors of the intention to delay sexual intercourse, linear regression analyses were conducted. Table 2.4 shows the main results of the linear regression model predicting the intention to delay sexual intercourse. For participants without previous sexual experience, age $(b=-.07 ; p<.05)$ was negatively related to the intention to delay intercourse, thus showing that the older the participant is, the less likely it is that he or she intends to delay sexual intercourse. Furthermore, beliefs about pregnancy $(B=.07, p<.05)$, attitudes towards delaying sexual intercourse $(B=.13, p<.001)$, the perceived social norms $(\beta=.15, p<.001)$, and self-efficacy for delayed sexual intercourse $(\beta=.30, p<.001)$ were positively associated with the intention to delay sexual intercourse. Together, these predictors explained $23 \%$ of the variance for adolescents without previous sexual experience. 
Table 2.1 Demographic and sexual history profile of the respondents

\begin{tabular}{|c|c|c|c|c|c|}
\hline & & $\begin{array}{l}\text { Sexually } \\
\text { experienced }\end{array}$ & $\begin{array}{l}\text { Not sexually } \\
\text { experienced }\end{array}$ & Unknown & Total (N) \\
\hline \multirow[t]{6}{*}{ Male } & $=<12$ & $16.7 \%$ & $50.0 \%$ & $33.3 \%$ & 12 \\
\hline & $13-14$ & $24.1 \%$ & $42.4 \%$ & $33.5 \%$ & 158 \\
\hline & $15-16$ & $36.2 \%$ & $36.6 \%$ & $27.2 \%$ & 298 \\
\hline & $17-18$ & $42.8 \%$ & $36.7 \%$ & $20.5 \%$ & 278 \\
\hline & $=>19$ & $44.6 \%$ & $28.8 \%$ & $26.6 \%$ & 139 \\
\hline & Male total & $37.2 \%$ & $36.6 \%$ & $26.2 \%$ & 885 \\
\hline \multirow[t]{6}{*}{ Female } & $=<12$ & $15.8 \%$ & $57.9 \%$ & $26.3 \%$ & 19 \\
\hline & $13-14$ & $10.0 \%$ & $65.7 \%$ & $24.3 \%$ & 239 \\
\hline & $15-16$ & $17.3 \%$ & $61.1 \%$ & $21.6 \%$ & 468 \\
\hline & $17-18$ & $28.7 \%$ & $50.2 \%$ & $21.2 \%$ & 293 \\
\hline & $=>19$ & $27.0 \%$ & $50.0 \%$ & $23.0 \%$ & 74 \\
\hline & Female total & $19.4 \%$ & $58.4 \%$ & $22.2 \%$ & 1093 \\
\hline \multirow[t]{6}{*}{ All participants } & $=<12$ & $16.1 \%$ & $54.8 \%$ & $29.0 \%$ & 31 \\
\hline & $13-14$ & $15.6 \%$ & $56.4 \%$ & $28.0 \%$ & 397 \\
\hline & $15-16$ & $24.7 \%$ & $51.6 \%$ & $23.8 \%$ & 766 \\
\hline & $17-18$ & $35.6 \%$ & $43.6 \%$ & $20.8 \%$ & 571 \\
\hline & $=>19$ & $38.5 \%$ & $36.2 \%$ & $25.4 \%$ & 213 \\
\hline & Total & 541 & 962 & 475 & 1978 \\
\hline
\end{tabular}

Table 2.2 Means, standard deviations and intercorrelations of the determinants of the intention to delay sexual intercourse

\begin{tabular}{lllllllll}
\hline Variable & $\mathrm{M}(\mathrm{SD})$ & 1 & 2 & 3 & 4 & 5 & 6 & 7 \\
\hline $\begin{array}{l}\text { 1. Intention to delay } \\
\text { sexual intercourse }\end{array}$ & $3.98(1.28)$ & - & $14^{*}$ & $.09^{*}$ & $.09^{*}$ & $.36^{*}$ & $.46^{*}$ & $.07^{*}$ \\
2. Beliefs about pregnancy & $3.78(.99)$ & & - & $.36^{*}$ & $.33^{*}$ & $.14^{*}$ & $.22^{*}$ & .03 \\
3. Beliefs about HIV & $3.57(.97)$ & & & - & $.30^{*}$ & $.10^{*}$ & $.12^{*}$ & .01 \\
4. Beliefs about STI & $3.25(.96)$ & & & - & $.13^{*}$ & $.18^{*}$ & .01 \\
5. Attitude & $4.11(.96)$ & & & & - & $.36^{*}$ & $.18^{*}$ \\
6. Perceived social norm & $3.65(1.35)$ & & & & & - & .06 \\
7. Self-efficacy & $3.97(1.04)$ & & & & & & - \\
\hline$N=1978 ; * p<.01$ (two tailed) & & & & & & & &
\end{tabular}


Table 2.3 Means, standard deviations and intercorrelations of the determinants of the intention to use condoms

\begin{tabular}{|c|c|c|c|c|c|c|c|c|c|}
\hline Variable & $\mathrm{M}(\mathrm{SD})$ & 1 & 2 & 3 & 4 & 5 & 6 & 7 & 8 \\
\hline 1. Intention condom use & $3.79(1.30)$ & - & .05 & .02 & .04 & $.15^{*}$ & $.08^{*}$ & $.29 *$ & $.18^{*}$ \\
\hline 2. Beliefs about pregnancy & $3.78(.99)$ & & - & $.36^{*}$ & $.33^{*}$ & .05 & $-.13^{*}$ & $.07^{*}$ & .00 \\
\hline 3. Beliefs about HIV & $3.57(.97)$ & & & - & $30 *$ & .04 & -.07 & .05 & .02 \\
\hline 4. Belief s about STI & $3.25(.96)$ & & & & - & .04 & $-.10^{*}$ & .04 & .01 \\
\hline $\begin{array}{l}\text { 5. Attitude to condom use } \\
\text { as wise }\end{array}$ & $3.94(1.20)$ & & & & & - & $.16^{*}$ & $.18^{*}$ & $.23 *$ \\
\hline $\begin{array}{l}\text { 6. Attitude to condom use } \\
\text { as pleasant }\end{array}$ & $3.52(1.29)$ & & & & & & - & $.14^{*}$ & $.16^{*}$ \\
\hline 7. Perceived social norm & $3.82(1.22)$ & & & & & & & - & $.19 *$ \\
\hline 8. Self-efficacy & 3.33 (1.04) & & & & & & & & - \\
\hline
\end{tabular}

Table 2.4 Results of linear regression analyses predicting the intention to delay

\begin{tabular}{|c|c|c|c|c|}
\hline & \multirow{2}{*}{\multicolumn{2}{|c|}{$\begin{array}{l}\text { Intention Delay } \\
\text { No sexual experience } \\
(N=962)\end{array}$}} & \multirow{2}{*}{\multicolumn{2}{|c|}{$\begin{array}{l}\text { Intention Delay } \\
\text { Sexual experience } \\
(N=541)\end{array}$}} \\
\hline & & & & \\
\hline & $R^{2}$ & B & $R^{2}$ & B \\
\hline Step 1 & .23 & & .21 & \\
\hline 1. Age & & $-.07 *$ & & -.02 \\
\hline 2. Beliefs about pregnancy & & $.07^{*}$ & & -.05 \\
\hline 3. Beliefs about HIV & & .06 & & .03 \\
\hline 4. Beliefs about STI & & .01 & & .00 \\
\hline 5. Attitudes towards delay & & $.13^{* * *}$ & & $.18^{* * *}$ \\
\hline 6. perceived social norm & & $.15 * * *$ & & $.15^{* *}$ \\
\hline 7. Self-efficacy & & $.30 * * *$ & & $.30 * * *$ \\
\hline
\end{tabular}
${ }^{*} p<.05 ;{ }^{* *} p<.01 ;{ }^{* *} p<.001$.

Among participants with previous sexual experience, the intention to secondary abstinence was positively related to attitude towards delayed intercourse $(B=.18$, $p<.001)$, the perceived social norm towards delayed sexual intercourse $(b=.15$, $p<.01)$ and self-efficacy to delay intercourse $(b=.30, p<.001)$. Together, these predictors explained $21 \%$ of the variance for adolescents with previous sexual experience. 


\section{Predictors of intention to use condoms}

Table 2.5 shows the main results of the linear regression analyses predicting the intention to use a condom. Among participants without previous sexual experience, the attitude that using condoms is wise $(B=.11 ; p<.01)$, the perceived social norm towards condom use $(b=.10 ; p<.01)$ and self-efficacy to use condoms $(b=.33 ; p<.001)$ were positively associated with the intention to use a condom, and, together, explained $17 \%$ of the variance in the intention to use a condom. Among participants with previous sexual experience, the perceived social norm was the only correlate $(b=.14, p<.01)$, explaining $7 \%$ of the variance in the intention to use a condom among this group.

Table 2.5 Results of linear regression analyses predicting the intention to condom use

\begin{tabular}{lll}
\hline $\begin{array}{l}\text { Intention to use condoms } \\
\text { No sexual experience } \\
(N=962)\end{array}$ & $\begin{array}{l}\text { Intention to use condoms } \\
\text { Sexual experience } \\
(N=541)\end{array}$ \\
\hline$R^{2} \quad B \quad$ & $R^{2} \quad B$
\end{tabular}

Step 1

.17

.07

1. Age

$-.03$

.06

2. Beliefs about pregnancy

$-.04$

3. Beliefs about HIV

.01

4. Beliefs about STI

.04

5. Attitude to condom use as being wise

6. Attitude to condom use as being pleasant

7. Perceived social norm

8. Self-efficacy $.33 * * *$ .09 ${ }^{*} p<.05 ;{ }^{* *} p<.01 ; * * * p<.001$.

\section{Discussion}

The present study examined, among adolescents in Uganda, the predictors of the intention to delay sexual intercourse (for virgins), the intention to secondary abstinence (for non-virgins) and the intention to use a condom the next time one has sex. This study has shown that when it comes to the intention to delay sexual intercourse, compared to the intention to secondary abstinence, the predictors are relatively similar. 
For both groups (virgins and non-virgins), attitudes towards, perceived social norms regarding and self-efficacy to delay sexual intercourse were significant predictors of the intention to delay sexual intercourse. Additionally, among those without previous sexual experience, age was negatively related to the intention to delay intercourse thus implying that the likelihood that adolescents delay sexual intercourse decreases with age. Furthermore, among adolescents without previous sexual experience, beliefs about pregnancy were positively related to the intention to delay sexual intercourse. In SSA, including Uganda, "secondary abstinence" is common among young people (Tumwesigye et al., 2008; Marindo, Pearson, \& Casterline, 2003; Kabiru \& Ezeh, 2007; Cleland \& Ali, 2006). This might explain the similarity in predictors of delayed sexual intercourse between participants with and participants without previous sexual experience.

With respect to the predictors of the intention to use condoms, the findings demonstrate a clear difference between adolescents with and adolescents without previous sexual experience. Among those without previous experience, attitudes towards condom use, the perceived social norm regarding condom use and self-efficacy to use a condom were important predictors of the intention to use a condom. Among those with previous sexual experience, only the perceived social norm appeared to predict intention to use a condom. With this group, self-efficacy and attitude were non-significant.

Overall, the findings support, at least in part, the RAA as a means of understanding what underlies the intention to delay sexual intercourse, secondary abstinence and the intention to use condoms among SSA adolescents. However, the variance explained by the predictors (.23 for the intention to delay sexual intercourse and .17 for the intention to use a condom) was lower than what is normally found in studies conducted in Europe and the USA. On average, RAA factors explain about 39\% of variance in intention to perform a certain behaviour in European and American contexts (Armitage \& Conner, 2001; Sheeran et al., 1999; Albarraci'n et al., 2001). African studies tend to show less explained variance. In fact, of the few studies conducted in an African context, only one demonstrated an explained variance comparable to studies conducted in Europe and the USA (Schaalma et al., 2009). In that study, not only so- 
cio-cognitive factors but also geographic variables, socio-economic factors and access to condoms were included as predictors of condom use. In line with Fishbein (1998), Ajzen (1991), and supported by the fact that the explained variance in our study is different from that in other studies conducted in Europe and the USA, the author contends that the relative importance of each of the RAA variables may vary according to the behaviour, the population targeted and the socio-cultural context in which that behaviour takes place.

Further, the results of current study show that, among adolescents with previous sexual experience, only the perceived social norm predicted condom use. This is supported by other studies conducted in an African context where subjective norms were found to be (one of) the strongest predictors of condom use (Gilles, Liddell, \& Bydawell, 2005; Fekadu \& Kraft, 2002; Bosompra, 2001). This dominant role of perceived norm may be, at least in part, attributable to the more collectivist nature of African societies in contrast to the more individualistic decision-making that occurs in Europe and North America (Yeboah \& Maticka-Tyndale, 2008; Benefo, 2010).

Although this study has demonstrated that there are important socio-cognitive predictors of delayed sexual intercourse and condom use, it must be recognized that actual delay in sexual intercourse and actual condom use is also impacted by environmental factors (e.g., access to condoms) (Adih \& Alexander, 1999; Ukwuani, Tsui, \& Suchindran, 2003), structural factors (e.g., poverty and legal context) (Parker, Easton, \& Klein, 2000; Gillespie, 2006), and one's ability (e.g., skills necessary to discuss delayed sexual intercourse or use condoms) (Peters, Wiefferink, Hoekstra, Buijs, ten Dam, \& Paulussen, 2009; Schaalma et al., 2004). Additionally, socio-cultural factors, like gender roles that impact the degree to which girls can discuss condom use or buy and carry condoms, the presence of HIV-related stigma, and taboos on discussing sexuality in general, are all negatively related to condom use (Vermeer, Bos, Mbwambo, Kaaya, \& Schaalma, 2009; Bos, Schaalma, \& Pryor, 2008).

\section{Strengths and limitations}

This study is one of the few to assess the socio-cognitive predictors of delayed sexual intercourse and condom use among a large sample of young people in a SSA context. 
Furthermore, it is, to our knowledge, the first study to explore the influence of previous sexual experience on the intention to use condoms and (secondary) delayed sexual intercourse. As such, it contributes to filling the gap in the current literature on the determinants of safe sex behaviour among adolescents in low-income countries where HIV and AIDS are major health risks for young people, and where secondary abstinence is more common than in other parts of the world (UNAIDS, 2008). Furthermore, knowing that the determinants of safe sex behaviour differ for those with and those without previous sexual experience provides valuable input for the development of safe sex interventions among Ugandan adolescents.

This study also has some limitations. First, the questionnaire was in English, which for some participants may have been difficult to comprehend. Problems with comprehension were dealt with by training research assistants to provide vernacular translations for texts that students found difficult to understand. Second, the questionnaires were administered in classrooms where privacy was not always possible. Despite having given research assistants careful instructions to secure privacy and confidentiality, this could not always be guaranteed (e.g. teacher walking around the classroom). Third, the Principles of the schools were asked to select the participants based on an equal distribution of gender (if possible) and age. This non-random selection may lead to biased results, as the Principals may have selected those students who are "positive" role-models. Fourth, this study investigated only socio-cognitive factors. It is possible that other factors such as environmental factors (e.g. availability of affordable condoms), structural factors (poverty and legal context), factors related to ability (e.g. being able to discuss delayed sexual intercourse or condom use) and socio-cultural factors (e.g. gender norms, HIV-related stigma and taboos on talking about sexuality) could explain some variance in the intention to delay sexual intercourse, intention to secondary abstinence and the intention to use condoms. Fifth, because only cross-sectional data were used, only associations between variables could be assessed. No conclusions regarding causality could be drawn. Sixth, actual sexual intercourse delay and actual condom use were not measured, relying on the fact that other studies have demonstrated a robust relationship between intention and actual behaviour (Webb \& Sheeran, 2006; Albarracı'n et al., 2001; Bryan et al., 2006). Sev- 
enth, the respondents were all secondary school students, which limit the conclusions made to this group only. This fact should be taken into account when interpreting the results of this study, as adolescents who are not attending school may be more vulnerable to early sexual debut, HIV and other sexually transmitted infections and unintended pregnancy (Karim, Magnani, Morgan, \& Bond, 2003). Finally, the socio-cognitive factors were assessed using single items or two-items constructs. This could be seen as a possible shortcoming. However, it has previously been argued that the use of single items or two-item constructs is viable if the item correctly measures the core element of the construct (Bos, Kok, \& Dijker, 2001). The single-item and two-item measures were indeed contructed in such a way that they represented the central aspect of the construct being measured.

Future research should employ a longitudinal research design thereby enabling causal inferences regarding the impact of the determinants of delayed sexual intercourse and condom use on the actual behaviour using scales that are reliable in a SSA context.

\section{Conclusions}

In conclusion, this study has improved our understanding of the socio-cognitive predictors of the intention to delayed sexual intercourse, to secondary abstinence and condom use among Ugandan adolescents with and without previous sexual experience. The findings have several implications for the development of comprehensive sex education programmes geared to adolescents in Uganda.

Firstly, the RAA has proven to be a useful framework for assessing correlates of safe sex behaviour, also in the Ugandan context. It is therefore suggested that comprehensive sex education programmes geared to young Ugandans address the socio-cognitive predictors found in this study, namely attitudes towards, social norms about and self-efficacy to delay intercourse among both adolescents with and adolescents without previous sexual experience, and, for adolescents with previous sexual experience, social norms towards condom use. For adolescents without previous sexual experience, attitudes towards, social norms about and self-efficacy to use condoms must also be addressed. 
Secondly, a segmented approach based on actual previous sexual experience is important in order to take into account the differences between adolescents with and adolescents without previous sexual experience. As the likelihood of sexual activity increases with age, it would be wise to start comprehensive sex education before adolescents start experimenting with sexual intercourse. This contention is reinforced by previous research demonstrating that it is easier to change socio-cognitive variables and promote actual safe sex behaviour among adolescents who are not yet sexually active than among those who are (Stanton et al., 1998). It is recommended that such programmes address attitudes, social norms and self-efficacy to delay sexual intercourse and to use condoms. From about the age of 15 on, sex education should focus on (perceived) social norms, i.e., emphasizing that important others (peers) want to delay sexual intercourse, do not want to feel pressured to have sex, and do intend to use a condom when they do decide to have sex. This can be done using role models and peer education (Mellanby, Rees, \& Tripp, 2000), as peer-educators are considered to be credible sources of information by the adolescent target group (Stakic, Zielony, Bodiroza, \& Kimzeke, 2003), who are more likely to understand their situation (Bluhm, Volik, \& Morgan, 2003), and who can support young people in developing positive group norms and in making healthy decisions about sex (Mellanby et al., 2000; Walker \& Avis, 1999). A prerequisite for using peer-education as a strategy is that the peer educators are adequately trained and well supported by professional health educators to be able to educate their peers effectively (Mellanby et al., 2000; Walker \& Avis, 1999).

Also, facilitating an open discussion and interaction among young people could be a useful strategy as it would enable them to hear what their peers really think and (intend to) do and because it may encourage them to form their own opinions and norms.

Finally, as sex education programmes are most likely to be effective when they are theory and evidence based, intervention development should be rooted in a context-specific needs assessment that assesses, among other things, specific religious, economic, political and cultural factors that may influence safe sex behaviour (Bartholomew et al., 2011). As such, a needs assessment in the Ugandan context should explore the environmental constraints (e.g. access to condoms), abilities (e.g. skills to 
discuss delayed sexual intercourse or use condoms) and socio-economic and cultural factors (e.g. gender norms concerning sexuality, stigma and taboos, poverty leading to risky sexual behaviour, collectivism) present in a Sub-Saharan context. 


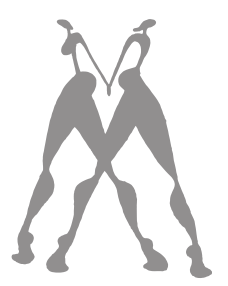

\section{Chapter 3 Sexual and reproductive health and rights: Implications for comprehensive sex education among adolescents in Uganda}

This chapter has been published in similar form as:

Rijsdijk, E.L., Lie, R., Bos, A.E.R., Leerlooijer, J.N., Kok, G. (2012). Sexual and Reproductive Health and Rights: Implications for comprehensive sex education among adolescents in Uganda. Sex Education: Sexuality, Society and Learning, 1-14, iFirst article. 


\begin{abstract}
This Chapter presents the findings of an explorative study, comparing universal declared Sexual and Reproductive Health and Rights (SRHR) with the local realities of young people in Uganda. This is done by analysing statements of Ugandan adolescents extracted from Focus Group Discussions (FGD) relating to two sexual and reproductive health rights central in this research: (1) the right of young people to complete and accurate information and (2) the right to self-determination. Discrepancies were found between these universally formulated SRHR and the (political, economic and community) context young Ugandans live in. Consequently, it is argued how comprehensive rights-based sex education could take this local reality into account in order to make SRHR meaningful for Ugandan adolescents. Implications for the content, form and context of comprehensive rights-based sex education are discussed.
\end{abstract}




\section{Introduction}

Since 1994, when reproductive health and gender equality were specifically placed in a human rights-based framework in the Cairo Programme of Action (UN, 1995), the so-called rights-based approach towards sex education has emerged and gained more and more popularity, especially among Western-based, non-US, donors.

According to Braeken \& Cardinal (2008), the rights-based approach is one of three main approaches combined in comprehensive sex education, next to a morality approach (enabling young people to develop their own values and to make their own personal choices, while appreciating the impact their choices can have on others) and a health promotion approach (focusing on sexual and reproductive health outcomes from a medical and technical perspective). The rights-based approach focuses on rights within cultural and power dynamics, emphasising social inclusion, equality and empowerment. According to IPPF, a rights-based approach to comprehensive sex education “(...) seeks to equip young people with the knowledge, skills, attitudes and values they need to determine and enjoy their sexuality - physically and emotionally, individually and in relationships." (IPPF, 2010, p. 6). Comprehensive rights-based sex education (CRSE) is considered to be an important strategy to ensure that young people receive the necessary information and education to take their own well-informed decisions on sexuality and sexual behaviour.

Although important, CRSE is only one of the many factors influencing young people's choices in sexuality. In the reality of many young peoples' lives, especially in developing countries, individual choices impacted by economic circumstances, socio-cultural norms, practices and religious and legal factors (Parker, Easton, \& Klein, 2000). Chalmers, Aggleton, Ingham, \& Stone (2006) distinguish different contexts that should be considered when exploring young people's sexual health and the factors that may affect it: (1) political context including legal and policy issues; (2) socio-economic context including demographic patterns, patterns of employment and unemployment, educational opportunities; (3) community context including cultural, religious and traditional influences on young people; (4) interpersonal context in which young people live their lives and negotiate their relationships; and (5) programmatic context in which responses to young people's sexual health needs take place. In our view, both 
interpersonal and programmatic contexts are embedded in and influenced by the other three context levels: the political, socio-economic and community context. Sexual and Reproductive Health and Rights are considered universal, but if not connected to the local context in which they have to take form, CRSE runs the risk of remaining a 'paper reality' (Thomas, 2007).

The aim of this study is to compare universal declared SRHR with the local realities of young people in Uganda, taking above discussed contexts (political, socio-economic and community) into account. This study focuses on two rights which are central in CRSE: (1) the right to complete and accurate information and (2) the right to self-determination. We also discuss the implications of our findings for content, form and context of CRSE.

\section{The right to complete and accurate information}

The right to complete and accurate information and education on SRHR is a fundamental right of young people, enshrined in the Convention on the Rights of the Child and the International Conference on Population and Development (ICPD). Complete information covers a wide variety of sexual and reproductive health topics, ranging from information on gender relations and equality to responsible sexual behaviour and the prevention of sexually transmitted infections (STIs) and HIV (UN, 1995).

\section{Political context}

The national policy guidelines towards sexuality education of the Ugandan Ministry of Education and Sports (MoES) aims to provide all learners with life-skills and age appropriate, accurate, complete and scientifically factual information on HIV/AIDS (MoES, 2006). Most issues related to sexuality and marriage are taught as part of the Uganda Ordinary Certificate of Education in Religious classes (Christian and Islamic) and Biology. In some schools, classes on Social Etiquette and Moral Education address moral values and norms related to sexuality matters (Muhanguzi \& Ninsiima, 2011). Since 2004, (public) primary and secondary schools in Uganda run the Presidential Initiative on AIDS Strategy for Communication to Youth (PIASCY). This programme promotes in essence abstinence until marriage, influenced by religious groups and the abstinence-on- 
ly policy of the US government at that time, through the 2003 President's Emergency Plan for AIDS relief (PEPFAR), the main funder of PIASCY (Cohen \& Tate, 2006; lyer \& Aggleton, 2012). Several (international) NGOs and community/religious based groups are also important actors in sex education, both in formal (school-based) and informal settings. Depending on the vision and (religious) foundation of the NGO, the approach taken is abstinence only, abstinence+ (including condom use) or rights-based.

\section{Socio-economic context}

The majority (80\%) of young people in Uganda live in rural areas, and approximately $63 \%$ have less than 7 years of schooling (Bankole, Singh, Woogh, \& Wulf, 2004). Recent studies among rural youth show that they assess the information and education they receive from parents and school on sexuality issues as "(...) being "under-resourced", "one-sided-feminised", "authoritarian", "theoretical", and "prescriptive"." (in-school youth; Muhanguzi \& Ninsiima, 2011, p. 60), and as "flawed or insufficient" (out-ofschool youth; Nobelius et al., 2010, p. 91). In general, young people prefer sexuality information and education that is in line with their real life experiences, which is non-judgmental, non-authoritative and positively framed (Muhanguzi \& Ninsiima, 2011; Nobelius et al., 2010).

Young people in Uganda refer to a wide variety of informal information sources for sexuality issues (e.g. peers, mass media, family members) and to more formal sources, like school-based sex education (Bohmer \& Kirumira, 2000; AmuyunzuNyamongo, Biddlecom, Ouedraogo, \& Woog, 2005; Nobelius et al., 2010). Remarkably, neither in-school nor out-of- school young people mentioned church and religious leaders as information sources (Amuyunzu-Nyamongo et al., 2005; Nobelius et al., 2010). In contrast, mass media, in particular radio, are an increasingly important information source (Neema, Musisi, \& Kibombo, 2004), although not all young people in SSA have regular access to radio or newspaper. Apart from the mainstream information sources, pornography and blue movies are also mentioned as information sources on different kinds of sexual activity (Amuyunzu-Nyamongo et al., 2005). 


\section{Community context}

In Uganda, communication between young people and adults is often considered taboo. Also, asking questions on sexuality issues makes an adolescent a suspect of being sexual active which is why young people, being uncertain about their discretion, do not often consult medical personnel at local clinic-based health centres (Nobelius et al., 2010). Traditionally, paternal aunts (called ssenga) play an important role in educating ("instructing") Ugandan girls about sex and marriage, including how to become a 'good' wife, i.e. being submissive to their husbands and his relatives as well as ensuring all his needs, including sexual needs. This form of traditional sex education is diminishing, due to social and economic changes in the extended family system (Kinsman, Nyanzi, \& Pool, 2000; Muyinda, Kengeya, Pool, \& Whitworth, 2001).

Although young people do not mention church or religious leaders as important information sources (Amuyunzu-Nyamongo et al., 2005; Nobelius et al., 2010), religious norms prescribing abstinence until marriage, condemning condom use, and spreading rumours about the dangers of condom use, could play a confounding role in safe sex behaviour messages (Nobelius et al., 2010), and, more generally, in how young people view their sexuality.

\section{The right to self-determination}

Sexual self-determination is the right to make your own choices regarding the enjoyment of a safe and pleasurable sexual life on an equal basis, free from any form of violence or pressure, and free from economic, socio-cultural or political and institutional constraints (UNFPA, 1997; Jansen, 2007).

\section{Political context}

According to Section 123 of the Ugandan Penal Code, a man who has sexual intercourse with a female younger than 18 years commits a capital offence for which the maximum sentence is death by hanging. The intention of this defilement law is to target perpetrators of sexual violence, but in practice it is often explained as consensual sex between young people being a criminal act (Parikh, 2012). The defilement law has led in the past to the arrest and imprisonment of adolescent boys under 18 years, for 
"being caught with a girl" (Barker \& Ricardo 2005, p. 18). Such criminal laws should set an age limit, but, as Kuate-Defo (2004) argues, if this age limit is set too high, the law can become a barrier to someone's capacity to self-determination.

\section{Socio-economic context}

Economic insecurity has implications for sexual self-determination. A growing number of studies address this issue, whereby it is often assumed that poverty and power inequality force girls to have (unprotected) sex with older men, referred to as "transactional sex" (Amuyunzu-Nyamongo et al., 2005). Different studies, however, show that there is a wide variety of practices, reasons and meanings which can be attached to transactional sex and that it can be part of coercive as well as non-coercive relationships (Moore, Biddlecom, \& Zulu, 2007; Bohmer \& Kirumira, 2000). Compared to other SSA countries, the prevalence of exchanging money and gifts in return for sex is high in Uganda (Luke \& Kurz, 2002; Nyanzi, Pool, \& Kinsman, 2010).

In general, Ugandan girls receive less pocket money than boys and have fewer opportunities to earn money (Iyer \& Aggleton, 2012), yet they have a growing need for nice cloths and toilet products, like soap and make-up (Nyanzi et al., 2010). In different studies, young people mentioned these needs as the main reason for engaging in transactional sex, including with older men (Bohmer \& Kirumira, 2000; Luke \& Kurz, 2002). In some instances, the exchange of gifts and money is considered a modern variant of the former bride price and as such a validation of the worth of the girl (Moore et al., 2007).

\section{Community context}

In Uganda, the socio-cultural and religious norm is abstinence until marriage. However, as in many other societies, a double standard concerning sexuality is prevalent, whereby girls are expected to be modest, tender, submissive and passive, while boys are 'encouraged to engage in behaviours that assert their masculinity, autonomy, assertiveness, activity and ambition (Muhanguzi, 2011, p. 714). Such sexual double standards constrain girls' sexual authority and self-determination (Wolff, Blanc, \& Gage, 2000), while reinforcing boys' view of being in control of sexual relationships (Muhanguzi, 2011). 


\section{Methods}

Focus group discussions (FGDs) were held with secondary school students in Lira (northern Uganda) and in Kasese (western Uganda). Lira is the municipality of Lira District and its main administrative and commercial centre. The population, mainly Lungo, has suffered tremendously due to the activities of the Lord's Resistance Army (LRA), causing massive population displacement in the region. At the time of the research, many people around Lira had just recently returned home, as the LRA forces had left Uganda, due to a signed truce between the Ugandan government and the LRA of August 26, 2006 (BBC News, 2006). Kasese, is the municipality of Kasese District. The two main ethnic groups are the Bakonjo (mainly cultivators) and the Basongora (mainly pastoralists) (Kirabo, Byakagaba, Buyinza, \& Namaalwa, 2011). Kasese district is, with 180 persons per square meter, more densely populated than Lira district (121 persons per square meter) (UBOS and Macro International Inc., 2007).

Two public secondary schools were selected that did not yet offer CRSE. The FGDs took place in May-June 2008 and were guided by a topic list. A total of 56 students participated in seven FDGs (two girls groups and two boys groups in Kasese and two boys groups and one mixed group in Lira). The (head)teacher, who formed the groups, was provided with a list of the following selection criteria: students should have indicated to be willing to participate and able to express themselves verbally in English; each group should contain students from different levels (senior 1 to senior 6 ) to ensure representatives of different age groups. The age difference within the groups varied from not more than three years (e.g. 15 to 18 years) up to 10 years ( 13 to 23 ) for one group, with an average age of 16.9 years. Each group consisted of eight students; the mixed group consisted of four girls and four boys. Each FGD took approximately 1.5 hours. The FGD leader was the principle researcher and author of this paper, a Dutch female, age 44 years.

Informed consent was sought from the students and the head teacher of the school. The Ethical Committee Psychology (ECP) of Maastricht University in The Netherlands granted ethical approval. Before starting the FGDs, the participating students were asked permission to record the discussion. The importance of confidentiality was stressed before the start of each FGD. Complete transcriptions of the recordings were 
made. The principal researcher read the transcriptions repeatedly and thoroughly. By using the Template Analysis method (King, 1998), relevant statements were extracted from the transcription and categorised in a template comprising themes relating to the two rights central in this research: (1) the right of young people to complete and accurate information and (2) the right to self-determination. Subsequently, the statements from the transcription were further clustered into subthemes (i.e. sex and money, under the right to self-determination) that emerged from the analysis.

\section{Limitations}

A number of potential limitations can be found in this study. First, the age-difference in some groups could have influenced the participation of the youngest students. In the group with the biggest age-difference, the youngest student did not participate as actively as the older ones. However, in the other groups, all students participated fully. In one group, the youngest (14-year) participant was the most actively involved. The FGD leader stressed the fact that each person's opinion is valued and that everything that would be said should stay within the group and would be reported anonymously.

A second limitation of this study derives from the fact that the FGDs were held in English, the official language in schools, but not the language in which young people normally discuss sexuality issues. Also, the fact that students were selected on the basis of being able to express themselves in English could lead to a bias, as these students might be more 'advanced' in general.

Finally, the sensitive nature of some of the topics discussed could collide with the fact that the FGD leader was a white middle-aged female. However, the FGD topic list was built up in such a way, that the discussion started with topics like subjects in school, gradually taking participants to discuss topics like boys' versus girls' roles, information needs, relationships and sexuality issues. 


\section{Results}

\section{The right to complete and accurate information}

Participants seek and receive information on sexuality issues from different sources, including family (aunts, uncles, older siblings, and grandparents), peers, school programmes, media and pornography. Some of these sources play a different role for girls and boys, providing different types of information.

Girls mentioned the ssenga (paternal aunt) as an information source concerning marriage, although they also argued that it is becoming more difficult to get information from their ssengas, as they often live far away with their husband's family. Girls discuss their feelings and sexual issues with their peers, but for detailed information they would still turn to either their ssenga or their older sisters. Out of respect, they would not easily turn to their mothers, as "she will think that now I am getting spoilt" (Mary, 18 years, Lira). Talking about sex with parents is considered taboo and it would raise the "suspicion" of parents that their child is sexually active. Only in case of problems, for instance unintended pregnancy, some girls said they would consult their mother or the Matron at school.

Male participants often referred to peers (boys) as information source for topics relating to relationships and sexual pleasure. They made a clear distinction between information sources on marital relationships, when they would consult a maternal uncle (kojja) or their grandparents, and on relationships for sexual pleasure, when they would consult peers.

Your question is to have a relationship with a girl for just sexual intercourse. These are two things. You can need a relationship with a lady just purposely for marriage and another one to satisfy your body, (...) for bodily desires, that's when you can consult your peers. (George, 15 years, Kasese).

Both girls and boys mentioned that at school, mainly during Biology and Religion, they are taught about adolescence, the technical aspects of reproduction and about marriage, with an absolute focus on sexual abstinence before and being faithful 
during marriage. Participants did not refer to PIASCY as being an important information source, nor to Social Etiquette or Moral Education.

Participants mentioned they have access to information through media, especially radio, and sometimes through the Straight Talk newspaper, published by the Straight Talk Foundation, which occasionally reached their schools. According to the participants, the focus of the media messages is abstinence and the risks of unprotected sex:

We always get a lot of information. More especially through the media we have in Lira here, like the radio stations. They always teach the youth how to behave, how dangerous the disease is and how to control [our sexual drive]. (...) In fact, we always hear that abstinence is the best (...). (Sylvia, 17 years, Lira).

Apart from the regular media, male participants referred to pornography and blue movies as information sources, obviously not focused on abstinence. According to participants even young children around 8 years watch these kinds of movies shown in public places, like the local market. Male participants in FGDs expressed their worries about the possible negative influence of these videos on children. They also linked these pornographic materials to the spread of AIDS:

These videos and TVs and magazines have led to the spread of AIDS, because they teach many people how to sleep with a girl when they are playing sex. Now if those Americans stop doing videos and TVs, it can be the simplest way of controlling the spread of AIDS. (David, 18 years, Kasese).

At the same time however, in absence of other (reliable) sources on sex and condom use, some of our male participants considered this kind of media content to be an important educational information source: 
(...) I watched one day a tape whereby a lady had sex with a man but unfortunately the condom remained inside the woman. But from that experience, I learned how to remove a condom where it has not come out with the erected penis. So some of those, we are the ones who are misinterpreting them but they are educative somewhere. (Kato, 18 years, Kasese).

\section{Informational and educational needs}

Both boys and girls felt that the information they received at school and through the media was insufficient, being focused mainly on abstinence and married relationships. Answers to the question 'what kind of information should be included in a comprehensive sex education programme, if this would be provided at your school?' can be divided in four categories: (1) objective and in-depth information on STIS, HIV, pregnancies and how to avoid these (technical information as well as negotiating skills); (2) information on how to abstain from sex (e.g. refusal skills), and on how to "control themselves" (specifically mentioned by boys); (3) information on how to form lasting relationships and (4) information on peer pressure and problems relating to transactional sex. Adolescents stressed the fact that information should be objective, explicit, clear and indepth enabling them to make their own decisions on sexuality and sexual behaviour.

We want to know about relationships that take place between a male and a female. In-deep. Relationship in-deep about sexuality. How diseases can be transmitted from one body to another. (Ellen, 18 years, Kasese).

Remarkably, both boys and girls felt that the other sex should be educated about pressures put on them relating to sex. Boys expressed the need for girls to be educated about not asking for money or presents, and on the risk they run of being forced into sex after accepting those:

\section{(...) [need] to teach them [girls] how to make relationships so that none of us is affected like in terms of using cash, so for them getting a problem of beating them or even taking them into sex. (Ibrahim, 17 years, Kasese).}


Girls expressed the need for boys to be educated on sexuality issues in general and their responsibilities in sexual relationships. Girls were mostly concerned about the harassment by boys demanding for sex:

(...) When they are teaching about sexual desires, if they are teaching both girls and boys, it helps the lady to pick [learn] something at the same time the boy picking something. Cause if you teach only girls, for us we shall pick something but the boys will continue disturbing us. But if they pick something too, their disturbing will decrease. (Ellen, 18 years, Kasese).

According to participants, young people should be educated in mixed gender groups, to be informed about and understand the views and opinions of the opposite sex. Participants agreed that the best age to start with sex education is before puberty, around the age of 12 because "when you grow [up] knowing everything, you don't normally get problems in future"(Susan, 18 years, Kasese) and "(...) so that you are not scared when your body is changing" (Peter, 18 years, Lira).

\section{The right to self-determination}

Participants' experience related to the right to sexual self-determination is influenced by the political, socio-economic and community context in which they live.

\section{Political context}

The defilement law was repeatedly mentioned and referred to by FGD participants as a reason not to have sex before the age of 18 . This law arouses fear and a negative framing of sexual intercourse and other sexual activities such as masturbation and oral sex as 'immoral' and a 'sin' among Ugandan youth:

According to the law of Uganda, if you practice what is called sexual intercourse when you have not reached the age of 18 years (...), when you have impregnated a lady of less than 18 years, you will be arrested and taken to prison. In addition to this, you should be able to abstain yourself from sexu- 
al immoralities like oral sex, masturbation, such immoralities that can lead us to imprisonment. (Steven, 15 years, mixed group Lira).

Although the defilement law is meant to protect children and adolescents under 18 from coercive sex enforced by adults, the participants generally interpret the law in a way that all sexual relations under 18, including consensual ones, are illegal. Examples were mentioned of boys who were arrested for impregnating a girl. Both girls and boys explained that early pregnancy would mean for the girl to leave school and possibly for both the girl and the boy to be forced to marry in order to avoid imprisonment of the boy. Alternatively, the parents of the girl could ask money from the family of the boy for not pressing charges.

\section{Economic context}

Economic circumstances influence the right to enjoy sexuality on an equal basis, free from any form of violence or pressure. Participants in our FGDs mentioned poverty as a reason to have early sex. Abstinence is just not always an option to choose:

You see, the choice can be hard for them to abstain where there is no money. (Kato, 18 years, Kasese).

Although never referring to personal experience, participants reported that transactional sex is common. The custom of giving presents and money to a girlfriend was associated with the fact that a man should cater for a woman. According to girls, the more a boy can give, the more likely it is that he will be able to fulfil his future role in providing for his family. Most boys agreed that having a girlfriend nowadays was expensive, and sometimes even unaffordable. Boys often felt tricked by a girl, as she would leave the boy if he does not have money to spent on her or she would take the money without giving sex in return:

Most girls ask for money, but leave the boys as soon as he is poor. Sometimes they ask money and don't give sex in return. A boy cannot ask money back from 
a girl. That is shameful, because men should cater for the women. (Ibrahim, 17 years, Kasese).

Girls acknowledged that many girls ask for presents or money when a boy shows his interest in her. At the other hand, girls mentioned feeling almost obliged to return the favours with sex, as they know that this is expected from them:

If you have a boyfriend, he will give you money. He will think that if he gives you money, he will play sex with you. And sex will be the return for the money he gave you. (Sarah, 16 years, Kasese).

Boys expressed their sincere worries about this development. They argued that the fact that girls are taking money from different men puts them in a difficult position where they have to compete financially with other boys and men. They also referred to "old times" when parents would choose their partner and take care of financial arrangements to be made:

Before, there was not a problem of money and sex because the parents would choose your partner and your parents would already pay money to the parents of the girl. So you as a boy did not have that problem. It was more official. But nowadays, girls take money from different men. (Michael, 17 years, Kasese).

Although not often, boys in FGDs did mention that some of their peers would have sex with older women, in order to pay for necessary goods and services, as well as for increasing their pocket money:

You may find that if you are not given enough necessities for life like school money to pay the school fees and other things like pocket money, you may be tempted by those older women. (Fred, 16 years, Lira). 
According to girls in Kasese, sugar-mummies are mostly widows who are looking for ways to satisfy their sexual desires, while sugar-daddies are mostly married men. Participants of the mixed FGD in Lira, stated that older men and women have paid sex with girls and boys because they are HIV infected and they want to spread it in order not to die alone:

They just think that if they are to die, they have to leave the virus with someone (Frank, 15 years, Lira).

Transactional and intergenerational sex are complex social phenomena, which cannot be explained by economic insecurity only. Giving presents and money to a girl is a way for a boy to express his interest in and love for the girl, and to show that he is able to cater for her. This custom becomes complicated when girls start asking presents and money, not only from their boyfriends, but also from (older) men, who are able to give more. Boys, in turn, feel they have to compete with others, and consequently they sometimes have sex with elderly women to increase their pocket money.

\section{Community context}

Participants receive different messages on the timing of first sex: after becoming 18, when married, after being economically independent or after finishing education. The law, parents and religion play an important role in setting the norms, but these are not always in line with the actual sexual behaviour of young people:

The parents do not allow it to happen. So when someone is doing, you might also be doing it from outside and not make them know. (...) So if you are doing [having sex]...maybe you are doing it illegally. (Jennifer, 14 years, Lira).

Boys underlined the view that males' sexuality and sexual drive are considered natural and given by God, a drive which they cannot easily control: 
(...) in fact somebody who's saying that he is abstaining, or who is saying that for his case he has abstained, in fact I feel like he is deceiving himself. (...) In fact it is nature and it is from God that one can want to have sexuality but, despite that fact, it is disadvantageous. (John, 21 years, Kasese).

At the same time, religion is used as a way to 'control oneself' and as a reason to abstain:

But I think sexual desires can be controlled. One through prayers. Some of us abstain because we pray to God (...) to continue abstaining till the period which God has planned for us to have wives in future. (Martin, 23 years, Kasese).

In other words, although boys consider their sexual drive as given by God, 'natural' and not easy to control, they refer to the same God and religion when it comes to 'controlling themselves' and abstaining until the time that God has planned for them to be sexual active. Unlike boys, girls should not show any sexual interest, and are not supposed to initiate a relationship, sex or marriage:

You [girl] can like to get married to him but you will not go and marry him. You will talk to him, so that he comes for you. But not you coming for him (...). He's the one who marries, and not the woman who marries. (Felicia, 15 years, Kasese).

Participants clearly experience internal struggle and contrary feelings and thoughts about their sexuality. On the one hand, sexual intercourse under 18 is forbidden for both boys and girls, not only by law, but also by the social network of parents, religious leaders, teachers and others. On the other hand, both boys and girls do experience sexual feelings and find it difficult "to control themselves". From boys it is socially expected and more accepted that he cannot control himself, being his natural drive, but girls cannot openly express if they want to be sexually active. In combination this often leads to 'sneaky behaviour', as one of the participants had put it. 


\section{Implications for comprehensive rights-based sex education}

The main challenge for CRSE is to enable young people to make universal SRHR relevant in their own local realities. From the FGDs, several implications for the content and form of CRSE in Uganda and for the context in which this education takes place can be drawn.

\section{Content and form}

The implications of our findings are discussed for content and form together, as they are interlinked. Firstly, CRSE should provide clear, objective and in-depth information on sexuality issues, including STIs, HIV, pregnancies and how to avoid these; ways in which adolescents can abstain and 'control' themselves; how to form lasting relationships; dealing with peer pressure and problems relating to transactional sex. Second, as the information young people receive from different sources is often contradictory (see also Nobelius et al., 2010; Muhanguzi \& Ninsiima, 2011), it is difficult for them to assess which information is correct. CRSE should therefore include discussion on the role and validity of these information sources, enabling young people critically to reflect upon the accuracy and relevance of the information they receive. Information they get through watching blue movies and pornography should also be part of this (see also Kinsman et al., 2000). A third implication is that SRHR can best be discussed in mixed groups and in the context of examples of adolescents' daily reality. Many existing sexuality values, attitudes, norms, beliefs and practices relate to gender and power issues (Muhanguzi, 2011), such as the norm that boys need to provide for girls and the more he can give, the better candidate he is; the practice that girls ask presents and money from boys or men and the subsequent pressure put on a girl to engage in sex once she has accepted them. Possible topics for discussion are the (cultural) background and history of the custom of giving presents and money; the purpose it served in previous times and how it has evolved in current times; how boys and girls feel about the custom and the consequences for each of them. By critically discussing these topics, challenging existing values, norms and practices, and gaining insight in each other's perspective as equals, positive and empowering change will be possible (Schaalma et al., 2004; Muhanguzi, 2011). We are not advocating for peer education 
as such, but for including peer discussions as a method within CRSE. Although young people do not assess peers as trustworthy sources (Muhanguzi \& Ninsiima, 2011), peers do play an important role as an informal information source outside the classroom. Based on their comparative study of peer-led and adult-led sex education in the UK, Mellanby, Newcombe, Rees, \& Tripp (2001), conclude that peer educators are less effective than adults in conveying factual information and getting adolescents involved in classroom activities, but are more effective in influencing the perceived norms and attitudes related to sexual behaviour towards the actual norms. Making mixed peer discussions a formal part of CRSE enables the formal teacher to correct false information, while at the same time facilitating students to critically discuss, reflect upon and challenge existing values, norms and customs. In case of single sex schools, a linkage between two schools within the same region is recommended, enabling interaction between girls and boys in mixed groups.

\section{Context}

CRSE takes place within a political, socio-economic and community context. As argued by Schaalma et al. (2004), to be successful, CRSE should be accompanied by advocacy aiming at a supportive political context for acknowledging young people's sexuality and CRSE. Furthermore, rights-based approaches to sex education cannot be dissociated from other rights at the socio-economic level, i.e. the right to an education and the right to be able to provide for oneself. If the most basic rights are not secured, CRSE is likely to fail achieving its goals. We argue that in poor settings CRSE should be accompanied by income-generating activities for young people, especially girls. Finally, to ensure that the community context of young people is supportive, outreach programmes aimed at stimulating dialogue and action among young people, teachers, parents/family, religious leaders, media and health institutions, is essential.

\section{Discussion}

This paper aimed to compare universal declared SRHR with the local realities of Ugandan adolescents, and to explore how CRSE can become meaningful in these local settings. The findings cannot be generalised to a wider population of Ugandan adoles- 
cents because the sample size was small and participants were only secondary school students.

The comparison between the right to complete and accurate information and the local reality of rural secondary school students in Uganda reveals two discrepancies. First, despite the fact that young people do have access to a variety of information sources on sexuality issues, the information they receive and can access is not complete. The main focus of the information is on abstinence (mass media and schoolbased sex education), on technical aspects of reproduction (Biology) and on preparation for marriage (religious classes and ssenga). For in-depth information on sexuality issues, adolescents rely on peers (boys and girls) or sisters (mainly girls), but at the same time they feel the reliability of the information is problematic (see also Nobelius et al., 2010; Muhanguzi \& Ninsiima 2011). The information young people receive is mostly fear-based and normative. Remarkably, only one participant said he had learned how to use a condom correctly, and he learned this from watching a blue movie.

Second, young people do not know which information is accurate and which is not. Conflicting messages lead to uncertainty and intrapersonal struggle in young people about whether and when to be sexually active (above 18 years old, after marriage, when economic independent), to negative framing of sexual behaviour as 'immoral' and a 'sin,' and as something natural (for boys) and something taboo (for girls). It also leads to 'sneaky' sexual behaviour, with all the related risks of unprotected sexual intercourse.

With regard to the right to self-determination, three discrepancies can be identified. Firstly, the defilement law, developed with the intention to protect girls from coercive sex with men, creates an environment in which fear, taboo and secrecy around young peoples' sexuality dominate. This is opposite to what CRSE aims for: an open and positive non-judgmental approach towards young people's sexuality, not based on fear and taboos (IPPF, 2010).

Secondly, our findings on transactional sex confirm the findings from other studies (Moore et al., 2007; Bohmer \& Kirumira, 2000; Nyanzi et al., 2010) that this practice is related to coercive as well as non-coercive sexual relationships. However, our findings show that also in non-coercive relationships, transactional sex is becom- 
ing problematic and that we cannot automatically assume that girls and boys make their own decisions relating to sex on an equal basis, free from any form of pressure. Girls expressed they felt pressured to have sex when accepting gifts or money from boys. At the same time, in order to have money for necessities or luxury items, girls ask money and gifts from different boys and men. Boys, at the other hand, are expected to show their masculinity by taking initiative towards girls and that they do have money to cater for their girlfriend. Both sexes expressed that they feel "trapped" in this situation and that they want to change this. Some authors (Moore et al., 2007) argue that the practice of giving presents and money in forming relationships can be considered as a "modern" variant of the bride price and as a validation of the worth of the girl. Our male participants, however, made very clear that the traditional bride price did not cause financial problems for boys, whereas nowadays they find themselves in a difficult competitive position, which they do not consider an advantageous development.

Thirdly, there is a discrepancy between the right to self-determination and the existing norms of abstinence until 18 years (political norm), until marriage (social and religious norm) or until one has finished his education and is economically independent (social norm). Young people experience internal struggle due to the norm (no sex) and their own emerging sexual feelings. Because of the norm to abstain, Ugandan adolescents do not have the right to make their own choices regarding when to start being sexually active. In addition, the double sexual standard in Uganda which defines 'men as active and dominant and women as passive and submissive' (Muhanguzi, 2011, pp. 716-717), leading to a lack of female sexual autonomy (Wolff et al., 2000) opposed to a dominant male sexual autonomy (Muhanguzi, 2011), was also apparent in our FGDs.

\section{Conclusion}

It is one thing to be educated about rights, another to be supported to exert them. Apart from providing complete and accurate information, CRSE needs to encourage adolescents to critically discuss and reflect on the information they receive from different sources (school, media, family and friends). Furthermore, young people should be 
supported to critically discuss and challenge, in mixed groups, the existing socio-cultural, political and religious norms and practices. Finally, to be effective, CRSE should be accompanied by interventions aiming at supportive political, socio-economic and community contexts. 


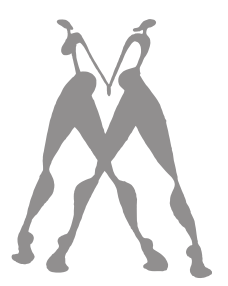

Implementation of The World Starts With Me, a comprehensive rights-based sex education programme in Uganda

This chapter has been submitted for publication in similar form as:

Rijsdijk, E.L., Bos, A.E.R., Lie, R., Leerlooijer, J.N., Eiling, E, Atema, V., Gebhardt, W., \& Ruiter, R.A.C. Implementation of The World Starts With Me, a comprehensive rights-basedsex education programme in Uganda.

Under review. 


\begin{abstract}
This paper reports on the results of a process evaluation of the implementation of the sex education programme (WSWM) for secondary school students in Uganda. Drawing on quantitative and qualitative data provided by teachers, we examined factors associated with dose delivered (number of lessons implemented) and fidelity of implementation (implementation according to the manual), as well as the main barriers and facilitators of implementation. Teachers' confidence in teaching WSWM was negatively associated with dose delivered. Confidence in educating and discussing sexuality issues in class was positively associated with fidelity of implementation, whereas the importance teachers attach to open sex education showed a negative association with fidelity. Main barriers for implementing WSWM were lack of time, unavailability of computers, lack of student manuals, and lack of financial support and rewards. Other barriers for successful implementation were related to high turnover of staff and insufficient training and guidance of intermediates. Teachers' beliefs/attitudes towards sexuality of adolescents, condom use and sex education were found to be important facilitators of implementing WSWM. It is concluded that sex education programmes in Uganda have great potential if adapted to the (special needs of the) local reality of the implementation context.
\end{abstract}




\section{Introduction}

Reviews of school-based sex education programmes show mixed evidence for the effectiveness of such interventions (Gallant \& Maticka-Tyndale, 2004; Jemmott \& Jemmott, 2000; Kirby, 2002a, 2002b; Paul-Ebhohimhen, Poobalan, \& van Teijlingen, 2008). Most evaluation studies only address changes in or effects on (determinants of) sexual behaviour of the target group, without considering the implementation process of the intervention (Mũkoma \& Flisher, 2008; Hardeman et al., 2008). This is remarkable, as quality of implementation is considered an important factor for the effectiveness of school-based interventions (Dusenbury, Brannigan, Hansen, Walsh, \& Falco, 2005; Wight \& Obasi, 2003; Durlak \& DuPre, 2008), especially in resource-poor settings (Gallant \& Maticka-Tyndale, 2004; Lloyd, 2010; Harrison, Newell, Imrie, \& Hoddinott, 2010; Michielsen et al., 2010). The results of a process evaluation not only give an indication of the extent to which the intervention was implemented the way it was intended, it also gives a better understanding of the context in which the intervention took place and of the interpretation of the results of the effect evaluation (Hall et al., 2012).

With the recognition that high-quality implementation is important to ensure that evidence-based programmes will be effective (Dusenbury et al., 2005; Bartholomew et al., 2011), the importance of process evaluations is also more and more recognised (Harrison et al., 2010; Michielsen et al., 2011; Strange et al., 2006). However, published process evaluations of school-based comprehensive sex education programmes in SSA are still rare. In the current process evaluation, we focus on the implementation of The World Starts With Me (WSWM), a comprehensive sex education programme, from the perspective of teachers. WSWM has been implemented since 2003 in over 150 schools throughout Uganda. WSWM is one of the 18 curricula underlying UNESCO's technical guidance on sex education (UNESCO, 2009). WSWM addresses the SRHR needs of secondary school students in Uganda. The development of WSWM was based on a combination of a needs assessment and evidence-based approaches in sex education (i.e. rights-based, health promotion, behaviour change, and adolescents developmental approaches).

Teachers are the main implementers of WSWM and play a significant role in both fidelity of implementation and in dose delivery. Previous research shows that 
teachers' skills, beliefs and practices (Peterson \& Bickman, 1998); teachers' moral views on adolescents' sexuality (Ahmed, Flisher, Mathews, Mũkoma, \& Jansen, 2009; Schaalma, Abraham, Gillmore, \& Kok, 2004); teachers' attitudes, subjective norms and self-efficacy; teachers' general disposition (like student-centeredness and sexual morality); and, a supportive school environment for sex education (Paulussen, Kok, \& Schaalma, 1994), are important (socio-cognitive) factors in adoption and quality of implementation (i.e. dose delivered and fidelity of implementation) of a sex education programme. Dusenbury et al. (2005) also argue that teachers' understanding of the programme and teachers' prior experience in teaching the programme or a similar programme enhances fidelity of implementation.

This study adds to the above research on (socio-cognitive) factors affecting the quality of implementation (i.e. fidelity and dose delivery) of comprehensive rights-based sex education programs in a Sub-Saharan context. The study examines socio-cognitive correlates (e.g., teachers' attitudes towards WSWM and confidence in teaching sex education) of dose delivery and fidelity of implementation of WSWM. Furthermore, this study explores the perceived barriers and facilitators of implementation, which provides insight in the context in which teachers are required to implement comprehensive sex education in Uganda.

\section{Methods}

\section{Participants and procedure}

The study includes a survey among WSWM teachers with a baseline and follow-up measurement, and in-depth interviews with a small subset of teachers in between the two survey measurements. The selection of teachers took place during a mid-term review meeting of WSWM teachers in May 2008, Kampala, which was organised by SchoolNet Uganda (SNU), the implementing partner of the World Population Foundation (WPF). Approximately 100 teachers were present, among them 24 from schools which were part of the intervention group of the simultaneous effect evaluation study (Rijsdijk et al., 2011). Teachers from these 24 schools were included in the process evaluation on a voluntary basis. The remaining WSWM teachers were asked if they wanted to participate in the study, and 56 of them responded positively. 
Before completing the questionnaire, teachers were given an instruction by a trained Dutch female Health Psychology Master student and SNU staff about the goal and content of the questionnaire, about giving consent, and about their confidentiality being assured. The questionnaires were completed in English at the site of the meeting in approximately one hour. Of the 80 questionnaires handed out, 75 were returned completed (T0). The post-test took place upon completion of the programme, between September 2008 and February 2009. Of the 75 teachers participating at T0, $65(87 \%)$ returned the post-test questionnaire (T1), among them the 24 teachers of the intervention group of the effect evaluation study. The analysis was conducted with the data of the teachers who had completed both baseline and post-test questionnaire ( $N=65$, from 54 different schools). Almost half of them were female (49.2\%), $46.2 \%$ was male, and $4.6 \%$ unknown. The mean age was 32.5 years $(S D=6.5)$, ranging from 24 to 52 at the time of the pre-test.

Of the 24 teachers from the intervention schools, eight were selected for indepth interviews, which were conducted in between the administration of the baseline and follow-up questionnaires of the process evaluation (June-August 2008). The selection of the teachers was based on gender ( 4 males; 4 females), on location of the school (spread throughout Uganda and both rural and urban), and type of school (boys-; girls; and mixed schools). However, some schools in the North of Uganda were considered to be too dangerous to travel to and were therefore not selected for the indepth interviews. The age of the teachers in the in-depth interviews ranged from 26 to 53 years. All interviews were recorded and transcribed verbatim. Teachers received an incentive of 30.000 UGX (= around €9.00) after the interview. See Table 4.1 for an overview of respondents and school types. The in-depth interviews of approximately 45 minutes to an hour, took place at the school site in between the pre- and the post-test. A trained Dutch female Health Psychology Master student conducted the interviews. 
Table 4.1 Characteristics respondents and school types

\begin{tabular}{lllll}
\hline $\mathrm{nr}$ & Fictive name & Gender & School type & Boarding/Day \\
\hline 1 & Mary & $\mathrm{F}$ & Girls & Boarding \\
2 & Allen & $\mathrm{F}$ & Mixed & Boarding/Day \\
3 & Grace & $\mathrm{F}$ & Girls & Boarding \\
4 & Madina & $\mathrm{F}$ & Mixed & Boarding/Day \\
5 & Joseph & M & Girls & Boarding \\
6 & Alex & M & Boys & Boarding \\
7 & Stephen & M & Mixed & Boarding/Day \\
8 & Fred & M & Mixed & Boarding/Day \\
\hline
\end{tabular}

\section{Ethical approval}

The Ethical Committee Psychology (ECP) of Maastricht University in the Netherlands approved the study. Each of the respondents signed an informed consent stating that they completed the questionnaire on a voluntary basis and that they understood that they could stop at any time.

\section{The questionnaire}

The questionnaire was administered at baseline, when teachers just had started implementing the first lesson(s) of WSWM, and at post-test, directly after completion of the programme. The questionnaire was based on the Theory of Planned Behaviour model (see also the SHARE intervention questionnaire developed by Wight et al. (Wight et al., 2002). The questionnaire consisted of socio-demographic questions, such as age, gender and religion, and socio-cognitive characteristics, such as the attitudes of teachers towards sex education and their confidence in teaching about sexuality. The pre-test included questions related to intention. The post-test consisted of relevant outcome measures such as fidelity of implementation and dose delivered, and experienced barriers of and support for implementation. Items were scored either on a binary scale ("no" or "yes") or on a five-point Likert scale. Items were recoded such that higher scores reflect a stronger presence of the concerned variable. For all scales used, mean scores of the construct variables were calculated. The reliability of the scales used was assessed using Cronbach's alpha in case the scale consisted of minimal 3 items. 
For two items constructs, Pearson correlation coefficient was used, with a significant correlation level of $p<.01$.

\section{Questionnaire at baseline (TO)}

\section{Background variables}

Demographic variables, including gender of the teacher, age, religious background, years of teaching experience, and having taught WSWM before were assessed with appropriate items. To gain a better understanding of the implementation context, questions were asked about whether the programme was implemented with, without or partially with computers. Another question related to whether WSWM was implemented in extra-curricular time, within the time of the regular curriculum or both.

\section{Intentions}

Teachers' intentions towards full dose of delivery, was measured by the following question: "Do you intend to finish teaching the WSWM programme?" ( $0=$ no; 1 = yes). Intention towards fidelity of implementation, was measured by the following item: "Do you intend to follow the WSWM manual (protocol) in your teaching?" ( $0=$ no; $1=$ yes).

\section{Attitudes}

The general attitude towards sex education was measured by five statements $(\alpha=.68)$, such as "I think sex education for students in Uganda is important." (1 = very unimportant; 5 = very important). The attitude towards the importance of comprehensive and open sex education for young people was measured by two items $(r=.58, p=$ .001), such as: "It is important to talk about sex with young people in an open way" ( 1 = totally disagree; 5 = totally agree). The attitude towards the WSWM programme was measured by six items $(\alpha=.81)$, such as "Do you think the WSWM programme is important?" ( 1 = totally disagree; 5 = totally agree). The attitude towards teaching about contraceptives was measured by two questions $(r=.61, p=.001)$, like "We have to teach young people about condoms" ( $1=$ total disagree; $5=$ totally agree). Finally, the attitudes towards young peoples' sexual rights was measured by three items, like "Young people have the right to make their own decisions on their sexual life." $(\alpha=.69)$. 


\section{Subjective norms}

The subjective norm regarding fidelity of implementation was measured by the following question: "Do you think the following people find it important that you teach the programme according to the WSWM manual?" ( 1 = totally disagree; 5 = totally agree), followed by nine different people, like "other WSWM teachers" and "head teacher" $(\alpha=.90)$. Support from other people was measured by the following question: "I ex-

perience support for teaching the WSWM programme from the following people" (1 = totally disagree; 5 = totally agree), followed by nine categories, like "other school teachers" and "parents" ( $\alpha=.76)$.

\section{Confidence and self-efficacy}

Teachers' confidence in educating and discussing sexuality in the classroom was measured by the question "How confident do you feel about doing the following in the classroom?" ( 1 = unconfident; 5 = confident), followed by 19 items such as 'Educating about sexual development and puberty', and 'Discussing masturbation' ( $\alpha=.84)$. Teachers' confidence in creating a safe and non-judgmental atmosphere in class, was measured by three statements, such as "How confident did you feel about doing the following in the classroom?: non-judgemental teaching of sexuality" ( 1 = unconfident; $5=$ confident; $\alpha=.67)$. The confidence of teachers in dealing with different teaching methods was measured by five questions, like "How confident do you feel about doing the following in the classroom?" Organising role-plays" ( $1=$ unconfident; $5=$ confident; $\alpha=.80)$. Teachers' confidence in teaching WSWM was measured by eight statements, like: "I can deal with critical reaction of students regarding the fact that I am teaching the WSWM programme", "If needed, I can act as a process facilitator instead of a teacher" and "I find myself skilled in teaching WSWM" (1 = totally disagree; $5=$ totally agree; $\alpha=.83$ ). Finally, teachers' self-efficacy in implementing the WSWM programme was assessed by two single items ( 1 = totally disagree; 5 = totally agree): “I feel like I am able to complete teaching the whole WSWM programme" (self-efficacy completeness of implementation) and "I feel like I am able to teach the WSWM programme according to the manual" (self-efficacy fidelity of implementation). 


\section{Questionnaire at post-test (T1)}

Dose delivered and fidelity of implementation

Dose delivered was measured by the following questions: "Have you taught all the lessons of the WSWM programme?", followed by a list of the names of all 14 lessons ( $0=$ no; 1 = yes). Respondents who completed all 14 lessons, or who completed 13 and had the planned the final lesson, scored "complete dose delivery". All others were coded "no complete dose delivery.".

Fidelity of implementation was measured by two items: (1) 'Of all the assignments/exercises that you taught, did you conduct them in the way they were described in the teacher manual/instruction (following the exact description)?' (1 = no, not at all according to the manual; 5 = Yes, totally according to the manual), and (2) 'Did you teach the lessons in the order that is stated in the manual?' ( $0=$ no; $1=$ yes). Respondents who scored ' 5 ' on the first question (following the exact description of assignments in the manual) and ' 1 ' on the second question were recoded as "full fidelity". All other respondents were recoded as "partial fidelity".

\section{Barriers of and support for implementation}

Teachers' experienced barriers of implementing the WSWM programme, were measured at T1 by 13 single statements, such as "The classes are too big" and "It was difficult to relate to young people regarding sexuality" ( 1 = very much; $5=$ not at all; $\alpha$ $=.77$ ). The experienced support from relevant others (such as other teachers, school management and parents) to teach WSWM was measured by the following question: "I experienced support for teaching the WSWM programme from the following people...", after which a list of eight people followed, including 'other WSWM teachers', 'school management', and 'parents of WSWM students' (1 = totally disagree; 5 = totally agree; $\alpha=.81$ ).

\section{In-depth interviews}

Each in-depth interview started with a short explanation about the background and objectives of the research, and some general questions about the teachers' main teaching subject. The interview protocol included the following topics: (1) experienced 
support from relevant others to teach WSWM; (2) attitudes towards adolescents' sexuality; (3) religious and cultural beliefs and WSWM; (4) confidence and self-efficacy in teaching sex education and WSWM; (5) fidelity and completeness of implementation; and (6) challenges and improvements of (implementing) the programme. Examples of questions that were included are: "Is the amount of support that you experience sufficient for you?" If no: "What kind of support do you need?" and "Do you follow the WSWM manual/protocol in your teaching? Why (not)?".

\section{Data analysis}

The quantitative data from the teacher questionnaires were analysed using SPSS (17.0). Bivariate logistic regression was employed to determine the association between the dose of delivery and the fidelity of implementation on the one hand and the relevant determinants on the other hand. A $p$-value of .05 was used at a $95 \%$ confidence interval.

The principle researcher read and re-read the data from the in-depth interviews and analysed them using the template method (King, 1998). A priori codes were included, reflecting the main interview topics. This way, clarification of the experienced barriers and support as well as additional barriers and supportive factors emerged.

\section{Results}

\section{Correlates of dose delivered and fidelity of implementation}

The majority (52\%) of teachers taught all the lessons of the program. Two of them had not yet held the WSWM exhibition (lesson 14), but had this planned shortly after filling in the questionnaire. The first 11 lessons were taught by $86 \%$ of the teachers. Lesson 12 (Your future, Dreams and Plans) and lesson 13 (My Top Tips Peer Book) were skipped the most (respectively $28 \%$ and $23 \%$ of the respondents), and $80 \%$ had finished lesson 14 (the Exhibition). See Table 4.2 for an overview. Approximately onethird (35\%) of the schools implemented the programme using a computer, $28 \%$ without a computer and $34 \%$ of the schools implemented the programme partially using a computer. 
Table 4.2 Dose of delivery $(N=65)$

\begin{tabular}{llll}
\hline Lesson & Topic & $\begin{array}{l}\text { Number (\%) of teachers } \\
\text { having taught the lesson }\end{array}$ & $\begin{array}{l}\text { Number (\%) of teachers not } \\
\text { having taught the lesson }\end{array}$ \\
\hline 1 & The World Starts With Me & $61(93.8 \%)$ & $4(6.2 \%)$ \\
2 & Emotional ups and downs & $62(95.4 \%)$ & $3(4.6 \%)$ \\
3 & Is your body changing too? & $61(93.8 \%)$ & $4(6.2 \%)$ \\
4 & Friends and relationships & $61(93.8 \%)$ & $4(6.2 \%)$ \\
5 & Boys and girls, men and women & $61(93.8 \%)$ & $4(6.2 \%)$ \\
6 & Fight for your rights! & $56(86.2 \%)$ & $9(13.8 \%)$ \\
7 & Sexuality and love & $59(90.8 \%)$ & $6(9.2 \%)$ \\
8 & Pregnancy: 4 girls ànd boys & $60(92.3 \%)$ & $5(7.7 \%)$ \\
9 & Protect yourself: STIs and HIV/AIDS & $59(90.8 \%)$ & $6(9.2 \%)$ \\
10 & HIV/AIDS: U have a role 2 play & $59(90.8 \%)$ & $6(9.2 \%)$ \\
11 & Love shouldn't hurt & $59(90.8 \%)$ & $6(9.2 \%)$ \\
12 & Your future, dreams and plans & $47(72.3 \%)$ & $18(27.7 \%)$ \\
13 & My top tips peer book & $50(76.9 \%)$ & $15(23.1 \%)$ \\
14 & The exhibition & $52(80 \%)$ & $13(20 \%)$ \\
\hline
\end{tabular}

Of the total of 65 respondents, $48 \%$ scored "full fidelity", which is defined as conducted all assignments and exercises following the exact description in the manual, and teaching the lessons in the order as stated in the manual. More than half $(57 \%)$ of the respondents said they had implemented the assignments and exercises totally according to the manual, $38.5 \%$ partially, $3.1 \%$ not really according to the manual, and $1.5 \%$ was not sure. The majority (83\%) of the teachers reported they had followed the sequence of the lessons as stated in the WSWM manual, whereas twelve teachers (17\%) said they had not.

The univariate associations between dose delivery (= number of lessons implemented) as well as fidelity of implementation (= taught according to the manual) and the socio-cognitive variables are presented in Table 4.3 and Table 4.4. 'Confidence in teaching WSWM' was (negatively) associated with a higher score on full dose delivery, explaining $10 \%$ of the variance in full dose delivery (Nagelkerke $R^{2}=.10$ ). Full fidelity was associated positively with teachers' confidence in educating and discussing sexuality in class. Teachers who find comprehensive and open sex education for young people important, scored lower on fidelity of implementation. Together these significant correlates explained $30 \%$ of the variance in fidelity (Nagelkerke $R^{2}=.30$ ). 
Table 4.3 Results of univariate and multivariate logistic models with dose delivery (full dose delivered; no full dose delivered).

\begin{tabular}{|c|c|c|c|c|c|c|}
\hline \multirow[b]{2}{*}{ Variables } & \multicolumn{2}{|c|}{ Univariate Model } & \multicolumn{4}{|c|}{ Multivariate Model } \\
\hline & B & OR $(95 \% \mathrm{Cl})$ & $P$-Value & B & OR $(95 \% \mathrm{Cl})$ & $P$-Value \\
\hline $\begin{array}{l}\text { Intention to finish the } \\
\text { programme }\end{array}$ & $0.10(1.03)$ & $\begin{array}{l}1.11 \\
(0.15-8.40)\end{array}$ & .92 & $-0.77(2.03)$ & $\begin{array}{l}0.46 \\
(0.009-24.50)\end{array}$ & .70 \\
\hline $\begin{array}{l}\text { General attitude } \\
\text { towards sex education }\end{array}$ & $3.79(2.88)$ & $\begin{array}{l}44.11 \\
(0.16-12552.33)\end{array}$ & .19 & $7.20(4.78)$ & $\begin{array}{l}1342.91 \\
(.011-1.59)\end{array}$ & .13 \\
\hline $\begin{array}{l}\text { Attitude towards young } \\
\text { people's sexual rights }\end{array}$ & $0.04(0.27)$ & $\begin{array}{l}1.05 \\
(0.62-1.77)\end{array}$ & .87 & $0.17(0.39)$ & $\begin{array}{l}1.18 \\
(0.55-2.54)\end{array}$ & .67 \\
\hline $\begin{array}{l}\text { Attitude towards } \\
\text { importance of } \\
\text { comprehensive sex } \\
\text { education }\end{array}$ & $0.00(0.46)$ & $\begin{array}{l}1.00 \\
(0.41-2.46)\end{array}$ & 1.00 & $0.26(0.74)$ & $\begin{array}{l}1.30 \\
(0.31-5.56)\end{array}$ & .72 \\
\hline $\begin{array}{l}\text { Attitude towards } \\
\text { teaching about } \\
\text { contraceptives }\end{array}$ & $0.26(0.27)$ & $\begin{array}{l}1.28 \\
(0.76-2.16)\end{array}$ & .36 & $0.51(0.38)$ & $\begin{array}{l}1.66 \\
(0.79-3.51)\end{array}$ & .18 \\
\hline $\begin{array}{l}\text { Attitude towards the } \\
\text { WSWM programme }\end{array}$ & $-0.79(0.74)$ & $\begin{array}{l}0.46 \\
(0.11-1.94)\end{array}$ & .29 & $-0.48(1.01)$ & $\begin{array}{l}0.62 \\
(0.09-4.45)\end{array}$ & .64 \\
\hline $\begin{array}{l}\text { Support from other } \\
\text { people }\end{array}$ & $0.40(0.40)$ & $\begin{array}{l}1.48 \\
(0.67-3.27)\end{array}$ & .33 & $0.67(0.62)$ & $\begin{array}{l}1.95 \\
(0.58-6.50)\end{array}$ & .28 \\
\hline $\begin{array}{l}\text { Confidence in } \\
\text { educating and } \\
\text { discussing sexuality } \\
\text { in class }\end{array}$ & $-0.24(0.56)$ & $\begin{array}{l}0.79 \\
(0.26-2.37)\end{array}$ & .68 & $0.48(1.11)$ & $\begin{array}{l}1.62 \\
(0.18-14.29)\end{array}$ & .67 \\
\hline $\begin{array}{l}\text { Confidence in creating } \\
\text { a safe atmosphere }\end{array}$ & $1.06(0.71)$ & $\begin{array}{l}2.89 \\
(0.72-11.67)\end{array}$ & .14 & $3.20(1.27)$ & $\begin{array}{l}24.45 \\
(2.03-294.35)\end{array}$ & .012 \\
\hline $\begin{array}{l}\text { Confidence in dealing } \\
\text { with different teaching } \\
\text { methods }\end{array}$ & $-0.29(0.65)$ & $\begin{array}{l}0.75 \\
(0.21-2.70)\end{array}$ & .66 & $-1.28(1.36)$ & $\begin{array}{l}0.28 \\
(0.02-3.97)\end{array}$ & .35 \\
\hline $\begin{array}{l}\text { Confidence in teaching } \\
\text { WSWM }\end{array}$ & $-1,32(0.60)$ & $\begin{array}{l}0.27 \\
(0.08-0.87)\end{array}$ & .029 & $-2.73(1.04)$ & $\begin{array}{l}0.07 \\
(0.01-0.50)\end{array}$ & .009 \\
\hline $\begin{array}{l}\text { Self-efficacy in } \\
\text { implementing the } \\
\text { WSWM programme } \\
\text { completely (= full dose } \\
\text { delivery) }\end{array}$ & $-0.14(0.25)$ & $\begin{array}{l}0.87 \\
(0.53-1.42)\end{array}$ & .58 & $-0.07(0.36)$ & $\begin{array}{l}0.93 \\
(0.46-1.89)\end{array}$ & .84 \\
\hline $\begin{array}{l}\text { Constant } \\
\text { Nagelkerke } R^{2}=.41\end{array}$ & & & & $-9.37(9.66)$ & 0.00 & .33 \\
\hline
\end{tabular}


Table 4.4 Results of univariate and multivariate logistic models with fidelity of implementation (full fidelity; no full fidelity).

\begin{tabular}{|c|c|c|c|c|c|c|}
\hline \multirow[b]{2}{*}{ Variables } & \multicolumn{2}{|c|}{ Univariate Model } & \multirow[b]{2}{*}{$P$-Value } & \multicolumn{2}{|c|}{ Multivariate Model } & \multirow[b]{2}{*}{$P$-Value } \\
\hline & B & OR $(95 \% \mathrm{Cl})$ & & B & $O R(95 \% \mathrm{Cl})$ & \\
\hline $\begin{array}{l}\text { Intention to follow the } \\
\text { WSWM Manual in } \\
\text { teaching }\end{array}$ & $1.22(1.04)$ & $\begin{array}{l}3.40 \\
(0.44-26.31)\end{array}$ & .24 & $\begin{array}{l}-0.27 \\
(1.58)\end{array}$ & $\begin{array}{l}0.76 \\
(0.04-16.87)\end{array}$ & .87 \\
\hline $\begin{array}{l}\text { General attitude } \\
\text { towards sex education }\end{array}$ & $0.34(1.08)$ & $\begin{array}{l}1.40 \\
(0.17-11.70)\end{array}$ & .76 & $4.14(2.41)$ & $\begin{array}{l}26.88 \\
(0.56-7085.06)\end{array}$ & .09 \\
\hline $\begin{array}{l}\text { Attitude towards } \\
\text { young people's sexual } \\
\text { rights }\end{array}$ & $-0.04(0.27)$ & $\begin{array}{l}0.96 \\
(0.57-1.62)\end{array}$ & .87 & $\begin{array}{l}-.088 \\
(0.40)\end{array}$ & $\begin{array}{l}0.92 \\
(0.42-1.99)\end{array}$ & .82 \\
\hline $\begin{array}{l}\text { Attitude towards } \\
\text { importance of } \\
\text { comprehensive } \\
\text { sex education }\end{array}$ & $-1.33(0.56)$ & $\begin{array}{l}0.27 \\
(.09-.79)\end{array}$ & .017 & $\begin{array}{l}-2.71 \\
(0.10)\end{array}$ & $\begin{array}{l}0.07 \\
(0.01-0.47)\end{array}$ & .007 \\
\hline $\begin{array}{l}\text { Attitude towards } \\
\text { teaching about } \\
\text { contraceptives }\end{array}$ & $0.17(0.27)$ & $\begin{array}{l}1.19 \\
(0.71-2.00)\end{array}$ & .52 & $\begin{array}{l}-0.07 \\
(0.39)\end{array}$ & $\begin{array}{l}0.93 \\
(0.44-1.99)\end{array}$ & .86 \\
\hline $\begin{array}{l}\text { Attitude towards the } \\
\text { WSWM programme }\end{array}$ & $0.22(0.72)$ & $\begin{array}{l}1.25 \\
(0.31-5.00)\end{array}$ & .76 & $0.76(1.04)$ & $\begin{array}{l}2.15 \\
(0.28-16.54)\end{array}$ & .46 \\
\hline $\begin{array}{l}\text { Subjective norm } \\
\text { towards fidelity of } \\
\text { implementation }\end{array}$ & $0.53(0.37)$ & $\begin{array}{l}1.70 \\
(0.83-3.48)\end{array}$ & .15 & $1.16(0.61)$ & $\begin{array}{l}3.20 \\
(0.97-10.57)\end{array}$ & .056 \\
\hline $\begin{array}{l}\text { Confidence in } \\
\text { educating and } \\
\text { discussing } \\
\text { sexuality in class }\end{array}$ & $1.26(0.64)$ & $\begin{array}{l}3.51 \\
(1.00-12.31)\end{array}$ & .05 & $2.70(1.22)$ & $\begin{array}{l}14.92 \\
(1.38-161.44)\end{array}$ & .026 \\
\hline $\begin{array}{l}\text { Confidence in creating } \\
\text { a safe atmosphere }\end{array}$ & $1.27(0.78)$ & $\begin{array}{l}3.57 \\
(0.77-16.43)\end{array}$ & .10 & $\begin{array}{l}-1.32 \\
(1.62)\end{array}$ & $\begin{array}{l}0.27 \\
(0.01-6.34)\end{array}$ & .41 \\
\hline $\begin{array}{l}\text { Confidence in dealing } \\
\text { with different teaching } \\
\text { methods }\end{array}$ & $0.84(0.70)$ & $\begin{array}{l}2.31 \\
(0.58-9.15)\end{array}$ & .23 & $\begin{array}{l}-1.39 \\
(1.40)\end{array}$ & $\begin{array}{l}0.25 \\
(0.02-3.85)\end{array}$ & .32 \\
\hline $\begin{array}{l}\text { Confidence in teaching } \\
\text { WSWM }\end{array}$ & $0.93(0.58)$ & $\begin{array}{l}2.53 \\
(.81-7.88)\end{array}$ & .11 & $1.88(1.10)$ & $\begin{array}{l}6.53 \\
(0.79-54.04)\end{array}$ & .08 \\
\hline $\begin{array}{l}\text { Self-efficacy in } \\
\text { completing the } \\
\text { WSWM programme } \\
\text { according to the } \\
\text { manual (= full fidelity) }\end{array}$ & $0.20(0.31)$ & $\begin{array}{l}1.22 \\
(0.66-2.26)\end{array}$ & .53 & $.010(0.40)$ & $\begin{array}{l}1.10 \\
(0.51-2.41)\end{array}$ & .81 \\
\hline Constant & & & & $\begin{array}{l}-7.03 \\
(8.71)\end{array}$ & .001 & .42 \\
\hline Nagelkerke $R^{2}=.45$ & & & & & & \\
\hline
\end{tabular}




\section{Barriers of implementation}

Results from the post-test questionnaire show that 'lack of time' was most frequently mentioned by the teachers (77\%) as a barrier for implementation (answer categories 'very much' and 'a bit'). In the majority of the WSWM schools (76\%), the programme is taught in extra-curricular time, either right after the mandatory classes, or in the weekend. During the in-depth interviews, teachers indicated that this is problematic, especially for day schools, where the students have to return home after school. Some teachers mentioned that the need to balance between accommodating the students' needs and time was a major reason for them not to adhere strictly to the teachers' manual strictly. Role-plays were considered too time consuming and these were therefore often skipped. Other issues relating to lack of time mentioned are related to not being able to prepare for the lessons well, and irregular programming of the lessons.

After 'lack of time', teachers mentioned both 'lack of student manuals' (69\%) and 'lack of computers' (69\%) most frequently as barriers for implementing WSWM. During the in-depth interviews, all 8 teachers said to use the manual in class. In two schools the programme was implemented in the main hall, with a large number of students (50-100), which is a very difficult setting to work with a computer or to follow the manual (i.e. role plays, groups discussions). Some teachers said they would prefer the manual to have more simple explanations. The majority of teachers indicated that the manual should allow for more flexibility and should be more attuned to the Ugandan context:

For example, the book [manual] states the fact. But we needed a lot of Ugandan data, Ugandan examples, living examples on every topic, you know, where it is real life stories, real life pictures, you know. So that they don't think this is an international thing, they need to know the Ugandan experience. (Mary, girls boarding school).

In the in-depth interviews, teachers also mentioned the lack of computers as a main barrier of implementation. Even when computers were available, teachers experienced the problem of irregular electricity or the problem of computers being not 
available for the programme. Also, the issue of low quality computers was raised a couple of times: if computers were available, the computers were too slow to effectively run the programme, they did not have DVD-players nor projectors to show extra audio-visual materials.

'Lack of financial resources' was mentioned by just over half $(54 \%)$ of the teachers as a barrier of implementing WSWM. During the in-depth interviews, the lack of financial resources was broadened and explained as 'lack of financial motivation'. Despite teachers' enthusiasm to be involved in the teaching of this programme, their motivation declined as a result of lacking financial support for their efforts they put into the programme.

The survey questions on experienced barriers of implementation did not include an answer category related to 'lack of staff ' and 'high staff turnover'. However, both were mentioned as barriers of implementation during the in-depth interviews. Not all schools had the intended minimum of two trained WSWM teachers, meaning that in some cases only one teacher was responsible to cover all the lessons. During the indepth interviews, teachers mentioned that the government reallocates teachers every few years. Trained WSWM teachers might thus be transferred to another school, leaving the school with only one or no WSWM teacher.

'Lack of appropriate training' and 'lack of on-the-job guidance and support' of teachers were also not included in the questionnaire as a possible answer category, but were mentioned during the in-depth interviews. Some teachers started teaching WSWM without having had proper training. One teacher specifically expressed the need to receive training from Dutch trainers instead of trained Ugandan trainers. According to this teacher, Ugandan trainers are not so open about sexuality, and consequently teachers who are trained by these Ugandan trainers cannot change their attitudes about sexuality issues as much as when they are trained by Dutch trainers.

Some teachers specifically mentioned the need for more follow-up training, continuous support and on-the-job guidance and coaching during implementation. Related to this, is the fact that some teachers felt they lack knowledge about contraceptives and biological aspects of sexual health related topics included in the WSWM programme. One male teacher said he felt unconfident to explain 'female sexuality is- 
sues', and that it needs a professional, like someone from the health sector, to explain complicated issues like the menstruation cycle:

I feel much confident when I'm explaining issues to do with eh... with boys, and then when it comes on the side of girls, sometimes I feel that I'm really giving, you know, false information, particularly somebody is asking about the menstruation period. (....) But I mean, there are some particular areas, that I cannot really involve myself to talk about, which needed the help of either the senior woman teacher or the school nurse. (Joseph, girls boarding school).

Also some teachers mentioned that these complicated, biological issues are not clearly described in the manual.

\section{Supportive factors of implementation}

Results from the post-survey show that the majority of teachers felt most supported (answer categories 'totally agree' and 'agree') by their students (99\%), head teachers (97\%), school management (91\%), other WSWM teachers $(85 \%)$ and other teachers (72\%). Teachers felt less supported by parents (52\%), health care providers (49\%) and religious institutions (49\%). More than two-third (69\%) felt supported by their own family.

During the in-depth interviews, teachers mentioned school culture and the experienced support from school management, other teachers and community as important facilitating factors for implementation. One teacher explained that support from other teachers, the school management and parents made him feel motivated, rather than the financial reward he would receive for his efforts. Some teachers mentioned that other teachers do not want anything to do with WSWM or any other sex education programme and that the majority of the teachers are not supporting them. Gaining support from the other teachers is done through running workshops on WSWM for all the staff. Here again, the issue of lack of financial reward, was mentioned as a barrier to organise such workshops: 
(...) the other teachers wanted, want a one-day seminar rather than the 2-days workshop to be organized for them, on The World Starts With Me. They wanted to know the content, and what it is all about. But the school could not really raise money for organizing that workshop, because you know after workshop people expected some allowance to be given for them to go home. (Joseph, girls boarding school).

One teacher mentioned the valuable support of a regional network of other WSWM teachers in teaching, exchanging ideas and consultation. Support in teaching on technical or sensitive topics by the Science or Biology teachers or by the clinic officer to inform the students on STIs, was mentioned by a number of teachers as an additional facilitating factor for high quality implementation:

(...) we have a clinic officer here, in charge of the dispensary and she too comes in when it comes to STDs, STIS (...) whenever you had a chance you were to talk about one of those areas defined in WSWM, so we get a lot of support. That's why we have finished the programme. (Mary, girls boarding school).

Support from parents and the community was a concern to some of the teachers. They recognised the need to involve the community, and especially the parents, more in the sex education of their children, as to create a supportive attitude and norm concerning adolescents SRHR in line with the WSWM programme.

\section{(Non) Supportive beliefs and norms towards rights-based sex education}

Being a rights-based sex education programme, WSWM acknowledges adolescents sexuality and right to make informed choices about whether to be sexually active or not, with whom and to protect themselves from coerced sex, unintended pregnancy and STIs, including HIV. Teachers' beliefs and norms that are in line with the rightsbased approach, will facilitate implementation of WSWM. During the in-depth interviews, teachers also expressed their personal beliefs and norms towards sexuality 
of adolescents, sexual intercourse before marriage and condom use in particular. All eight teachers strongly disapproved their students having sexual intercourse and were in favour of abstinence until the age of 18 , preferably until marriage. They shared the opinion that students at secondary schools should focus on their studies only and not be involved in relationships and sexual intercourse. Also, the Ugandan Ministry of Education, supportive of abstinence-only sex education, does not support condom promotion at schools. The promotion of condom use among young people, remains a controversial topic, surrounded by myths and fear:

(...) We are not really telling them to actually go for condoms. (...) Because, you may think that somebody is protecting you and then this person might have even created actually, you know, a hole, I mean, on the condom and this is either going to make you pregnant despite the condom or the person is going to infect you and it has been a trick. You know, people with HIV/ AIDS have ever played, they will tell you that I, you'll find that protected when they've already done it, the condom. So with the ignorance you just get yourself in for it. (Joseph, girls boarding school).

Some teachers said they did not promote condom use, because of their religious views, others did feel the religious pressure, but decided to follow their own 'practical more realistic beliefs'. These teachers believe that promoting condoms is just necessary and feel comfortable by talking about condoms. Other teachers, although only teaching about abstinence, do hope that, if needed, the adolescent uses a condom:

Okay, they should use them. But at least.... Okay I just assume they find that option on themselves, on their own. But not I advertising for it. So, within myself, I can say okay, in that regard, they can use, but I don't feel, within myself, that I should tell them that option. I just pray if they fell like that, let them find that option on their own. (Allen, mixed girls and boys, boarding/ day school). 
Some teachers touched upon the issue of homosexuality, which in the Ugandan context is not only a taboo subject but same-sex practices is also a criminalized act. Homosexuality is framed as "deviant", "not-natural", and against the religious norms. In October 2009, an Anti-Homosexuality Bill was introduced in the Ugandan Parliament to expand existing anti-homosexuality laws. The Bill included heavier punishments and criminalization for direct and indirect support for same-sex practices; a requirement to report homosexuals, and to deny them shelter. After being time barred in the 8th parliament May 2011, it was reintroduced in parliament in February 2012 (Semugoma, Beyrer, \& Baral, 2012). In such a social, religious and political context, merely discussing homosexuality is already difficult to do. Teachers also referred to the chance to lose their job if discussing homosexuality in class:

Homosexuality is.. since the whole country is against that, I believe that, when somebody tempers, you know, to encourage homosexuality, particularly in school, which is actually at a mission, which is under church mission, definitely, it may end your job (laughing). Yes, so we're not actually talking and eh telling them that it is good practice to have homosexuality. (Alex, boys boarding school).

Only one teacher said she discussed the topic in class, because in her view homosexuality is a fact of life, which you just have to accept.

\section{Discussion}

The current study is one of the few process evaluations of a comprehensive sex education programme in a Sub-Saharan context, going beyond the mere statistics of dose delivered and fidelity rate by exploring correlates of dose delivered and infidelity of implementation as well as providing in depth analyses of experienced barriers and supportive factors from the perspective of the main implementers.

Overall, the percentage of teachers (52\%) who implemented all 14 WSWM lessons (dose delivered) and the percentage of teachers (48\%) who said they had implemented WSWM according to the manual (fidelity of implementation) were similar or 
lower compared to other sex education programmes in a Western as well as a Sub-Saharan context. Studies conducted in a Western context show higher percentages of teachers who fully implement the program and doing so according to the programs' manual or instructions. For instance, in a study conducted in the Netherlands, $81 \%$ of the teachers carried out most of the activities of a sex education programme they were supposed to (Wiefferink et al., 2005), and 71\% of the teachers in a Scottish context reported having followed the sex education package very closely (Buston, Wight, Hart, \& Scott, 2002). A process evaluation of a school-based sexual health intervention in Tanzania (Plummer et al., 2007) also shows very high percentages of around $90 \%$ curriculum coverage of those teachers who returned session reports and a 95\% fidelity rate. Other studies on implementation of HIV/AIDS and comprehensive sex education in schools in South Africa (Mũkoma et al., 2009b; Visser, Schoeman, \& Perold, 2004) show that some teachers implemented the program with more fidelity than others.

When looking at dose delivered, only confidence in teaching WSWM was found to be a correlate and, remarkably, the association was negative. The negative relation between confidence in teaching WSWM and dose delivered could be explained by the fact that teachers who were more confident at the start of WSWM did not expect to experience difficulties in implementation compared to those teachers who were less confident and therefore expected beforehand that they would find implementation difficult.

In line with other studies conducted in Europe (Paulussen, Kok, \& Schaalma, 1994) and in SSA (Helleve, Flisher, Onya, Mũkoma, \& Klepp, 2009; Matthews, Boon, Flisher, \& Schaalma, 2006), teachers' confidence in teaching and discussing sexuality issues in class (self-efficacy) appeared as an important associative positive factor of fidelity of implementation. Contrary to what is found in other studies (Paulussen et al., 1994; Helleve et al., 2009) factors such as attitudes, subjective norms and sexual morality, were not associated with high fidelity. Remarkably, our study shows that the importance teachers attach to open sex education for young people to prevent problems was negatively associated to full-fidelity of implementation. Recent research suggest that fidelity and adaptation often occur simultaneously and that both are important for effective outcomes. Modifying the programme to meet developmental and cultur- 
al needs is considered an important factor for high quality of implementation (Dusenbury et al., 2005; Durlak \& DuPre, 2008) and should not necessarily be considered an implementation failure (Matthews et al., 2006).

In line with other studies, the most frequently mentioned barriers of implementation were lack of time (Peterson \& Bickman, 1998; Buston et al., 2002; Kinsman et al., 1999), unavailability of student manuals (Dane \& Schneider, 1998), lack of financial resources and computers. For instance, a study on HIV education in South African schools revealed that insufficient time, lack of resources and large classes, posed serious challenges for teachers implementing sex education (Ahmed et al., 2009). The indepth interviews gave a better understanding of the implementation context and the barriers and facilitators for implementation. Negative personal attitudes and norms towards sex among adolescents, condom use and homosexuality, which are contrary to the WSWM curriculum content, hinder teachers in implementing WSWM the way it is intended. This was also found in HIV education programmes implemented in South African schools (Peterson \& Bickman, 1998; Ahmed et al., 2009), where a conflict was found between the teachers' personal beliefs and values (i.e. abstinence only, no condoms) and the messages that they were expected to communicate (i.e. promoting condom use). In Uganda, homosexual acts are illegal, and an anti-homosexuality attitude is apparent at all levels of society. Open and a rights-based discussion about homo-sexuality in schools is therefore very difficult to achieve.

Next to above mentioned factors, teachers mentioned lack of trained staff, high staff turnover, lack of follow-up training and on the spot guidance, lack of a detailed and simplified teacher manual and personal, cultural, religious norms and beliefs as barriers for full implementation. Similar findings are found in other studies in a SSA context (Mũkoma et al., 2009b; Visser et al., 2004; Matthews et al., 2006; Ahmed et al., 2006; Njue, Nzioka, Ahlberg, Pertet, \& Voeten, 2009; Kinsman et al., 2002). Teachers' lack of motivation has been linked to not receiving financial rewards. Some teachers even had to contribute their own resources to make sure the programme was implemented. 


\section{Conclusion}

School-based sex education in Uganda has great potential if adapted to the (special needs of the) local reality of the implementation context. To increase the feasibility of complete implementation, the programme should be flexible, consisting of an evidenced-based straightforward basic programme and add-on optional programme elements which the teacher can use depending on time and specific needs of the students. Teacher training should aim at increasing basic knowledge on SRHR, increasing teachers' self-efficacy to educate and discuss sexuality issues in class, identifying ways to discuss condom use in a cultural acceptable way, and critical reflection on conflicting norms and values which some teachers experience with comprehensive sex education for students. Furthermore, a supportive school and community environment, as well as supportive national policies and laws related to comprehensive rights-based sex education, are essential for high quality of implementation of such programmes at school level. Finally, in a limited resource context, basic teaching standards should first be established before more high-tech and interactive teaching can be successfully introduced (Plummer et al., 2007). Therefore, allocating funds for teaching the programme, especially if it is not part of the curriculum, and providing the necessary detailed and simplified manuals for teachers and students, are essential to effectively implement CSRE. Computer based programmes are a good option if the intervention ensures sufficient availability of good quality computers, a continuous electricity supply and a proper computer service attached to it, either provided by the government, the school, the implementing NGO or the funding agency. 


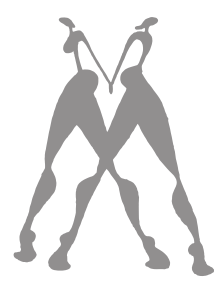

\section{Chapter 5 \\ The World Starts With Me: A multilevel evaluation of a comprehensive sex education programme targeting adolescents in Uganda}

This chapter is based on the following publication:

Rijsdijk L.E., Bos A.E.R., Ruiter R.A.C., Leerlooijer, J.N., de Haas, B., and Schaalma, H.P. (2011). The World Starts With Me: A multilevel evaluation of a comprehensive sex education programme targeting adolescents in Uganda. BMC Public Health, 11, 334. 


\begin{abstract}
The aim of the study discussed in this Chapter was to assess the effects of WSWM on socio-cognitive determinants of safe sex behaviour (delay; condom use and non-coercive sex). A survey was conducted both before and immediately after the intervention among students in intervention $(N=853)$ and comparison $(N=1011)$ groups. A mixed model repeated measures analysis was performed to assess the effectiveness of the WSWM programme on the main socio-cognitive determinants of safe sex behaviour at post-test. A similar post-hoc comparison was made between schools based on completeness and fidelity of implementation of WSWM. The study showed significant positive effects of WSMW were found on beliefs regarding what could or could not prevent pregnancy, the perceived social norm towards delaying sexual intercourse, and the intention to delay sexual intercourse. Furthermore, significant positive effects of WSWM were found on attitudes, self-efficacy and intention towards condom use and on self-efficacy in dealing with sexual violence (pressure and force for unwanted sex). A reversed effect of intervention was found on knowledge scores relating to non-causes of HIV (petting, fondling and deep kissing). A follow-up comparison between intervention schools based on completeness of the programme implementation revealed that almost all significant positive effects disappeared for those schools that only implemented up to 7 out of 14 lessons. Another follow-up analysis on the basis of implementation fidelity showed that schools with a "partial" fidelity score yielded more significant positive effects than schools with a "full" fidelity of implementation score. Although the study showed an intervention effect on a number of socio-cognitive determinants, the effectiveness of WSWM could be improved by giving more systematic attention to the context in which such a programme is to be implemented.
\end{abstract}




\section{Introduction}

In many Sub-Saharan countries, but also elsewhere, unsafe sexual behaviour among adolescents is widespread, as reflected by an early age onset of sexual intercourse, a large proportion of unprotected sexual intercourse, and multiple sexual partners among those who are sexually active (Kaaya et al., 2002; UAC, 2007; UBOS and Macro International Inc., 2007; Neema, Musisi, \& Kibombo, 2004; Darabi et al., 2008). In addition, coerced sexual intercourse among young people is a major problem in Sub-Saharan countries (UBOS and Macro International Inc., 2007; Neema et al., 2004; Darabi et al., 2008). Uganda, being one of the worlds' poorest countries and having the youngest population in the world with a median age of 15 , is no exception (Darabi et al., 2008).

Although Ugandan adolescents are now delaying (first) sexual intercourse more than before (UNAIDS, 2010), the majority have become sexually active by the age of 18 (UBOS and Macro International Inc., 2007; Zaba, Pisani, Slaymaker, \& Boerma, 2004). Ugandan girls start sexual intercourse at a younger age than boys: $15.5 \%$ of the girls have had sexual intercourse before the age of 15 , rising to $64.2 \%$ by the age of 18 , as compared to $12.2 \%$ and $49.9 \%$ of the boys (UBOS and Macro International Inc., 2007; UNAIDS, 2010). When sexually active, only around $15 \%$ of the young Ugandans aged 15 to 19 years have ever used a condom. Of those aged $15-24$ years who have ever had sex, $28 \%$ used a condom the first time that they had sex, with a slight difference between boys (29\%) and girls (27\%) (UBOS and Macro International Inc., 2007).

Until the end of 2000, HIV prevalence in Uganda was the highest among adolescents (age 15-19 years), but decreased in subsequent years below national levels of $6.5 \%$ (aged $15-49$ years) at $4.8 \%$ for females aged $15-24$ year old and at $2.3 \%$ for males aged 15-24 years (UNAIDS, 2010). Prevalence of other types of STIs (not HIV) are higher, varying from about 5\% among $10-14$ years old adolescents (4\% for boys and $6 \%$ for girls and) to around $12 \%$ among $20-24$ years old ( $10 \%$ among boys; $16 \%$ among girls) (Neema et al., 2004). In 2006, teenage pregnancy in Uganda was estimated at $25 \%$ (UBOS and Macro International Inc., 2007). Of the approximately 117,000 unsafe abortions which occur annually, 55\% are performed on 17-20 year old girls, with serious complications ( $23 \%$ ) and even death (2\%) occurring as a consequence. Compli- 
cations of pregnancy, (often illegal) abortion, and childbirth are the leading causes of disability and death among Ugandan girls aged 15 to 19 (UAC, 2007).

Coerced sexual intercourse is also a major problem for many young Ugandans, both girls and boys (Darabi et al., 2008; Koenig et al., 2004; Neema et al., 2006). Due to economic and socio-cultural factors, young people engage in transactional and intergenerational sex. Transactional sex refers to a situation in which an older man (or woman) gives money or gifts to a younger woman (or man), who makes it clear that she engages in sex only in exchange for payment, a ride in men's cars, good marks in school, employment or gifts (Darabi et al., 2008). It is estimated that approximately $30 \%$ of 15 to 24 years old Ugandan females are involved in such transactional relationships with men who are at least 10 years older (Darabi et al., 2008). Moreover, 16\% of the young women and $18 \%$ of the young men (age 15-19) are reported to have been engaged in giving or receiving money, gifts, or favours in exchange for sex in the past 12 months (UBOS and Macro International Inc., 2007). However, girls who receive gifts and money from their boyfriends, and the other way around, for having sex, is also often considered part of normal dating behaviour among Ugandan adolescents (Darabi et al., 2008).

These figures and data show that promoting safe sex behaviour (including strengthening personal decision making skills) among Ugandan adolescents is important. The important role of school-based comprehensive sex education programmes, especially in developing countries, to increase the delay of sexual debut, secondary delay and safe sex behaviour, has been demonstrated in different studies and reviews (Kirby, 2007; Paul-Ebhohimhen, Poobalan, \& van Teijlingen, 2008; Gallant \& Maticka-Tyndale, 2004).

The present study aims to assess the effects of a comprehensive sex education programme in Uganda, called The World Starts With Me (WSWM). It is one of the few large-scale evaluation studies of a school-based comprehensive sex education programme conducted in a Sub-Sahara African setting (Kaaya et al., 2002; Paul-Ebhohimhen et al., 2008). 


\section{The Intervention: The World Starts With Me}

WSWM is a comprehensive rights-based sex education programme, using low-tech computer-based learning, aimed at secondary school students (age 12-19). The experience of past programmes indicates that young people need programmes that are accessible, non-judgemental, and responsive to what young people want (McCauley, Salter, Kiragu, \& Senderowitz, 1995; Hughes \& McCauley, 1998). WSWM is based on the same principles, combining the development of computer skills and creative expression, and at the same time focusing on SRHR.

WSWM was designed for a setting, like in Uganda, where the computers used in schools tend to be basic and where four to five students have to share one computer. However, as many schools do not have (enough) computers, WSWM also allows students to read the information and to do the assignments and exercises without the computer, using hard copy manuals. This way, the same learning objectives can be met as when WSWM is followed using a computer, although the extra incentive of developing computer skills is lost. WSWM is carried out in English, which is the official language of Uganda.

The programme consists of 14 lessons, divided into four sections, with a focus on: (1) building self-esteem and personal decision-making, gaining insights into a person's identity and sexual development; (2) the role of the social environment (e.g. peers, family, close friends, teachers, and media), gender equity and sexual and reproductive rights; (3) sexual pleasure, sexual health problems and the life skills necessary to know how to avoid or deal with them; and (4) applying the lessons learned about goal setting regarding the students' future and on making booklets for use in peer education. The curriculum closes with an exhibition, at which young people show their parents and the community the results of the class efforts, such as slogans, posters and action plans.

The theoretical foundation of WSWM stems largely from two psychological theories of individual behaviour change: the theory of planned behaviour (TPB) (Ajzen, 1991; Ajzen, 2002) and the health belief model (HBM) (Becker, 1974). According to the TPB, (sexual) behaviour is determined by the intention to perform a certain behaviour, which in turn is influenced by attitudes, subjective norms and perceived behavioural 
control (or self-efficacy). An attitude is defined as a person's disposition to respond favourably or unfavourably towards certain behaviour. Subjective norms are functions of beliefs that specific, important individuals or groups (e.g. friends, parents, girlfriend, or husband) approve or disapprove of certain behaviour. The perceived behavioural control refers to a person's conviction regarding whether or not he has the required skills and resources (power) to perform the behaviour (Ajzen, 2002; Fishbein \& Ajzen, 2010). From the HBM (Becker, 1974), the constructs of perceived susceptibility and perceived severity were used as a basis for the development of the WSWM. Perceived susceptibility (or perceived personal risk) refers to a person's subjective perception of the risk of contracting a particular condition or illness. Perceived severity refers to a person's feelings concerning the seriousness of contracting an illness.

WSWM was first introduced in 30 secondary schools in Uganda in September 2003 as a club-based, extra-curricular programme. In subsequent years, the programme has been introduced in more than 150 schools throughout the country, reaching approximately 15.500 secondary school students in 2009 (WPF, 2010). It was intended that WSWM would be implemented over a 6-month period in each school. As WSWM is a club-based, extra-curricular programme, the students follow the programme on a voluntary basis, during hours outside the normal curriculum.

\section{The present study}

The present study examines the effectiveness of the WSWM programme in Uganda. It was hypothesized that, following the intervention, students in the intervention group would score significantly better than students in the comparison groups on the main socio-cognitive determinants (knowledge, beliefs, attitudes, perceived social norms, self-efficacy, risk perception and intention) of safe sex behaviour (delaying sexual intercourse; condom use and non-coercive sex).

\section{Methods}

\section{Study design and sample}

The evaluation had a quasi-experimental design, including pre- and post-test, intervention and comparison groups, and was conducted using a self-administered ques- 
tionnaire. As the intervention schools were already selected, based on the schedule of implementation of the non-governmental organisation SchoolNet Uganda (SNU), a randomized control trial could not be used. For each intervention school, a matching comparison school was selected on the basis of (1) type of school (boarding; day; mixed), (2) boys/girls/mixed school, and (3) geographical area (rural/urban). The comparison schools were promised that they would receive the WSWM programme next year if they were interested (waiting-list control group). The pre-test measurement took place in March 2008, just prior to the start of WSWM in the intervention schools (April 2008). The post-test measurement took place immediately following the end of the intervention period (September/October 2008).

A total of 48 schools (24 intervention and 24 comparison schools) were selected, equally distributed throughout Uganda. To ensure an equal distribution of gender and age, the (head) teachers were asked to select a group of 50 students on the basis of gender and age. The response rate was $83 \%(N=1986)$ for the pre-test (T0) and $67 \%(N$ = 1609) for the post-test (T1). Unavailability for post-test was primarily due to absenteeism, transfer to other schools and drop out. Data from two respondents at post-test were removed, because they had not completed the pre-test survey. Data from three intervention schools (in total 122 respondents) were also removed as these schools had finished only up to lesson 7 of the programme at post-test (two schools were at lesson 4 one school at lesson 7). The respondents of all comparison schools remained included in both pre-test and post-test. Outcome analysis was carried out with a final dataset comprising 1864 respondents at pre-test (853 intervention group; 1011 comparison group) and 1519 respondents at post-test (723 intervention group; 796 comparison group).

Drop out analysis, using one way ANOVA, revealed that those respondents who dropped out after pre-test $(N=345)$, compared with those who were present at both pre-test and post-test, were older $(M=16.29, S D=1.82$ vs. $M=16.04, S D=1.90 ; F(1$, $1743)=4,63, p<.05)$ and scored higher on performance behaviour of condom use $(M$ $=1.69 ; S D=1.13$ vs. $M=1.53 ; S D=1.04 ; F(1,1722)=4,00 p<.05)$. Furthermore, they scored lower on both beliefs about causes of HIV $(M=3.46 ; S D=.99$ vs. $M=3.58 ; S D$ $=.97 ; F(1,1428)=4,88, p<.05)$ and on attitudes towards delaying sexual intercourse $(M=3.97 ; S D=1.06$ vs. $M=4.13 ; S D=.93 ; F(1,1687)=7,84, p<.01)$. A chi-square 
analysis revealed that those respondents who dropped out were more often boys than girls $(53.3 \%$ vs. $\left.46.7 \%), \chi^{2}(1,1745)=10.8, p<.001\right)$.

\section{Procedure}

Research assistants (first year undergraduate students from the Makerere University in Kampala, Uganda) were selected by SNU and trained over the course of three days by two researchers, one from Uganda and one from the Netherlands. They were given an explanation of the objectives of the study, the objectives and content of the WSWM programme, the structure and rationale of the questionnaire, and the terminology (e.g. "petting \& fondling", "other sexual activities", "masturbation") and concepts (e.g., SRHR) involved. They were trained in responding to questions that students might have (e.g., what is meant by "mutual masturbation"?). The research assistants also received instruction on how the questionnaires should be administered for linking purposes; how to instruct the teachers and the students on filling in the questionnaire, and how to create a safe, quiet and anonymous environment in which students could complete the questionnaire.

Students completed the questionnaire in a classroom supervised by the trained research assistants. The research assistants explained to the class that confidentiality was assured by the fact that only the researchers had access to their questionnaires, that no names would be attached to the questionnaires, and that not one single questionnaire would be discussed with the school staff or any other person. Students received a list of definitions with terminology used, like "anal sexual intercourse =....". They also received a referral list with nearby counselling services. After the post-test, the students received a sheet with the main results from the pre-test survey and with correct information on sexual health issues. Participating schools received compensation (on average $\$ 50$ per school) for costs made to make the evaluation possible. Students received a drink and a snack after completing the questionnaire.

\section{Ethical clearance}

Ethical clearance was granted by the Ethical Committee Psychology (ECP) of Maastricht University in the Netherlands. Each of the respondents signed an informed consent form. 


\section{Study instruments and measures}

A pre-test semi-structured questionnaire was developed to collect data on the socio-demographic characteristics of the respondents, as well as on outcome variables that were central to the WSWM programme. Items and scales were based on a questionnaire previously used in Tanzania and South Africa (SATZ Project) (Mũkoma et al., 2009a). The questionnaire was pretested among secondary school students in Kampala, Uganda, after which some minor changes were made. The questionnaire had a boys- and girls-version, differing only in the wording of the questions (i.e., questions related to pregnancy, boyfriend vs. girlfriend). The same questionnaire was used at post-test.

Items were scored either on a 5-point Likert scale, ranging from 1 = lowest score to $5=$ highest score, or on a binary scale ("no" or "yes"). The reliability of the scales was assessed using Cronbach's alpha in cases where the scale consisted of a minimum of 3 items. For two items constructs, Pearson correlation coefficient was used, with a significant correlation level of $p<.01$. The following constructs were measured in the questionnaire:

Socio-demographic profile of respondents: Questions on gender, age, religion and sexual experience (having had sexual intercourse or not) were included in the questionnaire and measured using appropriate scales.

Knowledge concerning risky sexual behaviour leading to STI, HIV or pregnancy: Students were asked to respond to seven statements testing knowledge about which sexual behaviour could lead (or not lead) to (1) pregnancy, (2) STIs and (3) HIV (e.g., "deep kissing may lead to STI; no vs. yes). After dummy coding the scores to indicate incorrect (0) and correct answers (1), a factor analysis using orthogonal rotation (varimax), revealed five subscales: two scales were found measuring knowledge of the causes of STIs: knowledge about safe sexual behaviour not leading to STI (deep kissing; fondling; petting lead to STI; $\alpha=.67$ ) and knowledge about unsafe sexual behaviour and possible risk of STI (oral sex; vaginal sex; anal sex lead to STI; $\alpha=.57$ ). One scale was found measuring knowledge about causes of HIV infection (deep kissing; fondling; petting lead to HIV; $\alpha=.58$ ) and two scales were found measuring knowledge about (non) causes of pregnancy: (1) deep kissing; fondling; petting \& mutual masturbation 
cannot lead to pregnancy $(\alpha=.58)$ and (2) having oral sex and having anal sex cannot lead to pregnancy $(r=.18 ; p<.01)$.

Beliefs concerning pregnancy, STIs and HIV: Three two-item scales were used to measure respondents' beliefs about safe sex behaviour. Beliefs concerning pregnancy (e.g., "A girl cannot get pregnant the first time she has sex"; $r=.44 ; p<.01$ ), beliefs concerning HIV (e.g., "The HIV virus can be transmitted by mosquito bites"; $r=.16 ; p<$ .01), and beliefs concerning STIs (e.g. "Anal sexual intercourse is a safe way to protect oneself from sexually transmitted infections", $r=.22 ; p<.01$ ).

Risk perception was measured by three different constructs: two items measuring risk perception (i.e. susceptibility and severity) regarding getting pregnant (e.g., "If I have vaginal sexual intercourse without a condom or another contraceptive, this may lead to pregnancy"; "If I (my lover) become(s) pregnant, I will not be able to fulfil my dreams"; $r=.17 ; p<.01) ; 2$ similar items related to risk perception regarding HIV infection $(r=.22 ; p<.01)$, and 2 similar items related to risk perception regarding getting a $\mathrm{STI}(r=.20 ; p<.01)$.

Delay of sexual intercourse: Attitude towards delaying sexual intercourse was measured with two items: "It is better that young people my age, who are in a steady relationship, postpone sexual intercourse until they are older" and "Young people should not engage in sex until they are married" $(r=.29 ; p<.01)$; perceived social norm about delay of sexual intercourse was measured with a single item: "My friends believe that people my age should postpone sexual intercourse until they are older". Self-efficacy towards delaying sexual intercourse was measured with 2 items: "For me, waiting with sexual intercourse until I am older is difficult" and "I am confident that I can wait to have sexual intercourse until I am older" $(r=.45 ; p<.01)$. Intentions to delay sexual intercourse were measured by two single items: "Do you think you will wait with sexual intercourse until you are older?" (5-point scale; 1 = very unlikely and 5 = very likely) and "Do you plan to abstain from sexual intercourse until later?" $(0=$ no; 1 = yes).

Condom use: Condom use was measured with four items (e.g. "How often have you obtained a condom in the past 6 months?" and "In the past 6 months, did you use a condom when having sex?" $(\alpha=.84)$. Attitudes towards condom use were measured 
by two items, e.g. "using a condom is wise" $(r=.34 ; p<.01)$. Students were also asked whether they thought using a condom was pleasant. Perceived social norm regarding condom use was measured by one item: "My friends think that people my age should use a condom when having sexual intercourse". Self-efficacy for condom use was measured by two items: "For me, using a condom every time I have sexual intercourse is difficult" and "I am sure that I can use a condom every time I have sexual intercourse" $(r=.32 ; p<.01$.) Intention to use condoms was measured by two single items (e.g. "Do you think you and your (future) lover will use a condom when you will have sexual intercourse?").

Non-coercive sex: For "non-coercive sex", past behaviour regarding avoiding and escaping risky situations was measured with two items ("How often in the last 6 months did you avoid a situation in which you would have run the risk of unwanted sex?" and "How often in the last 6 months did you find yourself in a situation in which unwanted sex could have occurred and you managed to get out of it?"; $r=.54 ; p<$ .01). Attitudes towards sexual coercion and force were measured with three items (e.g. "When a boy is sexually excited and wants sex, his lover is allowed to refuse him"). Self-efficacy in dealing with situations where unwanted sex could happen was measured with six items (e.g. "Refusing a lover who pressures me to have sexual intercourse is difficult"; $\alpha=.70)$. Intention to deal with unwanted sex and force was measured with two items ("Do you think that in future you will avoid situations in which unwanted sex could happen?", and "Imagine you are in a situation with a lover and you don't want to have sex. Do you think you will refuse him/her?"; $r=.34 ; p<.01$ ).

\section{Data analysis}

The questionnaire data were coded, validated and cleaned. Data were analysed with SPSS 17.0. Frequency analysis was conducted to describe the demographic characteristics of the study sample at pre-test and one-way ANOVA's were carried out to determine possible statistically significant differences between the intervention and comparison groups at pre-test. To assess intervention effects, a linear mixed model procedure was used. Due to the fact that students belonged to different schools (hierarchical structure), the independence assumption is violated (Field, 2009). The Mixed 
Model procedure accounts for the hierarchical structure of the data and consequently tests the effects of intervention on the dependent variables for the random influence of school membership. Due to the non-random nature of the distribution of schools, and therefore also participants across the intervention and control conditions, we decided to use analysis of variance (ANOVA) of change from pre-test as the primary method of analysis rather than analysis of covariance (ANCOVA) of the outcome with the pre-test as covariate. In nonrandomized studies of pre-existing groups, ANOVA of change seems to be less biased than ANCOVA (van Breukelen, 2006). We further included age, gender and control/intervention variables as covariates. We were primarily interested in finding a significant group (intervention vs. control) x time (pre-test vs. post-test) interaction effect, which would suggest that the intervention had an effect on the outcome variable. In cases where there was a significant time $x$ group interaction effect, we conducted simple effects analyses testing the effect of group at both pre-test and post-test in order to understand the nature of the intervention effect. As the number and size of clusters were high (45 schools ( 21 intervention schools and 24 comparison schools) with an average of 42 participants per cluster), this same procedure also allowed us to interpret the significance of the effect of intervention on those dependent variables with a binary distribution. The significance level in this study was set at $p=.05$.

\section{Results}

\section{Socio-demographic profile of students}

The mean age of the students was 16.1 years $(S D=1.87)$. More than half of the students were girls (55.2\%) and $44.8 \%$ were boys. The majority of the students indicated that they were Christian (39.5\% Protestant, 34.2\% Catholic, 13\% Pentecostal), $11.5 \%$ were Muslim. At pre-test, $36.8 \%$ of the boys $(N=836)$, and $20.1 \%$ of the girls $(N=$ 1028), had engaged in sexual intercourse. More than half of those who were sexually experienced (60.3\%), said they had used a condom when they last had sexual intercourse $(56.1 \%$ of the boys and $67.3 \%$ of the girls). 


\section{Effects of The World Starts With Me}

Table 5.1 shows an overview of the mean scores $(S D)$ on the dependent variables at pre-test (T0) and post-test (T1) for both intervention and comparison groups, and the $F$-test statistic for the time $\mathrm{x}$ group interaction effect. Below we discuss the significant interaction effects on the different outcome variables.

Knowledge about risky sexual behaviour leading to STI, HIV or pregnancy: Multilevel analysis revealed a reversed effect of intervention on knowledge scores relating to non-causes of HIV (petting, fondling and deep kissing). At pre-test, a significant difference between groups was found, $F(1,1182)=18.27, p<.000)$, with the intervention group scoring significantly higher on knowledge of non-causes of HIV than the comparison group. At post-test, students who followed WSWM had, on average, lower knowledge scores as compared to pre-test, whereas students from the comparison group improved their knowledge at post-test as compared to pre-test. However, the intervention group still scored significantly higher at post-test than the comparison group, $F(1,1257)=4.22, p<.05)$. For the other knowledge scales, no significant effects of intervention were found.

Beliefs about STI, HIV and pregnancy: Students from the intervention schools scored significantly better than the comparison students at post-test as compared to pre-test when it came to wrong beliefs concerning pregnancy, like "a girl cannot get pregnant the first time she has sexual intercourse". At pre-test, there was no significant difference between intervention and comparison groups when it came to wrong beliefs concerning pregnancy, $F(1,1810)=1.12, p=.289)$. However, at post-test, the intervention group scored significantly higher than the comparison group, $F(1,1501)$ $=21.98, p<.001$. No significant effects were found for beliefs about STIs, or for beliefs about HIV.

Risk perception: No significant effects were found on risk perception.

Delaying sexual intercourse: We found an interaction effect for intervention over time for perceived social norm. At pre-test, there was no significant difference ( $F$ $(1,1745)=.13, p=1.30)$ between intervention and comparison groups. At post-test, both intervention and comparison groups agreed significantly more with the statement, "My friends believe that people my age should postpone sexual intercourse 
until they are older", as compared to pre-test, but this change was only significant for the intervention group. Furthermore, students who had followed WSWM were more convinced at post-test as compared to pre-test that they would wait with sexual intercourse until they were older (condition $x$ time interaction effect), $(F(1,1385)=11.18$, $p=.001)$, whereas there was no significant increase in agreement with this statement for the comparison group at post-test as compared to pre-test. At pre-test, there was no difference between intervention and comparison groups $(F(1,1655)=1.01, p=$ 3.15. The students from the intervention group also held a stronger intention to delay sexual intercourse at post-test, $F(1,1257)=7.22, p=.007$, again with no significant difference between the two groups at pre-test, $(F(1,1695)=.01, p=.937)$. No significant effects were found for attitudes towards delaying sexual intercourse, nor on self-efficacy towards delaying sexual intercourse.

Condom use: The analysis revealed a positive effect on attitude towards using condoms ("It is wise to use a condom" and "everybody should use one"). At pre-test, there was no significant difference between intervention and comparison groups, $F(1$, $1623)=.34, p=.853$. The difference at post-test was marginally significant, $F(1,1319)$ $=3.27, p=.07$, with an increase in positive attitude towards condom use among the intervention group students and a decrease in positive attitude among the comparison group students. After having followed WSWM, the intervention group students also scored significantly higher on self-efficacy using a condom than the comparison group, but this effect was primarily due to a marginally higher mean score on self-efficacy among the intervention group students at post-test as compared to pre-test, and a decrease in the mean score on self-efficacy among the comparison group students. At both pre-test $(F(1,1747)=2.12, p=.146)$ as well as post-test $(F(1,1415)=1.16, p$ $=.282$ ), there were no significant differences between intervention and comparison groups. Finally, the analysis showed an effect of intervention on the intention to use condoms. At pre-test, a significant difference was found between intervention and comparison groups, $F(1,1555)=4.59, p=.032$, with the intervention group being less inclined to use a condom than the comparison group. At post-test, students who followed WSWM showed an increase in intention to use a condom, whereas students from the comparison group had on average lower scores on intention to use a condom 
as compared to pre-test. Although the difference at post-test between the mean scores for intention to use a condom between the intervention and the comparison groups was not significant $(F(1,1275=.749, p=.387)$, the time $x$ group interaction was. This means that the intervention was relatively effective in increasing the intention to use a condom. No significant effects were found for past performance behaviour, or for perceived social norm towards condom use.

Non-coercive sex: The analysis showed a time $x$ group interaction effect for self-efficacy in dealing with sexual coercion. At pre-test, there was no significant difference between intervention and comparison groups, $F(1,1817)=.168, p=.682$. At post-test, both intervention group students and comparison students were more confident that they could deal with situations where sexual pressure and force would be used as compared to pre-test, but the increase in the mean score was significantly higher among the intervention group than in the comparison group, $F(1,1467)=7.73$, $p=.006)$. No significant effects were found for past performance behaviour regarding avoiding and escaping risky situations, for attitudes towards sexual coercion, or for intention to deal with unwanted sex and force. 
Table 5.1 Mean items scores or percentages for experimental and control groups at pre- test and post-test

\begin{tabular}{|c|c|c|c|c|c|}
\hline & \multicolumn{2}{|c|}{ Intervention } & \multicolumn{2}{|c|}{ Comparison } & \multirow[b]{2}{*}{$F$} \\
\hline & $\begin{array}{l}\text { Pre-test } \\
(N=853) \\
M(S D)\end{array}$ & $\begin{array}{l}\text { Post-test } \\
(N=723) \\
M(S D)\end{array}$ & $\begin{array}{l}\text { Pre-test } \\
(N=1011) \\
M(S D)\end{array}$ & $\begin{array}{l}\text { Post-test } \\
(N=796) \\
M(S D)\end{array}$ & \\
\hline \multicolumn{6}{|l|}{ Knowledge } \\
\hline $\begin{array}{l}\text { Knowledge about non-causes of STI (petting, } \\
\text { fondling, deep kissing) }\end{array}$ & $.37(.56)$ & $.31(.37)$ & $.32(.37)$ & $.28(.34)$ & .38 \\
\hline $\begin{array}{l}\text { Knowledge about causes of STI (anal sexual } \\
\text { intercourse; vaginal sexual intercourse; mutual } \\
\text { masturbation) }\end{array}$ & $.47(.46)$ & $.64(.43)$ & $.44(.37)$ & $.58(.38)$ & 2.20 \\
\hline $\begin{array}{l}\text { Knowledge about non-causes of HIV (petting, } \\
\text { fondling, deep kissing) }\end{array}$ & $.38(.55)$ & $.34(.38)$ & $.27(.34)$ & $.30(.34)$ & $6.02 *$ \\
\hline $\begin{array}{l}\text { Knowledge about non-causes of pregnancy } \\
\text { (petting, fondling, deep kissing) }\end{array}$ & $.93(.45)$ & $.89(.34)$ & $.90(.20)$ & $.90(.21)$ & .16 \\
\hline $\begin{array}{l}\text { Knowledge causes of pregnancy (vaginal sexual } \\
\text { intercourse; not anal intercourse) }\end{array}$ & $.26(.44)$ & $.23(.42)$ & $.22(.32)$ & $.20(.31)$ & .28 \\
\hline \multicolumn{6}{|l|}{ Beliefs } \\
\hline Beliefs about causes of pregnancy & $3.76(.99)$ & $4.18(.89)$ & $3.78(.98)$ & $4.03(.89)$ & $11.16^{* *}$ \\
\hline Beliefs about causes of HIV & $3.60(.96)$ & $3.74(.98)$ & $3.53(.97)$ & $3.72(.93)$ & .27 \\
\hline Beliefs about causes of STI & $3.27(.96)$ & $3.58(.89)$ & $3.25(.96)$ & $3.51(.87)$ & .67 \\
\hline \multicolumn{6}{|l|}{ Risk perception (perceived risk and perceived severity) } \\
\hline Risk perception towards HIV & $3.92(.94)$ & $3.90(.93)$ & $3.89(.94)$ & $3.95(.90)$ & 1.07 \\
\hline Risk perception towards STI & $3.45(1.00)$ & $3.55(.95)$ & $3.49(.97)$ & $3.55(.94)$ & .73 \\
\hline Risk perception towards pregnancy & $4.00(.90)$ & $4.04(.88)$ & $3.94(.89)$ & $4.02(.87)$ & .21 \\
\hline \multicolumn{6}{|l|}{ Delay } \\
\hline Attitudes & $4.10(.97)$ & $4.22(.94)$ & $4.11(.95)$ & $4.16(.97)$ & 1.51 \\
\hline Perceived social norm (single item) & $3.59(1.37)$ & $3.89(1.24)$ & $3.69(1.33)$ & $3.78(1.29)$ & $7.15^{* *}$ \\
\hline Self-efficacy & $4.02(1.03)$ & $4.17(.97)$ & $3.94(1.04)$ & $4.12(.98)$ & .03 \\
\hline Intention-1 & $4.01(1.27)$ & $4.16(1.15)$ & $3.93(1.29)$ & $3.94(1.26)$ & $4.11^{*}$ \\
\hline Intention-2 & $.91(.28)$ & $.92(.28)$ & $.92(.28)$ & $.87(.34)$ & $6.98^{* *}$ \\
\hline \multicolumn{6}{|l|}{ Condom use } \\
\hline Attitude (wise to use a condom) & $3.78(1.09)$ & $3.82(1.04)$ & $3.81(1.07)$ & $3.74(1.12)$ & $4.56^{*}$ \\
\hline Attitude (pleasant to use a condom) & $3.52(1.29)$ & $3.27(1.16)$ & $3.54(1.29)$ & $3.37(1.22)$ & 1.02 \\
\hline Perceived social norm towards condom use & $3.79(1.21)$ & $3.68(1.24)$ & $3.86(1.23)$ & $3.80(1.20)$ & .26 \\
\hline Self-efficacy towards condom use & $3.31(1.05)$ & $3.37(1.01)$ & $3.34(1.04)$ & $3.27(1.01)$ & $5.09 *$ \\
\hline Performance behaviour (buy, carry a condom etc.) & $1.94(1.14)$ & $2.14(1.11)$ & $2.23(1.25)$ & $2.53(1.22)$ & .46 \\
\hline Intention to use a condom & $3.70(1.35)$ & $3.79(1.27)$ & $3.82(1.26)$ & $3.75(1.27)$ & $3.96^{*}$ \\
\hline \multicolumn{6}{|l|}{ Non-coercive sex } \\
\hline $\begin{array}{l}\text { Performance behaviour to escape and avoid } \\
\text { situations where unwanted sex could happen }\end{array}$ & $2.24(1.33)$ & $2.21(1.27)$ & $2.28(1.35)$ & $2.25(1.30)$ & .000 \\
\hline Attitudes towards using force for getting sex & $3.65(1.04)$ & $3.78(.97)$ & $3.64(1.06)$ & $3.69(1.04)$ & 1.82 \\
\hline Self-efficacy in dealing with coercive sex & $3.74(.82)$ & $3.96(.79)$ & $3.76(.77)$ & $3.88(.76)$ & $5.51^{*}$ \\
\hline Intention to deal with coercive sex & $3.93(1.01)$ & $4.02(.91)$ & $3.95(.96)$ & $3.93(.99)$ & 2.69 \\
\hline
\end{tabular}

${ }^{*} p<.05 ;{ }^{*} p<.01$ (two-tailed) 


\section{Completeness and fidelity of implementation: Additional analyses}

As mentioned before, not all schools had implemented the 14 lessons at post-test (T1). The three intervention schools which had only implemented the first seven lessons (17) were deleted from this effect study. In order to determine the role of implementation rate (completeness), we included those schools that were originally dropped, back into the analyses. We then compared the scores of learners from these schools with learners in the intervention schools in the original analyses that implemented at least lesson 1 to 10 (21 intervention schools, 853 students), and those in the comparison schools, again using a multilevel approach to the analyses. This analysis revealed that all of the above mentioned significant effects disappeared for the schools that implemented less than $50 \%$ of the lessons. However, unexpectedly, we found two reversed effects for the schools which implemented no more than the first seven lessons. One on the beliefs towards HIV, where both the students in the comparison group as well as the intervention group scored lower at post-test (T1) than on pre-test (T0), but the intervention students significantly lower than the comparison group, $F(1,345)=4.07$, $p<.05$. Another reversed effect appeared for perceived social norm towards delaying sexual intercourse, $F(1,363)=5.70, p<.05$. Students in the comparison group agreed significantly more with the statement, "My friends believe that people my age should postpone sexual intercourse until they are older" than students from the schools that implemented only lesson 1-7.

We also explored the possible effects of the differences in the fidelity of programme implementation. Based on the results from a process evaluation conducted among 16 (out of the 21) intervention schools, we were able to distinguish between those schools that implemented the programme according to the manual (= full fidelity) and those schools that implemented the programme not totally according to the manual (= partial fidelity). As there were not enough schools which used computers for delivering the programme, we did not distinguish on the basis of computer use. All teachers, whether they would run the programme using computers or not, implemented the programme by using the WSWM manual. Three questions answered by teachers were used: (1) "Did you teach the lessons in the order that is stated in the WSWM manual" (yes = fully = 1; no = partial = 0); (2) "Of all the assignments/exercises 
that you taught, did you conduct them in the way they were described in the teacher manual (following the exact description)?" (Yes totally = fully $=1$; Yes, partially; not sure; not really; not at all = partial =0) and (3) "I have closely followed the WSWM manual when conducting the lessons" (Totally agree; agree = fully = 1 ; neither agree nor disagree; disagree and totally disagree $=$ partial $=0$ ).

Full fidelity schools ( 8 intervention schools; $N=344$ ) were compared with partial fidelity schools ( 8 intervention schools; $N=325$ ) in a multilevel mixed model design, with gender, age and pre-test measures as covariates. This follow-up analysis revealed that the partial fidelity group scored significantly better on beliefs concerning pregnancy and on knowledge concerning non-causes of pregnancy. At pre-test, the partial fidelity group scored lower than the full fidelity group concerning beliefs towards pregnancy, but not significantly lower. Both partial and full fidelity groups showed an increased mean score at post-test, but the increase among the partial fidelity group was significantly higher than the full fidelity group, $F(1,587)=8.53, p<.01$. Also for knowledge concerning non-causes of pregnancy, the partial fidelity group scored lower on average at pre-test than the full fidelity group. However, students in the partial fidelity group improved their knowledge significantly more than the full fidelity group at post-test, $F(1,514)=8.51, p<.01$.

\section{Discussion}

The present study is one of the few large-scale evaluations of a school-based sex education programme in SSA (Kaaya et al., 2002; Paul-Ebhohimhen et al., 2008). The findings of this study show that students from the intervention group which completed at least the first 10 out of the 14 lessons were significantly better able to detect wrong beliefs on how to prevent pregnancy; had a significantly higher score on perceived social norm towards delaying sexual intercourse; were more convinced that they would delay until they were older, and also scored higher on the actual intention to delay sexual intercourse. Students from the intervention group held a significantly more positive attitude towards condom use, and were more convinced that they would be able and self-confident enough to use a condom in future when having sexual intercourse. They also had a significant higher intention to use a condom in future. Final- 
ly, the intervention group scored significantly higher than the comparison group on self-efficacy in dealing with sexual violence (pressure and force for unwanted sex). The comparison group had significantly improved their knowledge on the (non) causes of HIV from pre- to post-test compared to the intervention group. However, the intervention group had an overall better knowledge on all issues than the comparison group at both pre-test as post-test, except for the non-causes of pregnancy at post-test. The absence of some effects could be explained by the fact that both intervention as well as comparison groups already had a high score at pre-test. Attitude towards delay, for instance, was already positive at pre-test for both intervention and comparison groups (see Table 5.1).

The determinants on which the intervention had a significant positive effect mainly stem from the TPB-model. Risk perception (perceived severity and perceived susceptibility), a construct stemming from the HBM, did not significantly change due to the intervention. This is in line with previous research, which concluded that the TPB has received considerably more support from research for its predictive power of safe sex behaviour than the HBM (Godin \& Kok, 1996; Albarraci'n, Johnson, Fishbein, \& Muellerleile, 2001; Sheeran, Abraham, \& Orbell, 1999; Vermeer, Bos, Mbwambo, Kaaya, \& Schaalma, 2009). On the other hand, both intervention and comparison groups already held high scores regarding risk perception at pre-test (see Table 5.1). This is in line with results from the 2004 national survey among adolescents in Uganda (Neema et al., 2004).

In general, the results on intervention effects are in line with results from previous studies conducted in a (Sub-Saharan) African context (Kaaya et al., 2002; Koenig et al., 2004; Gallant \& Maticka-Tyndale, 2004). Systematic reviews of studies on schoolbased sexual health interventions to prevent unintended pregnancies, STIs and HIV in (Sub-Saharan) Africa have shown that knowledge and attitudes regarding STIs, HIV and AIDS can be changed positively, provided that the programme has been carefully designed to suit the (Sub-Saharan) African context. Changing intentions regarding safe sex, especially intention to use condoms, is more difficult. Results from different studies show that actual condom use requires more than knowledge, positive attitudes, and beliefs related to condom use, especially in a Sub-Saharan context where the so- 
cial norms dictate no sex until marriage (Gallant \& Maticka-Tyndale, 2004), a notion supported in Uganda by law and religion (Kinsman et al., 2001). Self-efficacy and skills (for example being able to openly discuss and negotiate condom use), especially for girls, need to be addressed explicitly in interventions (Figueroa, Kincaid, Rani, \& Lewis, 2002; Paul-Ebhohimhen et al., 2008). It is important not only to provide information, but also to take the wider (community and school based) context into account (Gallant \& Maticka-Tyndale, 2004; Schaalma et al., 2004). Questions like, "Do students have easy access to condoms if needed?"; "Can they talk with some adult confidentially about sexual issues?", and "What happens if a girl gets pregnant whilst still at school?" raise important socio-cultural issues that should be taken into account. Interventions only aiming at an increase of knowledge are known to be unsuccessful in changing behaviour, irrespective of which health behaviour is being addressed (Peters, Wiefferink, Hoekstra, Buijs, ten Dam, \& Paulussen, 2009).

As full implementation of interventions cannot automatically be assumed, especially not in a context where time, financial and other capacity barriers interfere with full implementation (Gallant \& Maticka-Tyndale, 2004; Kinsman et al., 2001; Lloyd, 2010; Hardeman et al., 2008), we also looked at whether all lessons were implemented at post-test (completeness of implementation) and whether teachers implemented the programme according to the manual or not (fidelity of implementation). Follow-up analysis between those schools which implemented at least 10 out of the 14 lessons at post-test and schools which did not complete more than the first seven lessons at post-test (completeness of implementation) revealed that in the latter group, all positive effects disappeared. Two reversed effects appeared, one for perceived social norm towards delaying sexual intercourse and one for beliefs towards HIV. The results from the follow-up comparative analysis based on fidelity of implementation revealed that the partial-fidelity group scored significantly better on beliefs towards pregnancy and on knowledge of non-causes of pregnancy than the full-fidelity group. In other words, whether a teacher strictly followed the instruction manual or not, did not have a big impact on the effectiveness of WSWM. On the contrary, the limited effects found were in favour of the partial-fidelity group. These results suggest that it is important to implement the programme completely and that the programme itself should be 
flexible enough for teachers to use and adapt it according to the specific context in which they have to implement the programme (i.e. adapting to accommodate specific questions and needs of the students and coping with the limited time and resources available), without having to skip lessons.

WSWM was developed as a computer-based programme, enabling students to follow the lessons relatively autonomously, offering them privacy to explore and discuss sex-related issues among themselves. Although WSWM can also be implemented without computers, by making use of a Student Manual, the use of computers makes it easier for teachers and students to deal with sensitive topics and makes following the programme more attractive and fun. The use of computers also enables young people to learn important computer skills that would be an asset to them in the labour market after graduation. However, in practice, the use of computers for WSWM appeared to be very limited. Process evaluation showed that most schools did not have enough computers. If there were any, they had to be shared by a group of students (sometimes up to 50) at the same time. Also, broken computers and lack of electricity were major implementation problems faced by most of the schools (Versteegen, 2009). We were not able to make a sensible distinction on the basis of computer use, as there were practically no schools where the WSWM was implemented by the use of computers in the way it was intended. The fact that WSWM was implemented in most schools without (enough) computers available for the students, could partly explain the limited effects we found, especially when it comes to very sensitive topics like "coercive sex". When planning for a computer-based programme in a context like Uganda, where many schools do not have (enough) computers and/or do not have a secure access to energy, the implementation plan of the programme should contain a school computerisation component.

The role of teachers is to guide and coach the students through the 14 lessons, facilitating the process of learning, coaching students to explore opinions, and practising skills. In order for programmes to be faithfully implemented, it is important that teachers are properly trained and committed to the programme (Gallant \& Maticka-Tyndale, 2004). WSWM teachers were trained to do this in a 5 to 6-day training course, conducted by Ugandan trainers, who were trained themselves by either Dutch 
trainers or Ugandan trainers (Train the Trainer concept). The group of trainers that have trained new WSWM teachers in recent years is different to the first group of Dutch trainers. Some teachers expressed their concern about the differences in openness between the WSWM teacher trainers. Issues such as, for example, homosexuality and condom use were said to be approached differently by the different trainers. This suggests that teachers were not trained effectively in this regard. The process of evaluation also revealed that teachers felt that one training course lasting six days was a good start, but did not provide sufficient support to implement WSWM. They particularly indicated the need for more support, for instance by having a team of experts visiting the schools during implementation of the programme, and the need for follow-up training (Versteegen, 2009).

Many of these problems could be addressed in a more structural way if the programme could be part of the school curriculum (Figueroa et al., 2002). The few recent studies conducted in SSA indicate that curriculum-based, adult-led interventions show stronger evidence of effectiveness than non-curriculum based interventions (Napierala Mavedzenge, Doyle, \& Ross, 2010).

Most evaluation studies focus on the effects of the intervention on change in (determinants) of sexual behaviour of the target group only. Process evaluations focusing on how the intervention was implemented are often neglected or less widely publicised. This is remarkable, as a successful adoption and implementation of an intervention is crucial for its success and effectiveness. If the implementation of programmes is not assessed, it is difficult to determine why outcomes were or were not achieved and erroneous conclusions may then be drawn stating that a programme is not effective, when it was simply not delivered as planned (Vermeer et al., 2009; Hardeman et al., 2008). Specific attention should be paid to the context of intervention implementation (Gallant \& Maticka-Tyndale, 2004; Lloyd, 2010). This is especially true for school-based sex education programmes implemented in developing countries, in a context of limited time and (financial) resources, shortage of staff and in which teachers are only allowed to promote abstinence, which is not in line with the reality of the students and which does not help them to distinguish between more and less risky behaviour. Involvement of relevant stakeholders like the Ministry of Education, 
(Head) teachers, SRHR Specialists, and students in the development, implementation and evaluation of an intervention is crucial for its success. Long-term training and onthe-job support of teachers so that they are able to deliver a programme the way it is intended, are important determinants of success. Systematic planning, implementation and evaluation of interventions are much needed to achieve these goals (Schaalma et al., 2004; Bartholomew et al., 2011).

Our study had a non-randomised experimental design. Due to practical considerations, we were not able to randomise our sample. We did, however, have a large sample of intervention schools (24) and were able to find comparable schools (24) for each intervention school, based on geographical area, boys/girls/mixed school and boarding versus day school. The questionnaire was not translated into local languages. As the level of the students' English differed, we realised that some questions may have been difficult to understand for some respondents. We tried to accommodate for this by training the research assistants to give vernacular translations for those students who failed to understand certain words or concepts. Unfortunately, this was not always possible, as some research assistants did not speak the local language. We tried to assure anonymity in responding, by having no names attached to the questionnaires and by instructing the research assistants to create a safe and quiet environment in which the respondents could fill in the questionnaire. We are not sure if this was achieved at all schools in which the students completed the questionnaire. Students had to sit in the classroom, and sometimes the teacher would also be present, despite the request from the research assistants to leave the room. The scales that we used did not always show the required reliability (Cronbach's $\alpha$ ), which is why we mostly had to rely on two-items and single item constructs. As the study covered a period of only 6 months, and the post-test was conducted immediately at the end of the implementation period of the programme, we did not include change in actual sexual risk behaviour following the programme. Future research should have follow-up measurements at 6 months and 12 months after the intervention period has finished to measure change in actual sexual behaviour. 


\section{Conclusions}

The World Starts With Me is a comprehensive sex education programme, which if implemented completely, can affect changes in socio-cognitive determinants of safe sexual behaviour among young adolescents in Uganda. The finding that the effects of intervention disappeared for those schools that did not complete the programme in time, and the fact that schools where the teacher did not implement the programme fully according to the manual were slightly more effective than those schools that did stick to the manual, raise questions about the role of implementation and the context in which implementation takes place. Socio-cultural (e.g. condom use among young people is a taboo, so teachers are reluctant to promote condom use), political (e.g. homosexuality is a criminal offence, so it is impossible to talk about homosexuality as a human right) and economic (e.g. schools do not have a lot of money to spend, so the use of computers is low; time constraints) characteristics of the context might either facilitate or prevent sound implementation of the programme. Although the WSWM programme in itself seems to be effective, it needs to be developed in such a way that it can be easily adapted to suit the implementation context in each specific school. As WSWM is not part of the school curriculum, the programme should be made more flexible in such a way that it enables teachers to make logical adaptations according to time constraints and to address specific problems and issues faced by the students. When planning for a computer-based programme in a context like Uganda, where many schools do not have (enough) computers and/or do not have a secure access to energy, the programme implementation plan should contain a specific section addressing this issue. Apart from the reason of having limited time, it is unknown why some schools only had implemented $50 \%$ of the lessons at post-test, whereas other schools did manage to implement the full 14 lessons in time. More research is needed on factors influencing the complete and successful implementation of comprehensive sex education programmes such as WSWM in Uganda. 


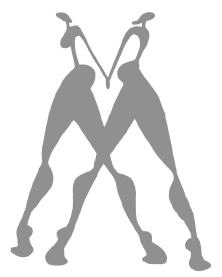

\section{Chapter 6 General Discussion}




\section{Introduction}

The empirical studies described in the present dissertation focused on the socio-cognitive determinants of safe sex behaviour among Ugandan adolescents, on the comparison between the universal SRHR and the constellation of socio-cultural, economic, community and political contextual factors in which Ugandan adolescents grow up, and on the implementation and effectiveness of WSWM. In this concluding chapter, the results of the studies described in this thesis are summarised and discussed in the context of the existing literature. In addition, the methodological limitations of the studies, practical implications for comprehensive rights-based sex education and recommendations for future research on comprehensive rights-based sex education programmes in a Sub-Saharan context are being discussed.

\section{Socio-cognitive correlates of safe sex behaviour}

Chapter 2 described the socio-cognitive correlates associated with safe sex behaviour (i.e. intention to delay sexual intercourse and intention to use condoms) among adolescents in Uganda assessing differences between adolescents with and without previous sexual experience. This way, a comparison could be made on the intention to delay sexual intercourse between correlates of primary and secondary delay. Secondary delay, meaning that after initiating sexual intercourse, adolescents decide to abstain from sex again until later, for example when they are married or have a paid job (Tumwesigye, Ingham, \& Holmes, 2008; Kabiru \& Ezeh, 2007), is a relevant safe sex option among adolescents in SSA (Khan \& Mishra, 2008; UNAIDS, 2008). The choice to delay sexual intercourse is considered to be a sexual right of adolescents (i.e. the right to personal autonomy), as long as the decision to delay sexual intercourse is based on their own, well informed choices (IPPF, 2008; Shaw, 2009).

The results of the study showed that attitudes, perceived social norms and self-efficacy towards delaying sexual intercourse were significant correlates of the intention to delay sexual intercourse, irrespective whether the proposed delay was primary in the group of sexually non-experienced adolescents or secondary in the group of sexual experienced adolescent. Furthermore, beliefs about pregnancy were positively related to the intention to delay first sexual intercourse. Among those with- 
out previous sexual experience, age was negatively related to the intention to delay intercourse thus implying that the likelihood that adolescents delay sexual intercourse decreases with age.

These results are in line with results from other studies, mainly conducted in the US and Europe, but also in SSA. Carjaval et al. (1999) conducted a study among US adolescents who never had sexual intercourse, and found that especially positive attitudes and normative beliefs towards delaying first sexual intercourse were significant socio-cognitive predictors of actual delay. They also found that only in the age group younger than 15 years the psychosocial predictors were uniformly significant. Another study, conducted among US adolescents by Santelli et al. (2004), showed that personal and perceived norms about abstinence were strong predictors of delay. A review of 69 published studies (US) showed that besides intention and perceived norms to delay, an environmental variable "spending time home alone" appeared as a stable predictor of early sexual debut (Buhi \& Goodson, 2007). Studies among African American (pre-) adolescents showed that peers have an influence in shaping sexual attitudes and behaviour, both for girls and boys, that perceived peer norms were positively related to being sexually active or not (Wallace, Miller, \& Forehand, 2008; DiLorio et al., 2001), and that adolescents who held positive attitudes about the personal benefits of abstinence were less likely to have initiated sex (DiLorio et al., 2001).

Remarkably, there is a paucity of research focusing on socio-cognitive determinants of delaying sexual intercourse in a Sub-Saharan context, especially compared to studies focusing on predictors of risky sexual behaviour and on (intention) to use condoms (Kabiru \& Ezeh, 2007; Eggers et al., 2013). However, the studies that were conducted in SSA do support the findings from the current study, concerning the importance of social norms in predicting condom use. Studies conducted in a SSA context also reflect the importance of self-efficacy to refuse sex. A study conducted in Rwanda (Babalola, Awasum, \& Quenum-Renaud, 2002) showed that perceptions of the sexual behaviour of peers, perceived self-efficacy to refuse sex with someone known for more than three months, self-esteem and attitudes towards pre-marital sex were significantly associated with primary sexual abstinence. Among Ugandan girls, social norms and pressure seem to play an important role in delaying sexual inter- 
course, as the proportion of girls reporting to be socially pressured (by family, religious leaders and others) to abstain from sex is with 60\% particularly high (Kabiru \& Ezeh, 2007). Other studies suggest that many adolescents in SSA, mostly girls, have sex the first time because of pressure (Tenkorang \& Maticka-Tyndale, 2008). This seems also the case for Ugandan adolescents (Nobelius et al., 2010; Neema, Musisi, \& Kibombo, 2004; Moore, Biddlecom, \& Zulu, 2007; Biddlecom, Hessburg, Singh, Bankole, \& Darabi, 2007). Either way, the choice of Ugandan adolescents, both boys and girls to abstain or to be sexually active, is not always an autonomous choice.

When looking at correlates of the intention to use condoms, the findings demonstrate a clear difference between those with sexual experience and those without. Among the non-experienced respondents, the three main social cognition variables (attitudes towards condom use, the perceived social norm regarding condom use and self-efficacy to use a condom) were significantly associated with the intention to use a condom. These findings are supported by many other studies, mainly conducted in Europe and the US (Peters, Wiefferink, Hoekstra, Buijs, ten Dam, \& Paulussen, 2009; Schaalma, Kok, \& Peters, 1993; Sheeran, Abraham, \& Orbell, 1999; Bennet \& Bozionelos, 2000; Albarracín, Johnson, Fishbein, \& Muellerleile, 2001; Jemmott \& Jemmott, 2000; Dilorio et al., 2001), as well as by studies conducted in SSA. Most of these latter studies are conducted in South Africa (Boer \& Mashamba, 2005, 2007; Bryan, Kagee, \& Broaddus, 2006; Giles, Liddell, \& Bydawell, 2005; Heeren, Jemmott, Mandeya, \& Tyler, 2007; Fekadu \& Kraft, 2002), but also in Tanzania (Schaalma et al., 2009), Ghana (Bosompra, 2001) and Ethiopia (Taffa, Klepp, Sundby, \& Bjune, 2002; Molla, Åstrøm, \& Brehane 2007). In these studies, no comparison was made between respondents who were sexual experienced and who were not, and as such no differences in significant correlates of condom use intentions between these two groups were assessed. In the current study, this comparison was made. Among those without previous experience, attitudes towards and the perceived social norm regarding condom use and self-efficacy to use a condom were all important predictors of the intention to use a condom. Among sexually experienced adolescents only the perceived social norm was found to significantly correlate with the intention to use a condom. Neither self-efficacy nor attitude were found to be significantly associated with the intention to use a condom 
among this group. Other studies conducted in a sub-Sahara African context show that subjective norms are (one of) the strongest predictors of condom use among adolescents in general (Giles et al., 2005; Fekadu \& Kraft, 2002; Bosompra, 2001). The important role of perceived social norm might, at least partly, be explained by the more collectivistic nature of African communities and hence decision-making compared to the more individualistic decision-making that occurs in Europe and North America (Yeboah \& Maticka-Tyndale, 2008; Benefo, 2010). This finding could also be explained by the greater reliance of young people on their social networks for condom use decisions (Albarracı'n, Johnson, Fishbein, \& Muellerleile, 2001). Another explanation can be found in the suggestion that condom use differs from other behaviours because it depends on the availability and accessibility of condoms, the opportunity (e.g., a prospective sexual partner) and interpersonal cooperation (Kashima et al., 1993; Liska, 1984).

Although our findings support the TPB as a model to understand the factors associated with the intention to delay sexual intercourse, secondary abstinence and the intention to use condoms among SSA adolescents, the variance explained by the predictors $\left(R^{2}=.23\right.$ for the intention to delay sexual intercourse, and $R^{2}=.17$ for the intention to use a condom) was in general lower than is found in other studies conducted in a Western context. In their meta-analytic review, Armitage \& Conner (2001) found an average of $39 \%$ variance in predicting the intention of a certain behaviour from TPB constructs in a Western context (Armitage \& Conner, 2001). African studies tend to show less to similar explained variance: a study in South Africa resulted in $22 \%$ explained variance of intention to use condoms (Boer \& Mashamba, 2007), one study in Ethiopia showed 23\% explained variance in intentions to use condoms (Taffa et al. 2002), another study in Ethiopia showed 36\% explained variance (Molla et al., 2007), and a study on determinants of condom use intentions in Ghana showed an explained variance of $33 \%$ (Bosompra, 2001).

In fact, of the few studies conducted in an African context, two were found with explained variance higher than usually found in a Western context. A study conducted among South African adolescents showed a 67\% explained variance in the intention of condom use (Giles et al., 2005) and in another study conducted in South Africa 
and Tanzania (Schaalma et al., 2009), the explained variance was even 77\%, which is extremely high compared to other studies. The last mentioned study, however, included also geographic variables, socio-economic factors and access to condoms in the explanatory model. Indeed, the limited explained variance in intention to use a condom and to delay sexual intercourse in the current study might be explained by the fact that delay in sexual intercourse and condom use are also impacted by other factors, not included in current study. Studies that were conducted in a Sub-Saharan context focusing on demographic and other non socio-cognitive factors show that being out-of-school, male, being older, using alcohol or drugs (Taffa et al., 2002; Babalola et al., 2002), being a non-Muslim or a non-Christian, and being female in an urban area (Koffi \& Kawahara, 2008), enhanced the likelihood of adolescents engaging in sexual activity. A recent review on the sexual and reproductive behaviour of adolescents in SSA (particularly 15 to 19 years old), shows that early sexual debut and childbearing were more common among the least educated and/or rural females (Doyle, Napierala Mavedzenge, Plummer, \& Ross, 2012).

For condom use, environmental factors (e.g., access to condoms) (Adih \& Alexander, 1999; Ukwuani, Tsui, \& Suchindran, 2003; Benefo, 2010), structural factors like higher educational level, higher income and a supportive legal context (Parker, Easton, \& Klein, 2000; Gillespie, 2006), demographic factors such as lower age and marital status (Lagarde, Pison, \& Enel, 1996), interpersonal communication about HIV and AIDS (Benefo, 2010) and one's skills necessary to discuss condom use (Peters et al., 2009; Schaalma et al., 2004), were found to be associated with higher levels of (intention to) condom use. A study conducted in four SSA countries shows that poor females start sexual intercourse at a younger age and use condoms less frequently and consistent than their wealthier peers, although the correlation was not significant for Ugandan adolescents (Madise, Zulu, \& Ciera, 2007). Additionally, socio-cultural factors play a role, like gender roles dictating that girls cannot discuss condom use or buy and carry condoms (Kibombo, Neema, Moore, \& Ahmed, 2008; Moore \& Oppong, 2007). Also, distrust about the effectiveness of condoms and the perception that condoms may even lead to infection of HIV (Neema, Musisi, \& Kibombo, 2004), HIV-related stigma (Vanable, Carey, Blair, \& Littlewood, 2006) and taboos on discussing sexuality in gen- 
eral (Evans, Avery, \& Pederson, 1999; Nobelius et al., 2010). As the current study was part of a larger study on the effectiveness of WSWM, these other factors were not included in the research instrument.

Another explanation for the limited explained variance could be that the research instrument used in current study was not of the highest possible quality. Due to low internal consistency of most scales, single items or two-items constructs were used. Also, although the questionnaire was derived from a questionnaire previously used in Tanzania and South Africa (Mũkoma et al., 2009a) and pre-tested among adolescents from a school in Kampala, the instrument could have been less suitable for the Ugandan context, especially the rural areas.

In conclusion, in line with Fishbein (1998) and Ajzen (1991), and supported by the fact that the explained variance in our study is different from that in other studies conducted in Europe and the USA, the author contends that the relative importance of each of the RAA variables may vary according to the behaviour, the population targeted, and the socio-cultural, economic and political context in which that behaviour takes place. Furthermore, although the current study showed the relevance of the TPB to explain partly the intention to delay sexual intercourse and the intention to use a condom in a Ugandan context, future research should also include other (structural and environmental) factors to explain safe sex behaviour among Ugandan adolescents. The individual focused health behavioural models have been criticized for over-emphasizing the role of individual rationality and autonomy and for being less useful in African settings where social groups influence sexual behaviour more than in Western settings (Airhihenbuwa \& Obregon, 2000). Economic and structural models to connect economic and infrastructural opportunities and community access to health-related products with individual perceptions of the costs of risky sexual behaviour could be useful additions to the more individual focused TPB model (Ukwuani, Tsui, \& Suchindran, 2003; Kaufman, Clark, Manzini, \& May, 2004; Glick \& Sahn, 2008).

\section{Sexual and reproductive health and rights in the Ugandan context}

In Chapter 3, universal declared SRHR were compared with the local realities of young people in Uganda, based on the results from seven Focus Group Discussions (FGD) relat- 
ing to two sexual and reproductive health rights central in this research: (1) the right of young people to obtain complete and accurate information and (2) the right to self-determination. These two rights are also fundamental to comprehensive rights-based sex education (CRSE) (IPPF, 2010). One main conclusion drawn from this study is that it is one thing to be educated about rights, another to be supported in exerting them.

Discrepancies were identified between the universally formulated SRHR and the (political, socio-economic and community) context young Ugandans live in. The comparison between the right to obtain complete and accurate information and the local reality of rural secondary school students in Uganda reveals two discrepancies: (1) the narrow focus of the information on abstinence and technical aspects lead to fearbased and normative approaches and (2) the information received is mostly not accurate and often contradicting because coming from different sources. Findings from this study show that young people do not know which information is accurate and which is not, that they receive different information on whether and when to be sexually active (above 18 years old, after marriage, when economic independent), and that, in general, they frame sexual behaviour negatively as 'immoral' and a 'sin'. Also, sexual behaviour is considered as something natural for boys and something taboo for girls. If sexual intercourse occurs it is done in a 'sneaky' way, with all the related risks of unprotected sexual intercourse. Above mentioned findings are supported by findings from recent studies conducted in rural Uganda, where secondary school students assess the information and education they receive from parents and school on sexuality issues as "(...) being "under-resourced", "one-sided-feminised", "authoritarian", "theoretical", and "prescriptive" (Muhanguzi \& Ninsiima, 2011, p. 60), and as "flawed or insufficient" (out-of-school youth; Nobelius et al., 2010, p. 91). These studies show that in general, young people want sexuality information and education that is in line with their real life experiences, which is non-judgmental, non-authoritative and positively framed (Muhanguzi \& Ninsiima, 2011; Nobelius et al., 2010).

The comparison between the right to self-determination and the local reality of Ugandan adolescents revealed three discrepancies. First, the defilement law, which defines sexual relationships between a man (both adult and under 18 years) with a girl or young woman under 18 as a criminal act (Barker \& Ricardo, 2005), creates an 
environment in which fear, taboo and secrecy around young peoples' sexuality dominate, which is opposite to what CRSE aims for: an open and positive non-judgmental approach towards young people's sexuality, not based on fear and taboos (IPPF, 2010). The negative role of the defilement law on the fear of being caught when having sex under 18 is supported by other studies (Barker \& Ricardo, 2005; Parikh, 2012), which report on the arrest and imprisonment of adolescents boys under 18 years for having sex with a girl. Such criminal laws should be clear about sexual offences, i.e. coercive sexual acts with a minor, but if not explained in this way, the law can become a barrier to someone's capacity to self-determination (Kuate-Defo, 2004).

Second, the finding that transactional sex is not confined to intergenerational sex and can take place in coercive as well as non-coercive sexual relationships, confirm findings from other studies (Bohmer \& Kirumira, 2000; Moore et al., 2007; Nyanzi, Pool, \& Kinsman, 2010). The socio-economic context has led to a situation in which regular dating-behaviour (boys giving a present to a girl to express his interest in and respect for her) is changed into transactional sex, creating pressure on both girls and boys. Girls feel pressured to have sex when accepting gifts or money from boys. At the same time, due to the fact that girls receive less pocket money than boys, have fewer opportunities to earn money (lyer \& Aggleton, 2012), and have a growing need for nice cloths and toilet products, like soap and make-up (Nyanzi et al., 2010), girls ask money and gifts from different boys and men. In different other studies, young girls also mentioned these needs, rather than extreme poverty, as the main reason for engaging in transactional sex, including with older men (Bohmer \& Kirumira, 2000; Luke \& Kurz, 2002; Nyanzi et al., 2010). Young men in Uganda, in contrast, feel pressured to give presents or money as girls are demanding this, which puts them in an awkward competitive position with other boys and men. As in many cultures around the world, they experience social pressure, e.g. from peers, to show their masculinity by taking initiative towards girls, to be sexually active and have multiple partners. "Being a man" in an African context equals "(....) achieving some level of financial independence, employment or income and subsequently starting a family. In much of Africa- where bride-price is commonplace- marriage and family formation are thus directly tied to having income and/or property."(Barker \& Ricardo, 2005, p. 5). Some authors (Moore 
et al., 2007) argue that the practice of giving presents and money in forming relationships can be considered as a 'modern' variant of the bride price and as a validation of the worth of the girl. However, the male participants of the FGDs in the study reported in Chapter 3 of this thesis, expressed clearly that nowadays they find themselves in a difficult competitive position, which they do not consider an advantageous development. Both boys and girls participating in the FGDs expressed that they feel "trapped" in this situation and that they want to change this. Therefore, it is concluded that also in non-coercive relationships, transactional sex is becoming problematic and that it cannot automatically be assumed that girls and boys make their own decisions relating to sex on an equal basis, free from any form of pressure.

Third, the very strong social norm towards abstinence from sexual intercourse until 18 years (political norm), being married (social and religious norm), having finished education and being economically independent (social norm), in combination with a double sexual standard for boys (being sexually active is considered masculine) and girls (being passive, submissive and not sexual active is considered feminine), lead to internal struggle and lack of self-determination (Wolff, Blanc, \& Gage, 2000; Muhanguzi, 2011; Barker \& Ricardo, 2005). From the findings, it can be concluded that the role religion plays is double; adolescents say they are not allowed to have sex before marriage nor to use condoms because of their religion, but at the same time, the sexual drive of boys is considered to be a God given, and uncontrollable, nature. Girls are supposed to abstain from sex, to be submissive and passive towards male sexuality and not to negotiate or bring up condom use (see also Muhanguzi, 2011), but are at the same time "pestered" by boys and older men to have sex. This may lead to the situation that girls, once starting sexual intercourse prior to marriage, will not use a condom, as they are less able to decide the timing and conditions of the sexual encounter (Chatterji et al., 2004). This observation is confirmed by a study on the role of religion on delay and condom use among young women in Zambia. Young women who were affiliated with religious groups, that strongly opposed premarital sex and condom use, and that had a strong social control over them, were likely to delay sexual intercourse but at the same were also less likely to use a condom during first sex (Agha, Hutchinson, \& Kusanthan, 2006). 
Comprehensive rights-based sex education, focusing on rights within above described cultural and power dynamics, is considered to be an important strategy to ensure that young people receive the necessary information and education to take their own well-informed decisions on sexuality and sexual behaviour. However, implementation of such programmes in the Ugandan context, remain challenging. Teachers, as the main implementers of sex education programmes in schools, play an important role in good quality implementation. It is therefore important to know teachers' socio-cognitive factors that play a role in implementation, as well as teachers' perceptions of the main supporting and non-supporting elements for good implementation.

\section{Process evaluation of 'The World Starts With Me'}

Schools are generally seen as important settings to educate young people about SRHR (Stone \& Ingham, 2006; Braeken \& Cardinal, 2008), also in Uganda (Neema et al., 2006; Kibombo, Neema, Moore, \& Ahmed, 2008). The importance of sound implementation to resort intervention effects is becoming more clear in the past decade (Michielsen et al., 2010; Buston, Wight, Hart, \& Scott, 2002; Mũkoma et al., 2009b; Kinsman, Nyanzi, \& Pool, 2002). Michielsen et al. (2010) call for more research on implementation difficulties, which is especially important in resource limited settings where school teachers are already overstretched in the classroom (Lloyd, 2010). Dose delivery and fidelity of implementation are two important measures of quality of implementation (Dusenbury, Brannigan, Hansen, Walsh, \& Falco, 2005; Linnan \& Stecker, 2002). Consequently, Chapter 4 of this dissertation aimed to examine (the predictors of) dose delivered and fidelity of implementation of the comprehensive rights-based sex education programme, The World Starts With Me. Also, the barriers and facilitating factors of implementation from the perspective of the teachers were explored.

A multi-strategy design, combining a survey among WSWM teachers and indepth interviews with WSWM teachers, provided data for both a quantitative as well as qualitative analysis of the implementation process. Teachers play a central role in implementing school-based sex education programs by being responsible for delivering the full dosage and in adhering to the programmes' manual or protocol (fidelity of 
implementation). Previous research on implementation of sex education programmes in Western (European and US) as well as African contexts, have focused on barriers and facilitating factors, on fidelity of implementation, and dose delivered (Mũkoma et al., 2009b; Buston et al., 2002; Plummer et al., 2007; Njue, Nzioka, Ahlberg, Pertet, \& Voeten, 2009). There is a paucity of published articles on socio-cognitive predisposition of teachers as determinants of dose delivery and fidelity. This study added to the existing literature by examining socio-cognitive determinants of high quality implementation, such as confidence and self-efficacy in teaching, discussing sexuality issues in class and attitudes towards sex education. Also barriers and supportive factors of implementation were identified.

The findings from the study revealed that teachers who scored low on confidence in teaching WSWM had a significantly higher score on dose delivered. An explanation for the negative association between confidence in teaching WSWM and dose delivered could be that teachers who are more confident at the start of WSWM, experience more difficulties in for instance using participatory methods and dealing with students who do not show respect in class, than those who expected beforehand that they would find that difficult. In the South African context, where much more studies related to teaching sex education are conducted, teachers report being relatively confident in teaching HIV, AIDS and sexuality (Peltzer \& Promtussananon, 2003; Mathews, Boon, Flisher, \& Schaalma, 2006). However, at the same time teachers reported many challenges in teaching sexuality issues due to cultural as well as personal factors (Mbananga, 2004; Ahmed et al., 2006), as well as resistance to and inexperience in using participatory methods which hindered proper implementation of school-based sex education (Mũkoma et al., 2009b).

Teachers who implemented WSWM fully according to the manual (= full fidelity) were significantly more confident in teaching and discussing sexuality issues in class and attached significantly less importance to open sex education for young people to prevent problems. In line with other studies conducted in Europe (Paulussen et al., 1994) and in SSA (Helleve et al., 2009; Matthews et al., 2006), teachers' confidence in teaching and discussing sexuality issues in class (self-efficacy) appeared as an important associative positive factor of fidelity of implementation. Helleve et al. (2009) 
found a close association between confidence, training and having experience with implementing lessons in class.

Contrary to what is found in other studies (Paulussen, Kok, Schaalma, 1994; Helleve et al., 2009) relevant factors such as attitudes, subjective norms and sexual morality, were not associated with high fidelity. Remarkably, our study shows that the importance teachers attach to open sex education for young people to prevent problems was negatively associated to full-fidelity of implementation. This seemingly contradictory outcome could be explained by the tension between fidelity and adaptation. Based on findings from different studies that teachers' modification to a programme (not full-fidelity) has been found to improve intervention outcomes, Dusenbury, Branningan, Falco, and Hansen (2003) suggest that perhaps these modifications made the lessons more culturally sensitive and appropriate for the specific target group. They also suggest that teachers who modified the curriculum were more motivated and creative in general, and therefore better teachers.

The in-depth interviews of current study gave a better insight in and understanding of the local context of implementation and the experienced barriers and facilitators for implementation. In line with results from other studies conducted in SSA (Kinsman et al., 1999; Ahmed et al., 2009; Njue et al., 2009), the main barriers of implementation mentioned were lack of relevant resources, such as time, computers, student manuals and money. Teachers also experienced a lack of trained staff and high staff turnover, lack of follow-up training and on the spot guidance. A lack of motivation emerged because teachers did not receive financial compensation for their extra work done and sometimes even reported they had to put their own money in the programme to make sure it was implemented. Role plays were mentioned as being too time-consuming, and therefore often skipped, which is in line with another study conducted in Uganda (Kinsman et al., 1999). Other studies conducted in SSA revealed a general discomfort with role-play methods (Kinsman et al., 1999; Njue et al., 2009), which is not limited to a Sub-Saharan context, but also found in for instance the Netherlands (Paulussen et al., 1994) and Scotland (Buston, et al., 2002). In their study among teachers following a teachers training for a sex education programme in South Africa, Ahmed et al. (2006) found two reasons for teachers not willing to conduct role- 
play activities. First, teachers indicated that they think students would find role-plays difficult as they are not familiar with them, and second, teachers are not confident that they can facilitate them well enough due to large class sizes. Finally, personal attitudes and norms towards sex among adolescents, condom use and homosexuality, which were not in line with the WSWM curriculum, hindered teachers in implementing WSWM the way it is intended. This finding is supported by other studies conducted in SSA. A study conducted in South Africa revealed that teachers were focused on teaching abstinence only, spreading the message that if you don't abstain, you will get AIDS and die, a message that was inconsistent with the interventions' main message (Mũkoma et al., 2009b). Another study conducted in Kenya (Njue et al., 2009) showed that teachers felt uncomfortable with the topics of AIDS, condom use and other sexuality issues and lacked proper training on how to deal with these topics.

\section{Effect evaluation of 'The World Starts With Me'}

The aim of the effect evaluation (Chapter 5) was to assess the effects of WSWM on socio-cognitive determinants of safe sex behaviour (delay; condom use). A multilevel analysis was done on data derived from a quasi-experiment, comparing an intervention with a comparison group at post-test.

Overall, the results show that WSWM had a significant positive effect on important TPB determinants and aspects of safe sex behaviour. The intervention was effective in turning wrong beliefs concerning pregnancy into right beliefs, in improving the perceived social norms and intention towards delaying sexual and in increasing actual delay, as well as in promoting a positive attitude, self-efficacy and intention towards condom use. Also, the intervention was effective in increasing the self-efficacy in dealing with sexual violence. Finally, although the intervention group had an overall better knowledge on all issues than the comparison group at both pre-test as posttest, the knowledge on the non-causes of pregnancy improved significantly among the comparison group compared to the intervention group. For some determinants no effects were found, due to the fact that the scores of both intervention and comparison groups were already high at pre-test, like the attitude towards delaying sexual intercourse. Another explanation for the limited effects, especially when it comes to sensi- 
tive topics like "coercive sex", could be that WSWM was implemented in most schools without (enough) computers available for the students. Due to a lack of computers, the advantages of enabling students to follow the lessons relatively autonomously, offering them privacy to explore and discuss sex-related issues among themselves, also disappeared. This could have had a negative effect on the effectiveness of the programme.

A post-hoc comparison was then made between schools based on dose delivered and fidelity of implementation of WSWM, assessed through the process evaluation. Based on the results from the process evaluation, schools which implemented at least 10 out of the 14 lessons at post-test were compared to schools which did not complete more than the first seven lessons (completeness of implementation). All positive effects found previously, now disappeared for the schools that completed less than $50 \%$ of the lessons. Remarkably, two reversed effects appeared, one for perceived social norm towards delaying sexual intercourse and one for beliefs towards HIV, meaning that the students in the comparison scored significantly better at posttest compared to the intervention group.

Contrary to what was expected, the follow-up comparative analysis based on fidelity of implementation revealed that the partial-fidelity group scored significantly better on beliefs towards pregnancy and on knowledge of non-causes of pregnancy than the full-fidelity group. In other words, some positive effects were found in favour of the partial-fidelity group.

In general, the results on intervention effects are in line with results from previous studies conducted in a (Sub-Saharan) African context (Kaaya et al., 2002; Koenig et al., 2004). Systematic reviews of studies on school-based sexual health interventions in (Sub-Saharan) Africa (Paul-Ebhohimhen et al., 2008; Gallant \& Maticka-Tyndale, 2004) have shown that knowledge and attitudes regarding STIs, HIV and AIDS can be changed positively, provided that the programme has been carefully designed to suit the (Sub-Saharan) African context. Contrary to these reviews are the positive effects of WSWM on the intention to delaying sexual intercourse and actual delay, as well as on the intention to use a condom. According to above mentioned reviews, changing intentions regarding safe sex, especially (intention of) condom use, is more difficult 
in a context where the social norm dictates abstinence until marriage, as is the case in Uganda. However, caution is warranted to promote condom use and skills that in reality cannot be applied, if condoms are not widely available at a reasonable cost, or for free (Baldo \& Uzamugunda, 2000).

\section{Reflections on methodology}

The primary strength of this dissertation is the use of both quantitative and qualitative research methods, which is also known as a mixed methods approach or multi-strategy research design. Among the main advantages of employing a mixed methods approach are triangulation of data and providing a more complete and comprehensive picture of the research topic (Robson, 2011). Other strengths of this dissertation is the use of a large sample $(N=1986)$, being one of the few large-scale multilevel evaluations of a comprehensive rights-based sex education intervention implemented at secondary schools in a SSA setting (Kaaya et al., 2002; Paul-Ebhohimhen et al., 2008; Michielsen et al., 2010). Furthermore, this dissertation contributes to a paucity of research on the socio-cognitive predictors of delayed sexual intercourse and condom use among a large sample of young people in a SSA context. It is also one of the few attempts to explore the influence of previous sexual experience on the determinants of the intention to use condoms and (secondary) delayed sexual intercourse in low-income countries.

This dissertation also includes a qualitative explorative study among Ugandan adolescents to compare universal declared sexual and reproductive rights with the local reality Ugandan adolescents grow up in, which greatly enhanced our understanding of the structural socio-economic, cultural and political factors impacting young peoples' sexual behaviour. Finally, by combining the effect evaluation with the outcomes of the process evaluation, this dissertation enhances our understanding of the influence of quality of implementation on the effectiveness of Conducting research in a Sub-Saharan context on sensitive issues like SRHR and comprehensive sex education, however, does not remain without challenges. As far as the quantitative part of the research is concerned (Chapter 2 and Chapter 5), the main limitations are the cross-sectional nature of the data, which does not allow to draw conclusions about causality. In the effect study (Chapter 5), a non-randomised experimental design was 
used. Due to practical considerations, a random sample was not possible to select. Instead of control school, we were able to identify 24 comparison schools to the already selected 24 intervention schools. The selection criteria were geographical area, boys/girls/mixed school and boarding versus day school. Also, the questionnaire used among students had a number of limitations. First, the questionnaire was in English, and not translated into local languages. As English is the second language for all respondents, some questions may have been difficult to comprehend. By training the research assistants to give vernacular translations and by handing out a definition list explaining more technical terms like 'masturbation', the negative consequences of this limitation were addressed. Second, the questionnaire was too long. It took respondents up to 2.5 hours to complete, which does not enhance fidelity of completion. Together, the length of the questionnaire and the English language used could explain the low reliability of most of the scales used. When the Cronbach's alpha was under 0.60 , two-items and single item constructs were used instead which reduces certainty about the underlying construct that was measured as individuals might have different interpretations of the same item. Fourth, the questionnaire was only pretested among a small sample of secondary school students in Kampala. These respondents might not have been representative for the total sample. For instance, their knowledge of English and sexual behavioural terms is expected to be higher than of respondents residing in rural areas in Uganda. Also, the small sample size of the baseline survey did not allow us to check the reliability of the scales used. Finally, anonymity in responding was assured by having no names attached to the questionnaires and by instructing the research assistants to create a safe and quiet environment during implementation of the questionnaire. This appeared to be problematic in some cases, when a teacher would also be present in the class room, despite the request from the research assistants to leave the room.

The limitations of the qualitative study on the context of SRHR (Chapter 3), relate to the FGD conducted with adolescents. First, the qualitative data are collected on a small sample, which does not allow for generalising the findings to all Ugandan adolescents. Second, the FGDs were guided by the author of this dissertation (a middle-aged, Dutch woman), which could be colliding with the sensitive nature of the topics being 
discussed. To maximize a safe and anonymous environment, it was made sure that no teachers or other adults were present during the FGDs. Also, the topic list was built up in a way that the discussion started with general, non-sensitive topics, like subjects in school, and gradually taking the participants to more sensitive topics, like gender roles and relationships. The topic of coercive sex during the FDGs was introduced by using a story of a Ugandan boy and girl, who got involved in a coercive sex situation, ending with the girl being pregnant. After telling the story, the participants were invited to discuss the possible causes and consequence of the coercive sex example. This way, participants could be involved in the discussion without having to share their own experiences directly. Another limitation of the FGDs was that these were held in English. The fact that students were selected on the basis of being able to express themselves in English could lead to a bias, as these students might be in general the better students. Finally, the age-difference in some groups could have influenced the participation of the youngest students. Although the FGD leader did stress the value of each participant's opinion, the youngest student in the group with the biggest age difference, did not participate as actively as the older ones. However, in the other groups, all students participated fully.

The process evaluation study (Chapter 4) also had some limitations. Firstly, the cross-sectional nature of the data does not allow to draw conclusions about causality. Secondly, the questionnaire administered among teachers at pre-test was too long and was therefore shortened at post-test. The qualitative research part of the process evaluation consisted of in-depth interviews with teachers. The in-depth interviews with the teachers were also conducted in English, which did not impose major problems. These interviews were conducted by a Dutch female Master student, doing her master thesis research. Research on measurement of completeness and fidelity of implementation shows that self-reports by teachers and observations by others are not always congruent, which might be due to teachers' overestimation of their own competence (Dusenbury et al., 2005, 2007). Although these studies do not inform researchers which method is more valid to use, the current study did rely only on the self-reports of the teachers. Future research should include observational methods, next to self-reports, to enhance the validity of the data. 


\section{Recommendations for comprehensive rights-based sex education in Uganda and for future research}

The findings of the studies reported in this dissertation contribute to our understanding of correlates of safe sex behaviour of Ugandan adolescents and of how the context in which such sexual behaviour adolescents take place impact upon the right of young people to complete and accurate information and the right to sexual self-determination. Also, the findings add to the understanding of which barriers and facilitating factors teachers experience when implementing a comprehensive rights-based sex education as The World Starts With Me, and of the factors associated with dose delivered and fidelity of implementation. Finally, the study on the effectiveness of the World Starts With Me adds to our understanding of what changes such programmes are able to effectuate within the Ugandan context. Recommendations are made for intervention development, target group segmentation, change objectives, programme content, form and implementation context of comprehensive rights-based sex education programmes, such as The World Starts With Me. Also, recommendations for future research are given.

\section{Intervention development}

Based on the findings from the study on the context in which adolescents SRHR take form (Chapter 3) and on the findings from the process evaluation (Chapter 4), it is recommended that stakeholders at different levels of society be involved from the start of an intervention development.

At the national level, the Ministry of Education, of Health and of Justice are important relevant stakeholders when it comes to creating supportive sexual health and sex education policies and laws, for instance against discrimination of sexual minorities and people living with HIV and AIDS. The defilement law, although initially meant to protect girls under 18 years old from forced sex with older men, is currently working against SRHR of young people in Uganda, creating an environment of fear and anxiety. Media also play an important role in providing accurate and complete information on SRHR and media representatives at both national as well as regional and community level should be involved in intervention development. 
At the community level, local religious and political leaders, (women) NGOs, local media representatives, parents, as well as sexual health professionals and school managers are important stakeholders and social change agents. Their supportive norms, beliefs and attitudes towards adolescents sexuality and comprehensive rights-based sex education, including controversial issues like promotion of condom use and gender equality, are decisive for a supportive community environment for the promotion of young people's SRHR.

At the school level, teachers as the main implementers of school-based sex education should participate in intervention development. Teachers know best the implementation context and can assess the feasibility and acceptability of proposed intervention methods and strategies. Also, they can point out the necessary requirements for a high quality of intervention implementation, such as allocating sufficient time, funding and training. Last but not least, students should participate fully in intervention development aimed at them. It is not only their right to be actively participate in all stages of programme planning (IPPF, 2010; WPF, 2010), but they also know best what adolescents need and wish for in comprehensive rights-based sex education. They can assess the relevance of the content and the suitability of possible methods and strategies.

\section{Target group segmentation and change objectives}

The findings from the study on correlates of the intention to delay sexual intercourse and the intention to use condoms (Chapter 2), imply a segmented approach based on actual previous sexual experience. As the likelihood of sexual activity increases with age, we contend that it would be wise to start comprehensive sex education before adolescents start experimenting with sexual intercourse. Previous research (Stanton et al., 1998; Gallant \& Maticka-Tyndale, 2004) demonstrate that it is easier to change socio-cognitive variables and promote actual safe sex behaviour among adolescents who are not yet sexually active than among those who are. It is therefore recommended to start comprehensive sex education at school, before adolescents start experimenting with sexual intercourse (between 10 and 15 years; WHO, 2010a). Another reason to target younger adolescents is that in SSA, and also in Uganda, school attendance among this age group school attendance is relatively high (Bankole, Singh, Woogh, \& Wulf, 2004). 
It is furthermore recommended that the change objectives are focused on attitudes, social norms and self-efficacy of safe sexual behaviour, including condom use for the younger adolescents (10-14 years). For the group 15 years and older, comprising the higher classes of secondary school (from S3 onwards), it is recommended to focus on (perceived) social norms, i.e., emphasizing that the majority of important others (peers) want to delay sexual intercourse, do not want to feel pressured to have sex, and do intend to use a condom when they do decide to have sex. Finally, focus should be on the meaning and relevance of SRHR in the local context adolescents live in.

\section{Content and form of Comprehensive Rights-based Sex Education}

The findings from the study on SRHR in adolescents' local context (Chapter 3) show that comprehensive rights-based sex education need to provide complete and accurate information on sexual and reproductive health issues, such as technical aspects of reproduction, prevention of STIS, HIV and unintended pregnancies, as well as the pleasurable side of sexual relationships. This might seem trivial, but in the Ugandan context it is not. Although correct knowledge of sexual risk behaviour and high risk perception is not enough to evoke positive behaviour change (Stanton et al., 1999; Maswanya et al., 1999; Peters et al., 2009), also not in the Ugandan context (Hulton, Cullen, \& Khalokho, 2000), it is an important prerequisite for safe sex behaviour and just one of the fundamental basic sexual rights of young people (UN, 1995; IPPF, 2010). Adolescents can only make informed choices about their own sexuality, sexual behaviour and health if they have access to complete and reliable information. Apart from this, CRSE needs to encourage adolescents to critically discuss and reflect on the information they receive from different sources (school, media, family and friends).

Boys and girls should be educated in mixed groups (see Chapter 3), to allow critical discussion of SRHR topics, challenging the existing socio-cultural, political and religious norms and practices and gaining insight in each other's perspective as equals. It is important to equally involve female and male adolescents in these discussions, including a discussion of the gender specific realities of both girls and boys such as on issues of masculinity and femininity, as it is in the interaction between both sexes that change can occur. A review of specific programmes that have included a discussion of the gen- 
der-specific realities of young men showed that a dual gender perspective is a very promising approach to engage young men in SRHR issues and HIV and AIDS prevention: (1) gender specificity, meaning discussing how socialisation of young men is related to sexual and reproductive health issues, such as HIV and AIDS or gender-based violence and (2) gender equality, meaning that young men need to be involved in redressing gender inequalities, and as such in improving the health and well-being of young women (Barker \& Ricardo, 2005). The importance of including both young women and young men in sex education programmes cannot be overstressed, as the focus has too long been on young women only aiming at their empowerment or to the contrary aiming at promoting virginity values and disciplining them to prevent sexual intercourse. It is recommended to make mixed peer discussions a formal part of CRSE, enabling the formal teacher to correct false information, while at the same time facilitating students to critically discuss, reflect upon and challenge existing values, norms and customs. In case of single sex schools, a linkage between two schools within the same region is recommended, enabling interaction between girls and boys in mixed groups.

SRHR can best be discussed in in the context of examples of adolescents' daily reality. Many existing sexuality values, attitudes, norms, beliefs and practices relate to gender and power issues (Muhanguzi, 2011), such as the norm that boys need to provide for girls and the more he can give, the better candidate he is (Barker \& Ricardo, 2005); the practice that girls ask presents and money from boys or men and the subsequent pressure put on a girl to engage in sex once she has accepted them (Wagman et al., 2009; Nyanzi et al., 2001). Possible topics for discussion are the (cultural) background and history of the custom of giving presents and money; the purpose it served in previous times and how it has evolved in current times; how boys and girls feel about the custom and the consequences for each of them. By critically discussing these topics, challenging existing values, norms and practices, and gaining insight in each other's perspective as equals, positive and empowering change will be possible (Schaalma et al., 2004; Muhanguzi, 2011).

The results of the process- (Chapter 4 ) and effect evaluation (Chapter 5) suggest that it is important to implement the programme completely and that the programme itself should be flexible enough for teachers to use and adapt it according to the spe- 
cific context in which they have to implement the programme (i.e. adapting to accommodate specific questions and needs of the students and coping with the limited time and resources available), without having to skip lessons. This is in line with the results of the process evaluation, where teachers mentioned the need for more flexibility in implementation of the programme. This flexibility, without jeopardizing the core theory and evidence-based elements of the intervention, can be achieved by being clear about the essential, simplified, core programme (Plummer et al., 2007) and providing add-on optional programme elements which the teacher can use depending on time and specific needs of the adolescents.

Further, allocating enough funds for teaching the programme if it is extra-curricular, providing the necessary detailed and simplified manuals for teachers and students and ensuring follow-up training and on the job guidance and assistance are other important implementation prerequisites. Computer-based programmes are only an option if part of the programme ensures sufficient availability of computers and electricity and if a proper computer service is attached to it. Having said that, the use of computers, the internet and especially mobile phones in future interventions, can provide an enabling environment for interactive dialogue and critical discussion (Ziebland, 2004; Bloome, 2002), which is, as noted in Chapter 3, essential for social and behaviour change related to sexuality issues among Ugandan adolescents. A recent study among Uganda adolescents (12-18 years), revealed that the desired and actual use of the internet for information on HIV, AIDS and other health related topics is high (Ybarra, Kiwanuka, Emenyonu, \& Bangsberg, 2006).

\section{Implementation context}

In a resource limited setting, allocating funds for teaching the programme, especially if it is not part of the curriculum, and providing the necessary detailed and simplified manuals for teachers and students are essential to effectively implement CSRE. Computer based programmes are only an option if the intervention ensures sufficient availability of good quality computers, a continuous electricity supply and a proper computer service attached to it. 
Furthermore, a diverse array of factors, such as restrictive social and political norms regarding adolescents' sexuality and condoms use, gender inequality, sex and power dynamics combined with the economic disadvantaged positions of adolescents, impact upon their SRHR. Therefore, to be effective, CRSE should be accompanied by interventions aiming at supportive political, socio-economic, community and school management contexts (see also Matthews et al., 2006; Visser, Schoeman, \& Perold, 2004; Bonell et al., 2006).

Examples of interventions aiming at the political context are advocacy interventions aimed at the Ministry of Education to include condom promotion as a recommended sex education strategy, and aimed at the Ministry of Justice to change the defilement law in such a way that it is not used as a tool to charge adolescents under 18 who have consensual sex. Supportive economic contexts can be created by implementing interventions at schools to create small businesses for adolescents, especially girls. Through these small businesses, school fees, books and other necessary goods could be provided to the students, making them less vulnerable for intergenerational and transactional sex practices.

\section{Future research}

To improve the quality of research in a SSA context, reliable research instruments and scales should be developed and tested in local languages. Qualitative research among adolescents should take place, such as focus group discussions (FGDs) and in-depth interviews (IDI's), especially in new contexts, to identify salient beliefs, attitudes, norms, practices, which can be used as input for developing relevant questionnaires.

There is a need for research that can shed more light on the relative relevance of socio-cognitive factors in predicting safe sex behaviour in SSA context, in combination with the more structural factors, such as socio-economic, community, cultural and political context.

More research on how adolescents themselves would like to have transactional sex addressed in CRSR-interventions is necessary. The role of teachers in implementing CSRE, their own norms and beliefs, is another important research area, to improve 
the effectiveness of such programmes. Research should focus on identifying ways to discuss condom use in the class room in a cultural acceptable way.

Effect studies should be standard accompanied by implementation research, to give an indication of the extent to which the intervention was implemented the way it was intended, and to gain a better understanding of the context in which the intervention took place and of the interpretation of the results of the effect evaluation. To gain more insight in the reasons behind not adhering to the programme manual, future research should focus on when, why and how teachers divert from the manual. Also, future research should include the role of perceived teaching performance in the quality of implementation of sex education programmes in Uganda.

Finally, there is a need for research which can shed more light on how to achieve programme flexibility in such a way that the basic programme consists of the essential evidence based elements, and that the add-on optional programme elements do reflect the which the teacher can use depending on time and specific needs of the students.

\section{Conclusion}

This dissertation has investigated the socio-cognitive determinants of safe sex behaviour among Ugandan adolescents, has compared universal declared SRHR with the local realities of Ugandan adolescents, and has assessed the implementation and effectiveness of The World Starts With Me, a comprehensive rights-based sex education programme. The results of the studies give valuable input to the systematic design and implementation of comprehensive rights-based sex education programmes in a Sub-Saharan context. CRSE is likely to be most effective when it is based upon theory- and evidence-based needs assessments and intervention strategies. Understanding the socio-cognitive determinants of safe sex behaviour helps to specify which behaviour and determinants should be addressed to obtain the desired health outcomes (i.e., delaying (first) sexual intercourse and using condoms when sexually active based on own well-informed decision making), to prioritize age-, gender- or other segments, and to select behaviour change methods that are tailored to the needs of the target population and fit the intervention context. Also, understanding the socio-cultural, 
economic and political context in which sexual behaviour takes place, is essential to connect sexual and SRHR to the local context in which they have to take form. Understanding these contextual factors helps to determine which multi-sectoral approach should be taken and which supporting environments should be promoted. 


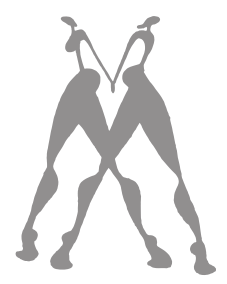

References 
Aarø, L. E., Schaalma, H., and Åstrøm, A. N. (2008). Social cognition models and Social Cognitive Theory. Predicting sexual- and reproductive behaviour among adolescents in Sub-Saharan Africa. In K.-I. Klepp, A. J. Flisher, \& S. F. Kaaya (Eds.), Promoting adolescent sexual and reproductive health in east and southern Africa (pp. 37-55). Uppsala, Sweden: Nordiska Afrikainstitutet.

Aarø, L. E., Flisher A. J., Kaaya S., Onya H., Fuglesang M., Klepp K. I., Schaalma H. P. (2006). Promoting sexual and reproductive health in early adolescence in South Africa and Tanzania: Development of a theory- and evidence based intervention programme. Scandinavian Journal of Public Health, 34(2), 150-158.

Adih, W. K., \& Alexander, C. S. (1999). Determinants of condom use to prevent HIV infection among youth in Ghana. Journal of Adolescent Health, 24, 63-72.

African Union Commission (2006). Maputo Plan of Action for the Operationalisation of the Continental Policy Framework for Sexual and Reproductive Health and Rights 2007-2010. Special Session the African Union Conference of Ministers of Health. Maputo, Mozambique (18-22 September 2006).

Agha, S., Hutchinson, P., \& Kusanthan, T. (2006). The effects of religious affiliation on sexual initiation and condom use in Zambia. Journal of Adolescents Health, 38(5), 550-555.

Ahmed, N., Flisher, A. J., Mathews, C., Jansen, S., Mũkoma, W., \& Schaalma, H. (2006). Process evaluation of the teacher training for an AIDS prevention programme. Health Education Research, 21(5), 621-632.

Ahmed, N., Flisher, A.J., Mathews, C., Mũkoma, W., and Jansen, S. (2009). HIV education in South African schools: The dilemma and conflicts of educators. Scandinavian Journal of Public Health, 37 (suppl 2), 48-54.

Airhihenbuwa, C. O. \& Obregon, R. (2000). A Critical Assessment of Theories/Models Used in Health Communication for HIV/AIDS. Journal of Health Communication, 5 (Suppl), 5-15. Retrieved from http://www.portalcomunicacion.com/obregon/ pdf/airhihenbuwa.pdf

Ajzen, I. (1991). The Theory of Planned Behavior. Organizational Behavior and Human Processes, 50, 179-211. 
Ajzen, I. (2002). Perceived Behavioral Control, Self-Efficacy, Locus of Control, and the Theory of Planned Behavior. Journal of Applied Social Psychology, 32, 665-683.

Albarraci'n, D., Johnson, B. T., Fishbein, M., \& Muellerleile, P. A. (2001). Theories of reasoned action and planned behavior as models of condom use: a metaanalysis. Psychological Bulletin, 127, 142-161.

Alford, S. (2003). Science and Success: Sex Education and Other Programs that Work to Prevent Teen Pregnancy, HIV \& Sexually Transmitted Infections. Washington, DC: Advocates for Youth.

Alford, S. (2008). Science and Success, Second Edition: Programs that Work to Prevent Teen Pregnancy, HIV \& Sexually Transmitted Infections. Washington, DC: Advocates for Youth.

Amuyunzu-Nyamongo, M., Biddlecom, A. E., Ouedraogo, C., \& Woog, V. (2005). Qualitative evidence on adolescents' views of sexual and reproductive health in Sub-Saharan Africa. Occasional Report, no. 16. New York: The Alan Guttmacher Institute.

Armitage, C. J., \& Conner, M. (2001). Efficacy of the theory of planned behaviour: A meta-analytic review. British Journal of Social Psychology, 40, 471-499.

Babalola, S., Awasum, D., \& Quenum-Renaud, B. (2002). The correlates of safe sex practices among Rwandan youth: A positive deviance approach. African Journal of AIDS Research, 1, 11-21.

Baldo, M., \& Uzamugunda, J. (2000). Evaluating Adolescents' AIDS Education: The Experience of Uganda. Journal of Health Management, 2(1), 81-97.

Bankole, A., Singh, S., Woog, V., \& Wulf, D. (2004). Risk and protection: Youth and HIV/ AIDS in Sub-Saharan Africa. New York: The Alan Guttmacher Institute.

Barker, G., \& Ricardo, C. (2005). Young men and the construction of masculinity in sub Saharan Africa. Washington DC: World Bank Social Development Papers.

Bartholomew, L. K. , Parcel G. S., Kok G., Gottlieb N., \& Fernandez M. E. (2011). Planning Health promotion Programs. An Intervention Mapping Approach (3rd ed.). San Francisco: Jossey-Bass. 
BBC News (2006). Uganda and LRA rebels sign truce. Story from BBC NEWS: http:// news.bbc.co.uk/go/pr/fr/-/2/hi/africa/5288776.stm Published: 2006/08/26 14:09:15 GMT

Becker, M. H. (1974). The Health Belief Model and Personal Health Behaviour. Health Education Monographs, 2(4), 324-473.

Benefo, K.D. (2010). Determinants of condom use in Zambia: A multilevel analysis. Studies in Family Planning, 41(1), 19-30.

Bennet, P., \& Bozionelos, G. (2000). The theory of planned behaviour as predictor of condom use: a narrative review. Psychology, Health \& Medicine, 5(3), 307-326.

Biddlecom, A. E., Hessburg, L., Singh, S., Bankole, A., \& Darabi, L. (2007). Protecting the next generation in Sub-Saharan Africa: Learning from Adolescents to prevent HIV and Unintended Pregnancy. New York: Guttmacher Institute. Retreived from: http://www.guttmacher.org/pubs/2007/12/12/PNG_monograph.pdf

Biraro, S., Shafer L. A., Kleinschmidt I., Wolff, B., Karabalinde, A., Nalwoga, A., ... Grosskurth, H. (2009). Is sexual risk taking behaviour changing in rural southwest Uganda? Behaviour trends in a rural population cohort 1993-2006. Sexually Transmitted Infections, 85 (Suppl I), i3-i11.

Bleakley, A., Hennessy, M., \& Fishbein, M. (2006). Public Opinion on Sex education in US Schools. Archives of Pediatrics \& Adolescent Medicine, 160, 1151-1156.

Bloome, A. (2002) "Do U Know?" Using ICT to Fight HIV/AIDS. Bulletin of Medicus Mundi, 85. Retrieved from: http://www.medicusmundi.ch/mms/services/ bulletin/bulletin200202/kap02/12bloome.html

Bluhm, J., Volik, M., \& Morgan, N. (2003). Sexual health peer education among youth in Samara: the Russian Federation. Entre Nous: The European Magazine for Sexual and Reproductive Health,56, 10-11.

Boer, H., \& Mashamba, M. T. (2005). Psychosocial correlates of HIV protection motivation among black adolescents from Venda, South Africa. Aids Education and Prevention, 17(6), 590-602.

Boer, H., \& Mashamba, M.T. (2007). Gender power imbalance and differential psychosocial correlates of intended condom use among male and female adolescents in Venda, South Africa. British Journal of Health Psychology, 12, 51-63. 
Bohmer, L., \& Kirumira, E. K. (2000). Socio-economic context and the sexual behaviour of Ugandan out of school youth. Culture, Health and Sexuality, 2(3), 269-285.

Bonell, C., Allen, E., Strange, V., Oakley, A., Copas, A., Johnson, A., \& Stephenson, J. (2006). Influence of family type and parenting behaviours on teenage sexual behaviour and conception. Journal of Epidemiology and Community Health, 60, 502-506. doi: 10.1136/jech.2005.042838

Bos, A. E. R., Kok, G., \& Dijker, A. J. (2001). Public reactions to people with HIV/AIDS in the Netherlands. AIDS Education and Prevention, 3, 219-228.

Bos, A. E. R., Schaalma, H. P., \& Pryor, J. B. (2008). Reducing AIDS-related stigma in developing countries: The importance of theory- and evidence based interventions. Psychology, Health \& Medicine, 13(4), 450-460.

Bosompra, K. (2001). Determinants of condom use intentions of university students in Ghana: An application of the theory of reasoned action. Social Science \& Medicine, 52(7), 1057-1069.

Braeken, D., \& Cardinal, M. (2008). Comprehensive sexuality education as a means of promoting sexual health. International Journal of Sexual Health, 20(1), 50-62.

Bryan, A., Kagee, A., \& Broaddus, M. R. (2006). Condom use among South African adolescents: Developing and testing theoretical models of intentions and behavior. AIDS and behavior, 10, 387-397.

Buhi, E. R., \& Goodson, P. (2007). Predictors of adolescent sexual behavior and intention: a theory-guided systematic review. Journal of Adolescent Health, $40(1), 4-21$.

Buhi, E. R., Goodson, P., Neilands, T. B., \& Blunt, H. (2011). Adolescent Sexual Abstinence: A Test of an Integrative Theoretical Framework. Health Education \& Behavior, 38(1), 63-79

Buston, K., Wight, D., Hart, G. \& Scott, S. (2002). Implementation of a teacher-delivered sex education programme: obstacles and facilitating factors. Health Education Research, $17(1), 59-72$.

Carjaval, S. C., Parcel, G. S., Banspach, S. W., Basen-Engquist, K., Coyle, K.K., \& Kirby, D. (1999). Psychosocial predictors of delay of first sexual intercourse by adolescents. Health Psychology, 18(5), 443-452. 
Chalmers, H., Aggleton, P., Ingham, R., \& Stone, N. (2006). Dynamic contextual analysis. A context specific approach to understanding barriers to and opportunities for change. Second ed. South Hampton, UK: Safe Passages to Adulthood Programme. http://www.safepassages.soton.ac.uk/pdfs/DCA2.pdf (accessed August 16, 2011).

Chatterji, M., Murray, N., London, D., \& Anglewicz, P. (2004). The Factors Influencing Transactional Sex Among Young Men and Women in 12 Sub-Saharan African Countries. Policy Report. USAID. Retrieved from: http://www.policyproject.com/ pubs/countryreports/Trans_Sex.pdf

Cleland, J., \& Ali, M.M. (2006). Sexual abstinence, contraception, and condom use by young African women: A secondary analysis of survey data. Lancet, 368, 1788-1793.

Cohen, J., \& Tate, T. (2006). The Less They Know, The Better: Abstinence-Only HIV/AIDS Programs in Uganda. Reproductive Health Matters, 14(28): 174-178.

Collins, C., Alagiri, P., \& Summers, T. (2002). Abstinence only vs. comprehensive sex education: What are the arguments? What is the evidence? AIDS Policy Research Center \& Center for AIDS Prevention Studies, AIDS Research Institute, University of California, San Francisco. Retrieved from: http://ari.ucsf.edu/science/reports/ abstinence.pdf

Cowan, F., \& Pettifor, A. (2009). HIV in adolescents in Sub-Saharan Africa. Current Opinion in HIV and AIDS, 4, 288-293.

Dane, A. U., \& Schneider, B. H. (1998). Program integrity in primary and early secondary prevention: Are implementation effects out of control? Clinical Psychology Review, 18(1), 23-45.

Darabi, L., Bankole, A., Serumaga, K., Neema, S., Kibombo, R., Ahmed, H., \& Banoba, P. (2008). Protecting the Next Generation in Uganda: New Evidence on Adolescent Sexual and Reproductive Health Needs. New York: Guttmacher Institute.

DiLorio C., Dudley W. N., Kelly M., Soet J. E., Mbwara J., \& Sharpe Potter J. (2001). Social cognitive correlates of sexual experience and condom use among 13through 15-year-old adolescents. Journal of Adolescent Health, 29(3), 208- 216. 
Doyle, A. M., Napierala Mavedzenge, S., Plummer, M. L., \& Ross, D.A. (2012). The sexual behaviour of adolescents in Sub-Saharan Africa: patterns and trends from national surveys. Tropical Medicine and International Health, 17(7), 796-807.

Durlak, J. A., \& DuPre, E. P. (2008). Implementation Matters: A Review of Research on the Influence of Implementation on Program Outcomes and the Factors Affecting Implementation. American Journal Community Psychology, 41, 327-350.

Dusenbury, L., Branningan, R., Falco, M., \& Hansen, W.B. (2003). A review of research on fidelity of implementation: Implications for drug abuse prevention in school settings. Health Education Research, Theory \& Practice, 18(2), 237-256.

Dusenbury, L., Brannigan, R., Hansen, W.B., Walsh, J., \& Falco, M. (2005). Quality of implementation: developing measures crucial to understanding the diffusion of preventive interventions. Health Education Research, Theory \& Practice, 20(3): 308-313.

Eggers, S. M., Aarø, L.E., Bos, A.E.R., Mathews, C., \& de Vries, H. (2013). Predicting Condom Use in South Africa: A Test of Two Integrative Models. AIDS and Behavior. Fekadu, Z., \& Kraft, P. (2002). Expanding the Theory of Planned Behaviour: The role of social norms and group identification. Journal of Health Psychology, 7, 33-43.

Field, A. (2009). Discovering Statistics USING SPSS. CA, USA: SAGE Publications Ltd.

Figueroa, M. E., Kincaid, D. L., Rani, M., \& Lewis, G. (2002). Communication for Social Change: An Integrated Model for Measuring the Process and Its Outcomes. The Rockefeller Foundation and Johns Hopkins University Centre for Communication Programs, New York. [Byrd BI (series editor): The Communication for Social Change Working Paper Series: No.1.].

Fishbein, M. (1998). Changing behavior to prevent STDs/AIDS. Int J Gynecol Obstet, 63(Suppl 1), 175-181.

Fishbein, M. (2000). The role of theory in HIV prevention. AIDS Care, 12, 273-278.

Fishbein, M., \& Ajzen, I. (2010). Predicting and changing Behavior. The Reasoned Action Approach. New York (NY): Psychology Press, Taylor and Francis Group.

Fisher, J. D., \& Fisher, W. A. (1992). Changing AIDS risk behaviour. Psychological Bulletin, $111,455-474$. 
Fitzgerald, A. M., Stanton, B. F., Terreri, N., Shipena, H., Li, X., Kahihuata, J.,... MatickaTyndale, E. (2004). School-based HIV prevention programmes for African youth. Social Science \& Medicine, 58, 1337-1351.

Giles, M., Liddell, C., \& Bydawell, M. (2005). Condom use in African adolescents: the role of individual and group factors. AIDS Care, 17(6), 729-39.

Gillespie, S. (2006). AIDS, poverty, and hunger: Challenges and responses. Highlights of the International Conference on HIV/AIDS and Food and Nutrition Security, Durban, South Africa, 14-16 April 2005. Washington, D.C: International Food Policy Research Institute.

Glick, P. J., \& Sahn, D. E. (2008). Are Africans Practicing Safer Sex? Evidence from Demographic and Health Surveys for Eight Countries. Economic Development and Cultural Change, 56, 397-439.

Godin, G., \& Kok, G. (1996). The theory of planned behavior: A review of its applications to health-related behaviors. American Journal of Health Promotion, 11, 87-98.

Gredig, D., Nideroest, S., Parpan-Blaser, A. (2006). HIV-protection through condom use: Testing the theory of planned behaviour in a community sample of heterosexual men in a high-income country. Psychology Health, 21(5), 541-555.

Green, E. C., Halperin, D. T., Nantulya, V., \& Hogle, J. A. (2006). Uganda's HIV Prevention Success: The Role of Sexual Behavior Change and the National Response. AIDS and Behavior, 10 (4), 335-346.

Government of Uganda: Uganda UNGASS Progress Report, Jan 2008-Dec 2009. Kampala: 2010. Retrieved from: http://www.unaids.org/en/dataanalysis/ monitoringcountryprogress/2010progressreportssubmittedbycountries/ uganda_2010_country_progress_report_en.pdf

Hall, W. J., Zeveloff, A., Steckler, A., Schneider, M., Thompson, D., Pham, T., ... McMurray, R. G. (2012). Process Evaluation results from the HEALTHY physical education intervention. Health Education Research, 27(2), 307-318.

Hardeman, W., Michie, S., Fanshawe, T., Prevost, T., Mcloughlin, K., \& Kinmonth, L. (2008). Fidelity of delivery of a physical activity intervention: predictors and consequences. Psychology \& Health, 23 (1): 11-24. 
Harrison, A., Newell, M., Imrie, J., \& Hoddinott, G. (2010). HIV prevention for South African youth; which interventions work? A systematic review of current evidence. BMC Public Health, 10, 102.

Heeren, G. A., Jemmott, J. B. III, Mandeya, A., \& Tyler, J. C. (2007). Theory-based predictors of condom use among university students in the United States and South Africa. AIDS Education and Prevention, 19(1):1-12.

Helleve, A., Flisher, A. J., Onya, H., Mũkoma, W., \& Klepp, K-I. (2009). South African teachers' reflections on the impact of culture on their teaching of sexuality and HIV/AIDS. Culture, Health \& Sexuality: An International Journal for Research, Intervention and Care, 11(2): 189-204.

Hughes, J., McCauley, A. P. (1998). Improving the Fit: Adolescents' Needs and Future Programs for Sexual and Reproductive Health in Developing Countries. Studies in Family Planning, 29(2), 233-245.

Hulton, L. A., Cullen, R., \& Khalokho, S. W. (2000). Perceptions of the Risks of Sexual Activity and Their Consequences Among Ugandan Adolescents. Studies in Family Planning, 31(1), 35-46.

Ingham, R. (2006). The importance of context in understanding and seeking to promote sexual health. In R. Ingham \& P. Aggleton (Eds.), Promoting Young People's Sexual Health. International Perspectives (pp. 41-60). New York, US: Routledge. IPPF (2003). IPPF Charter on Sexual and Reproductive Rights. London: IPPF IPPF (2008). Sexual Rights: An IPPF Declaration. London: IPPF. IPPF (2010). IPPF Framework for Comprehensive Sexuality Education. London: IPPF. Iyer, P., \& Aggleton, P. (2012). 'Sex education should be taught, fine...but we make sure they control themselves': teacher's beliefs and attitudes towards young people's sexual and reproductive health in a Ugandan secondary school. Sex Education: Sexuality, Society and learning, 1-14, iFirst article.

Jansen, Y. O. (2007). The right to freely have sex? Beyond biology: Reproductive rights and sexual self-determination. Akron Law Review, 40(2), 311-38.

Jemmott, J. B., \& Jemmott, L. S. (2000). HIV risk reduction behavioral interventions with heterosexual adolescents. AIDS, 14(Suppl 2), S40-S52. 
Kaaya, S. F., Flisher, A. J., Mbwambo, J. K., Schaalma, H., Aarø, L. E., \& Klepp, K. I. (2002). A review of studies of sexual behaviour of school students in Sub-Saharan Africa. Scandinavian Journal of Public Health, 30(Suppl 2), $148-160$.

Kabiru, C. W., \& Ezeh, A. (2007). Factors associated with sexual abstinence among adolescents in four Sub-Saharan African Countries. African Journal of Reproductive Health, 11(3), 111-132.

Karim, A. M., Magnani, R. J., Morgan, G. T., \& Bond, K. C. (2003). Reproductive health risk and protective factors among unmarried youth in Ghana. International Family Planning Perspectives, 29(1), 14-24.

Kashima, Y., Gallois, C., \& McCamish, M. (1993). The theory of reasoned action and cooperative behaviour: It takes two to use a condom. British Journal of Social Psychology, 32, 227-239.

Kaufman, C. E., Clark, S., Manzini, N., \& May, J. (2004) Communities, Opportunities, and Adolescents' Sexual Behavior in KwaZulu-Natal, South Africa. Studies in Family Planning, 35(4), 261-274.

Kelly, R. J., Gray, R. H., Sewankambo, N. K., Serwadda, D., Wabwire-Mangen, F., Lutalo, T., \& Wawer, M. J. (2003). Age differences in sexual partners and risk of HIV-1 infection in rural Uganda. Journal of Acquired Immune Deficiency Syndromes, 32(4), 446-451.

Khan, S., \& Mishra, V. (2008). Youth Reproductive and Sexual Health. DHS Comparative Reports No. 19. Calverton, Maryland, USA: Macro International Inc. Retrieved from: http://pdf.usaid.gov/pdf_docs/PNADM644.pdf

Kibombo, R., Neema, S., Moore, A. M., \& Ahmed, H. (2008). Adults' perceptions of adolescents' sexual and reproductive health: qualitative evidence from Uganda. New York: Guttmacher Institute. Retrieved from: http://d1lj51l9p3qzy9. cloudfront.net/handle/10207/bitstreams/6013.pdf

King, N. (1998). Template analysis. In G. Symon \& C. Cassell (Eds.), Qualitative methods and analysis in organizational research (pp. 256-270). London: Sage.

Kinsman, J. Harrison, S., Kengeya-Kayondo, J., Kanyesigye, E., Musoke, S., \& Whitworth, J. (1999). Implementation of a Comprehensive AIDS education programme for schools in Masaka District, Uganda. AIDS Care: Psychological and Socio-medical Aspects of AIDS/HIV, 11(5), 591-601. 
Kinsman, J., Nyanzi, S., \& Pool, R. (2000). Socializing influences and the value of sex: The experience of adolescent school girls in rural Masaka, Uganda. Culture, Health \& Sexuality 2(2), 151-66.

Kinsman, J., Nakiyingi, J., Kamali, A., Carpenter, L., Quigley, M., Pool, R., \& Whitworth, J. (2001). Evaluation of a comprehensive school-based AIDS education programme in rural Masaka, Uganda. Health Education Research 2001, 16(1), 85-100.

Kinsman, J., Kamali, A., Kanyesigye, E., Kamulegeya, I., Basajja, V., Nakiyingi, J., Schenk, K., \& Whitworth, J. (2002). Quantitative process evaluation of a communitybased HIV/AIDS behavioural intervention in rural Uganda. Health Education Research, Theory \& Practice, 17(2), 253-265.

Kirabo, A., Byakagaba, P., Buyinza, M., \& Namaalwa, J. (2011). Agroforestry as a Land Conflict Management Strategy in Western Uganda. Environmental Research Journal, 5, 42-48.

Kirby, D. (2002a). Do Abstinence-Only Programs Delay the Initiation of Sex Among Young People and Reduce Teen Pregnancy? Washington, DC: National Campaign to Prevent Teen Pregnancy.

Kirby, D. (2002b). Effective approaches to reducing adolescents unprotected sex, pregnancy and childbearing. The journal of Sex research, 39, 51-57.

Kirby, D. (2007). Emerging answers 2007: Research findings on programs to reduce the problems of teen pregnancy and sexually transmitted diseases. National Campaign to Prevent Teen and Unplanned Pregnancy. Washington, DC.

Kirby, D., \& Halperin, D. T. (2008). Success in Uganda: an analysis of behavior changes that led to declines in HIV prevalence in the early 1990s. Scotts Valley (CA): ETR Associates.

Kirby, D. (2008). The Impact of Abstinence and Comprehensive Sex and STD/HIV Education Programs on Adolescent Sexual Behavior. Sexuality Research and Social Policy, 5(3), 6-17.

Kirby, D., Obasi, A., \& Laris B. A. (2006). The effectiveness of sex education and HIV education interventions in schools in developing countries. In: Preventing HIV/ AIDS in Young People. A Systematic Review of the Evidence from Developing Countries. WHO Technical Report Series, no. 938. WHO Press, World Health Organization, Geneva: Switzerland. 
Kirby, D. (2011). Sex Education: Access and Impact on Sexual Behaviour of Young People. New York: United Nations.

Koenig, M., Zablostska, I., Lutalo, T., Nalugoda, F., Wagman, J., \& Gray, R. (2004a). Coerced first intercourse and reproductive health outcomes among adolescent women in Rakai,Uganda. International Family Planning Perspectives, 30, 156-163.

Koenig, M., Lutalo, T., Zhao, F., Nalugoda, F., Kiwanuka, N., Wabwire-Mangen, F. , ... Gray, R. (2004b). Coercive sex in rural Uganda: prevalence and associated risk factors. Social Science \& Medicine, 58, 787-798.

Koffi, A. K., \& Kawahara, K. (2008). Sexual abstinence behavior among never-married youths in ageneralized HIV epidemic country: evidence from the 2005 Côte d'Ivoire AIDS indicator survey. BMC Public Health, 8, 408.

Kok, G., Schaalma, H. P., Ruiter, R., van Empelen, P., \& Brug, J. (2004). Intervention Mapping: A protocol for applying health psychology theory to prevention programmes. Journal of Health Psychology, 9, 85-98.

Kok, G., Gottlieb, N. H., Panne, R., \& Smerecnik, C. (2012). Methods for environmental change; an exploratory study. BMC Public Health,12, 1037.

Kuate-Defo, B. (2004). Young People's Relationships with Sugar Daddies and Sugar Mummies: What do We Know and What Do We Need to Know? African Journal of Reproductive Health, 8 (2),13-37

Lagarde, E., Pison, G., \& Enel, C. (1996). A study of sexual behaviour change in rural Senegal. Journal of acquired immune deficiency syndromes and human retrovirology, 11(3), 282-287.

Lagarde, E., Auvert, B., Caraël, M., Laourou, M., Ferry, B., Akam, E., ... Buvé, A. (2001). Concurrent sexual partnerships and HIV prevalence in five urban communities of Sub-Saharan Africa. AIDS, 15, 877-884.

Leerlooijer, J. N., Ruiter, R., Reinders, J., Darwisyah, W., Kok, G., \& Bartholomew, L. (2011). The World Starts With Me: using intervention mapping for the systematic adaptation and transfer of school-based sexuality education from Uganda to Indonesia. Translational Behavioral Medicine, 1(2): 331-340.

Linnan, L., \& Stecker, A. (2002). Process Evaluation for Public Health Interventions and Research. San Fransisco, US: Jossey-Bass. 
Liska, A. E. (1984). A critical examination of the causal structure of the FishbeinAjzen model. Social Psychology Quarterly, 47, 61-74. http://www.jstor.org/ stable/3033889.

Lloyd, C. B. (2010). The role of schools in promoting sexual and reproductive health among adolescents in developing countries. In: Social Determinants of Sexual and Reproductive Health. Informing future research and programme implementation. Geneva, Switzerland: WHO.

Lugoe, W., \& Rise, J. (1999). Predicting Intended Condom Use among Tanzanian Students using the Theory of Planned Behaviour. Journal of Health Psychology, 4(4), 497-506.

Luke, N., \& Kurz, K. (2002). Cross-generational and transactional sexual relations in Sub-Saharan Africa: Prevalence of behavior and implications for negotiating safer sexual practices. Research Paper Series. Washington, DC: International Center for Research on Women.

Madise, N. J., Zulu, E. M., \& Ciera, J. (2007). Is Poverty a Driver for Risky Sexual Behaviour? Evidence from National Surveys of Adolescents in four African Countries. African Journal of Reproductive Health, 11(3), 83-98.

Marindo, R., Pearson, S., \& Casterline, J.B. (2003). Condom use and abstinence among unmarried young people in Zimbabwe: Which strategy, Whose agenda? Report No. 170. New York: Policy Research Division, Population Council; 2003. Retrieved from: http://www.popcouncil.org/pdfs/wp/170.pdf.

Martínez, J. L., Carcedo, R. J., Fuertes, A., Vicario-Molina, I., Andrés A. FernándezFuertes, A. A., \& Orgaz, B. (2012). Sex education in Spain: teachers' views of obstacles. Sex Education: Sexuality, Society and Learning, 12(4).

Maswanya, E. S., Moji, K., Horiguchi, I. Nagata, K. Aoyagi, K., Honda, S., \& Takemoto, T. (1999). Knowledge, risk perception of AIDS and reported sexual behaviour among students in secondary schools and colleges in Tanzania. Health Education Research. Theory \& Practice, 14(2), 185-196.

Matthews, C., Boon, H., Flisher, A. J., \& Schaalma, H. P. (2006). Factors associated with teachers' implementation of HIV/AIDS education in secondary schools in Cape Town, South Africa. AIDS Care, 18(4): 388-397. 
Mbananga, N. (2004). Cultural clashes in reproductive health in schools. Health Education, 104(3), 152-162.

McCauley, A. P., Salter, C., Kiragu, K., \& Senderowitz, J. (1995). Meeting the Needs of Young Adults. Population Reports. Series J. No. 41, 1995:1-43. Baltimore, Maryland: Population Information Program, Johns Hopkins School of Public Health.

Meekers, D., \& Klein, M. (2002). Determinants of Condom Use among Young People in Urban Cameroon. Studies in Family Planning, 33(4), 335-346.

Mellanby, A. R., Rees, J. B., \& Tripp, J. H. (2000). Peer-led and adult-led school health education: a critical review of available comparative research. Health Education Research, 15, 533-545.

Mellanby, A. R., Newcombe, R. G., Rees, J., \& Tripp, J. H. (2001). A comparative study of peer-led and adult-led school sex education. Health Education Research, 16(4), 481-492.

Mensch, B. S., Grant, M. J., \& Blanc, A. K. (2006). The Changing Context of Sexual Initiation in Sub-Saharan Africa. Population and Development Review, 32, 699-727.

Michielsen, K., Chersich, M.F ., Luchtersa, S., De Kokera, P., Van Rossem. R., \& Temmerman, M. (2010). Effectiveness of HIV prevention for youth in Sub-Saharan Africa: systematic review and meta-analysis of randomized and nonrandomized trials. AIDS, 24, 1193-1202.

MoES. (2006). Education \& Sports Sector National Policy Guidelines on HIV/AIDS. Retrieved from: http://hivaidsclearinghouse.unesco.org/search/resources/ Uganda\%20National\%20policy.pdf

Molla, M., Åstrøm, A.N., \& Brehane, Y. (2007). Applicability of the theory of planned behavior to intended and self-reported condom use in a rural Ethiopian population. AIDS Care: Psychological and Socio-medical Aspects of AIDS/HIV, 19(3), 425-431.

Moore, A. R., \& Oppong, J. (2007). Sexual risk behavior among people livingwith HIV/ AIDS in Togo. Social Science \& Medicine, 64, 1057-106

Moore, A. R., Biddlecom, A. E., \& Zulu, E. M. (2007). Prevalence and meanings of exchange of money or gifts for sex in unmarried adolescent sexual relationships in Sub-Saharan Africa. African Journal of Reproductive Health 11(3) 44-61. 
Muhanguzi, F. K. (2011). Gender and sexual vulnerability of young women in Africa: Experiences of young girls in secondary schools in Uganda. Culture, Health \& Sexuality, 13, 713-25.

Muhanguzi, F. K., \& Ninsiima, A. (2011). Embracing teen sexuality: Teenagers'assessment of sexuality education in Uganda. Agenda: Empowering women for gender equity, 2(3), 54-63.

Mũkoma, W., \& Flisher, A. J. (2008). A systematic review of school-based HIV prevention programmes in South Africa. In K. Klepp, A.J. Flisher, \& and Kaaya, S.F. (eds.), Promoting sexual and reproductive health in East and Southern Africa (pp.267287). Pretoria, ZA: HSRC Press.

Mũkoma, W., Flisher, A.J., Helleve, A., Aarø, L. E., Mathews, C., Kaaya, S., \& Klepp, K. (2009a). Development, reliability and validity of a research instrument designed to evaluate school-based HIV/AIDS interventions in South Africa and Tanzania. Scandinavian Journal of Public Health, 37(Suppl 2), 7-15.

Mũkoma, W., Flisher, A. J., Ahmed, N., Jansen, S., Mathews, C., Klepp, K.-I., \& Schaalma, H. (2009b). Process evaluation of a school-based HIV/AIDS intervention in South Africa. Scandinavian Journal of Public Health, 37(2 suppl), 37-47.

Muyinda H., Kengeya, J., Pool, R., \& Whitworth, J. (2001). Traditional sex counselling and STI/HIV prevention among young women in rural Uganda. Culture, Health \& Sexuality, 3(3), 353-361.

Napierala Mavedzenge, S. M, Doyle, A. M, \& Ross, D. A. (2010). HIV prevention in young people in Sub-Saharan Africa: A Systematic Review. Infectious Disease Epidemiology Unit, Department of Epidemiology and Population Health. London school of Hygiene \& Tropical Medicine.

Neema, S., Musisi, N., \& Kibombo, R. (2004). Adolescent Sexual and Reproductive Health in Uganda: A Synthesis of Research Evidence. Occasional Report, No. 14. New York: The Alan Guttmacher Institute.

Neema, S., Ahmed, H., Kibombo, R., \& Bankole A. (2006). Adolescent sexual and reproductive health in Uganda: results from the 2004 Uganda National Survey of Adolescents. Occasional Report, No.25. Guttmacher Institute, New York. 
Njue, C., Nzioka, C., Ahlberg, B. M., Pertet, A. M., \& Voeten, H. A . C. M. (2009). "If you don't abstain, you will die of AIDS": Aids Education in Kenyan Public Schools. AIDS Education and Prevention, 21(2): 169-179.

Noar, A. M., Black, H. G., \& Pierce, L. B. (2009). Efficacy of computer technology-based HIV prevention interventions: a meta-analysis. AIDS, 23, 107-115.

Nobelius, A., Kalina, B., Pool, R., Whitworth, J., Chesters, J. \& Power, R. (2010). Sexual and Reproductive health information sources preferred by out-of-school adolescents in rural southwest Uganda. Sex Education: Sexuality, Society and Learning, 10(1), 91-107.

Nyanzi S., Pool, R., \& Kinsman, J. (2010). Negotiation of sexual relationships among school-going adolescents. AIDS Care, 13, 83-98.

Opio, A., Mishra, V., Hong, R., Musinguzi, J., Kirungi, W., Cross, A., Mermin, J., \& Bunnell, R. (2008). Trends in HIV-related behaviors and knowledge in Uganda, 1989-2005: evidence of a shift toward more risk-taking behaviors. Journal of Acquired Immune Deficiency Syndromes, 49, 320-326.

Oronje, R. N., Crichton, J., Theobald, S., Lithur, N. O., \& Ibisomi, L. (2011). Operationalising sexual and reproductive health and rights in Sub-Saharan Africa: constraints, dilemmas and strategies. BMC International Health and Human Rights, 11(suppl.3), S8.

Panos Institute (2003). Missing the message? 20 years of learning from HIV/AIDS. London: Panos Institute.

Parikh, S. A. (2012). "They arrested me for loving a schoolgirl": Ethnography, HIV, and a feminist assessment of the age of consent law as a gender-based structural intervention in Uganda. Social Science \& Medicine, 74, 1774-1782.

Parker, G. P., Easton, D., \& Klein, H. (2000). Structural barriers and facilitators in HIV prevention: A review of international research. AIDS, 14(Suppl 1), S22-S32.

Parker, R. (2001). Sexuality, culture and power in HIV/AIDS research. Annual Review of Anthropology, 30,163-179.

Parker, R., \& Aggleton, P. (2003). HIV and AIDS-related stigma and discrimination: a conceptual framework and implications for action. Social Science \& Medicine, $57,13-24$. 
Paul-Ebhohimhen, V. A., Poobalan, A., \& van Teijlingen, E. (2008). A systematic review of school-based sexual health interventions to prevent STI/HIV in Sub-Saharan Africa. BMC Public Health, 8, 4.

Paulussen, T. G. W. , Kok, G.J., \& Schaalma, H.P. (1994). Antecedents to adoption of classroom-based AIDS education in secondary schools. Health Education Research, 9, 485-96.

Peltzer, K., \& Promtussananon, S. (2003). HIV/AIDS education in South Africa: Teacher knowledge about HIV/AIDS: Teacher attitude about and control of HIV/AIDS education. Social Behaviour and Personality, 31(4), 349-356.

Peters, L. W. H., Kok, G., Ten Dam, G. T. M., Buijs, G. J., \& Paulussen, T.G.W.M. (2009). Effective elements of school health promotion across behavioral domains: a systematic review of reviews. BMC Public Health, 9, 182.

Peters, L. W. H., Wiefferink, C. H., Hoekstra, F., Buijs, G. J., ten Dam, G. T. M., \& Paulussen, T. G. W. M. (2009). A review of similarities between domain-specific determinants of four health behaviors among adolescents. Health Education Research, 24(2),198-223.

Peterson, K. A., \& Bickman, L. (1988). Program personnel: the missing ingredient in describing the program environment. In Conrad, K. J. and Roberts-Gray, C. (eds), Evaluating Program Environments (pp. 83-92). San Francisco, CA: Jossey-Bass.

Pettifor, A. E., van der Straten, A., Dunbar, M., Shiboski, S., \& Padian, N. (2004). Early age of first sex: a risk factor for HIV infection among women in Zimbabwe. AIDS,18(10), 1435-1442.

Pettifor, A. E., O’Brien, K., MacPhail, C., Miller, W. C., \& Rees, H. (2009). Early Coital Debut and Associated HIV Risk Factors Among Young Women and Men in South Africa. International Perspectives on Sexual and Reproductive Health, 35(2), 74-82.

Plummer, M. L., Wight, D., Wamoyi, J., Nyalali, K., Ingall, T., Mshana, G., ... Ross, D. A. (2007). Are schools a good setting for adolescent sexual health promotion in rural Africa? A qualitative assessment from Tanzania. Health Education Research, Theory and Practice, 22(4), 483-499.

Robson, C. (2011). Real World Research. West Sussex, UK: John Wiley and Sons Ltd. 
Ross, D. A., Dick, B., \& Ferguson, J. (eds.) (2006). Preventing HIV/AIDS in young people: a systematic review of the evidence from developing countries. (WHO Technical Report Series no. 938). Geneva, Switzerland: WHO.

Rijsdijk, E. L., Bos, A. E. R., Ruiter, R. A. C., Leerlooijer, J. N., de Haas, B., \& Schaalma, H. P. (2011). The World Starts With Me: A multilevel evaluation of a comprehensive sex education programme targeting adolescents in Uganda. BMC Public Health, 11, 334. Santelli, J. S., Kaiser, J., Hirsch, L., Radosh, A., Simkin, L., Phil, M. \& Middlestadt, S. (2004). Initiation of Sexual Intercourse Among Middle School Adolescents: The Influence of Psychosocial Factors. Journal of Adolescent Health, 34, 200-208.

Schaalma, H. P., Kok, G., \& Peters, L. (1993). Determinants of consistent condom use by adolescents: The impact of experience of sexual intercourse. Health Education Research, 8, 255-269.

Schaalma, H. P., Kok, G., Poelman, J., \& Reinders, J. (1994). The development of AIDS education for Dutch secondary schools: a systematic approach based on theory, research and co-operation. In D.R. Rutter, \& L. Quine (eds), Social Psychology and Health: European Perspectives (pp. 175-194). Aldershot: Avebury.

Schaalma, H. P., Abraham, C., Gilmore, M. R., Kok, G. (2004). Sex education as health promotion: What does it take? Archives of Sexual Behaviour, 33(3), 259-269.

Schaalma, H.P., Aarø, L.E., Flisher, A.J., Mathews, C., Kaaya, S., Onya, H., Ragnarson, A., \& Klepp, K.I. (2009). Correlates of intention to use condoms among Sub-Saharan African youth: The applicability of the theory of planned behaviour. Scandinavian Journal of Public Health, 37 (Suppl 2), 87-91.

SchoolNet Uganda (n.d.). (http://schoolnetuganda.sc.ug/about-schoolnet-uganda).

Semugoma, P., Beyrer, C., \& Baral, S. (2012). Assessing the effects of anti-homosexuality legislation in Uganda on HIV prevention, treatment, and care services. Journal of Social Aspects of HIV/AIDS, 9(3), 172-176.

Shaw, D. (2009). Access to sexual and reproductive health for young people: Bridging the disconnect between rights and reality. International Journal of Gynecology and Obstetrics, 106, 132-136.

Sheeran, P., Abraham, C., \& Orbell, S. (1999). Psychosocial correlates of heterosexual condom use: A meta-analysis. Psychological Bulletin, 125, 90-132. 
Sheeran, P., \& Taylor, S. (1999). Predicting intentions to use condoms: A meta-analysis and comparison of the Theories of Reasoned Action and Planned Behaviour. Journal of Applied Social Psychology, 29, 1624-75.

Singh, S. (1998). Adolescent Childbearing in Developing Countries: A Global Review. Studies in Family Planning, 29(2), 117-136.

Sjödahl, S. (ed.) (2004). Reality Counts. Focusing on Sexuality and Rights in the Fight against HIV/AIDS. Retrieved from the Swedish Association for Sexuality Education (RFSU) website: http://www.rfsu.se/Bildbank/Dokument/Sexualpolitik/realitycounts.pdf?epslanguage $=e n$

Slaymaker, E., Bwanika, J. B., Kasamba, I., Lutalo, T., Maher, D., \& Todd, J. (2009). Trends in age at first sex in Uganda: evidence from Demographic and Health Survey data and longitudinal cohorts in Masaka and Rakai. Sexually Transmitted Infections, 85(Suppl I):i12-i19.

Stakic, S., Zielony, R., Bodiroza, A., \& Kimzeke, G. (2003). Peer education within a frame of theories and models of behaviour change. Entre Nous. The European Magazine for Sexual and Reproductive Health, 56, 4-6.

Stanton, B. F., Li, X., Kahihuata, J., Fitzgerald, A. M., Neumbo, S., Kanduuombe, G., Ricardo, I.B., ... Zimba, R.F. (1998). Increased protected sex and abstinence among Namibian youth following a HIV risk-reduction intervention: a randomized, longitudinal study. AIDS, 12, 2473-2480.

Stockman, J. K., Lucea, M. B., \& Campbell, J. C. (2012). Forced Sexual Initiation, Sexual Intimate Partner Violence and HIV Risk in Women: A Global Review of the Literature. AIDS and Behavior, 17, 832-847.

Stone, N., \& Ingham, R. (2006). Young people and sex and relationships education. In R. Ingham \& P. Aggleton (Eds.), Promoting Young People's Sexual Health. International Perspectives (pp. 41-60). New York, US: Routledge.

Strange, V., Allen, E., Oakley, A., Bonell, C., Johnson, A., \& Stephenson, J. (2006). Integrating Process with Outcome Data in a Randomized Controlled Trial of Sex Education Evaluation. London: Sage Publications. 
Taffa, N., Klepp, K-I., Sundby, J., \& Bjune, G. (2002). Psychosocial determinants of sexual activity and condom use intention among youth in Addis Ababa, Ethiopia. International Journal of STD \& AIDS, 13, 714-719.

Thomas, F. (2007). Global rights, local realities: Negotiating gender equality and sexual rights in the Caprivi region, Namibia. Culture, Health \& Sexuality, 9, 599-614.

Tumwesigye, N. M., Ingham, R., \& Holmes, D. (2008). The dynamics of secondary abstinence among unmarried young people: Analysis of event history calendar data from Kabale and Mukono in Uganda. The African Statistical Journal, 6, 67-86.

Uganda Aids Commission (2007). Young people, Health, HIV, AIDS and Development. A Case for Uganda. Kampala: UAC.

Uganda AIDS Commission (2010). Uganda UNGASS Progress Report, Jan 2008-Dec 2009. Kampala: UAC.

Uganda AIDS Commission (2012). Global AIDS Response Progress Report. Country Progress Report Uganda. Kampala: UAC.

Uganda Bureau of Statistics (UBOS) and Macro International Inc. (2007). Uganda Demographic and Health Survey 2006. Maryland, USA: Calverton.

Uganda Bureau of Statistics (UBOS) and ICF International Inc. (2012). Uganda Demographic and Health Survey 2011. Kampala, Uganda: UBOS and Calverton, Maryland: ICF International Inc.

Ukwuani, F. A., Tsui, A. O., \& Suchindran, C. M. (2003). Condom use for preventing HIV infection/AIDS in Sub-Saharan Africa: A comparative multilevel analysis of Uganda and Tanzania. Journal of Acquired Immune Deficiency Syndromes, 34(2), 203-213. UNAIDS (1997). Impact of HIV and Sexual Health Education on the Sexual Behaviour of Young People: a Review Update. Geneva, Switzerland: UNAIDS.

UNAIDS (2004). 2004 report on the global HIV/AIDS epidemic : 4th global report. Geneva, Switzerland: UNAIDS. Available at: http://data.unaids.org/GlobalReports/Bangkok 2004/unaidsbangkokpress/gar2004html/gar2004_00_en.htm. UNAIDS (2008). Report on the global HIV/AIDS Epidemic. Geneva, Switzerland: UNAIDS. UNAIDS (2010). Global Report. UNAIDS report on the global AIDS epidemic 2010. Geneva, Switzerland: UNAIDS.

UNAIDS (2012). World AIDS Day Report. Geneva: UNAIDS. 
UNESCO (2009). International technical guidance on sexuality education: an evidenceinformed approach for schools, teachers and health educators. Paris: UNESCO.

UNFPA (1997). The state of the world population 1997. Chapter 3: Sexual and reproductive self-determination. New York: UNFPA. Retrieved from: http://www. unfpa.org/swp/1997/swpmain.htm

UNFPA (2007). Giving Girls Today and Tomorrow. Breaking the Cycle of Adolescent Pregnancy. NY, USA: UNFPA.

UNFPA (2010). Comprehensive Sexuality Education: Advancing Human Rights, Gender Equality and Improved Sexual and Reproductive Health. A Report on an International Consultation to Review Current Evidence and Experience. Bogotá, Columbia.

United Nations (1995). Report of the international conference on population and development. Cairo 5-13 September 1994. New York: UN.

United Nations (2006). Demographic Yearbook 2006. New York: United Nations. United Nations Statistics Division.

Vanable, P. A., Carey, M.P ., Blair, D. C., \& Littlewood, R. A. (2006). Impact of HIV-related Stigma on Health Behaviors and Psychological Adjustment Among HIV-Positive Men and Women. AIDS and Behavior, 10(5), 473-482.

Van Breukelen, G. J. P. (2006). ANCOVA versus change from baseline: more power in randomized studies, more bias in nonrandomized studies. Journal of Clinical Epidemiology, 59, 920-925.

Vermeer, W., Bos, A. E. R., Schaalma, H. P., Kaaya, S., \& Mbwambo, J. (2009). Social and cognitive variables predicting voluntary HIV counseling and testing among Tanzanian medical students. Patient Education and Counseling, 75, 135-140.

Versteegen, M. (2009). The role of teachers in the delivery of sexuality education: complete and truthful? A process evaluation of a sexual reproductive health and rights programme in Uganda. Master Thesis, Leiden University, the Netherlands.

Visser, M. J., Schoeman, J. B., \& Perold, J. J. (2004). Evaluation of HIV/AIDS Prevention in South African Schools. Journal of Health Psychology, 9(2), 263-280. 
Wabwire-Mangen, F., Odiit, M., Kirungi, W., Kisitu, D.K., \& Wanyama, J.O. (2009). Uganda HIV modes of transmission and prevention response analysis. Final Report. Kampala: Uganda National AIDS Commission. Retrieved from: http:// siteresources.worldbank.org/INTHIVAIDS/Resources/375798-1103037153392/ UgandaMoTCountrySynthesisReport7April09.pdf.

Wagman, J., Baumgartner, J. N., Geary, C. W., Nakyanjo, N., Ddaaki, W. G., Serwadda, D., ... Wawer, M.J. (2009). Experiences of Sexual Coercion Among Adolescent Women: Qualitative Findings From Rakai District, Uganda. Journal of Interpersonal Violence, 24(12), 2073-2095.

Walker, S. A., \& Avis, M. (1999). Common reasons why peer education fails. Journal of Adolescence, 22(4), 573-577.

Wallace, S. A., Miller, K. S., \& Forehand, R. (2008). Perceived Peer Norms and Sexual Intentions among African American Preadolescents. AIDS Education and Prevention, 20(3), 360-369.

Webb, T. L., \& Sheeran, P. (2006). Does changing behavioural intentions engender behaviour change? A meta-analysis of the experimental evidence. Psychological Bulletin, 132(2), 249-268.

Wellings, K., Collumbien, M., Slaymaker, E., Singh, S., Hodges, Z., Patel, D., \& Bajos, N. (2006). Sexual behaviour in context: a global perspective. (series: Sexual and Reproductive Health 2). Lancet, 368, 1706-28.

WHO (2010b). Social determinants of sexual and reproductive health. Informing future research and programme implementation. Geneva: WHO Press.

WHO (2002). Defining sexual health Report of a technical consultation on sexual health, 28-31 January 2002, Geneva, Switzerland: WHO.

WHO (2010a). Developing sexual health programmes. A framework for action. Geneva, Switzerland: WHO Press.

WHO (2010b). Social determinants of sexual and reproductive health. Informing future research and programme implementation. Geneva: WHO Press. 
Wiefferink, C. H., Poelman, J., Linthorst, M., Vanwesenbeeck, I., van Wijngaarden, J. C. M., \& Paulussen, T. G. W. (2005). Outcomes of a systematically designed strategy for the implementation of sex education in Dutch secondary schools Outcomes of a systematically designed strategy for the implementation of sex education in Dutch secondary schools. Health Education Research, Theory \& Practice, 20(3), 323-333.

Wight, D., Raab G. M., Henderson, M., Abraham, C., Buston, K., Hart, G., \& Scott, S. (2002). Limits of teacher delivered sex education: interim behavioural outcomes from randomised trial. BMJ, 32, 1430.

Wight, D., \& Obasi, A. (2003). Unpacking the 'black box': the importance of process data to explain outcomes. In J. Stephenson, J. Imrie, C. Bonnell (Eds.), Effective Sexual Health Interventions - Issues in Experimental Evaluation (pp.151-166). Oxford: Oxford University Press.

Wolff, B., Blanc, A. K., \& Gage, A. J. (2000). Who Decides? Women's Status and Negotiation of Sex in Uganda. Culture, Health \& Sexuality, 2(3), 303-322.

World Population Foundation (WPF) (2010). Annual Report. Utrecht, the Netherlands: WPF.

Ybarra, M. L., Kiwanuka, J., Emenyonu, N., \& Bangsberg, D.R. (2006). Internet Use among Ugandan Adolescents: Implications for HIV Intervention. PLoS Med, 3(11), e433.

Yeboah, E., \& Maticka-Tyndale, E. (2008). Factors influencing the timing of first sexual intercourse among young people in Nyanza, Kenya. International Family Planning Perspectives, 34(4), 177-188.

Zaba, B., Pisani, E., Slaymaker, E., Boerma, J. T. (2004). Age at first sex: understanding recent trends in African demographic surveys. Sexually Transmitted Infections, 80: ii28-ii35.

Ziebland, S. (2004). The importance of being expert: the quest for cancer informationon the Internet. Social Science \& Medicine, 59, 1783-1793. 


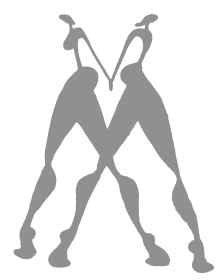

Summary 
Although adolescents are generally among the healthiest population group in Sub-Sahara African (SSA) countries, they are vulnerable when it comes to securing their sexual and reproductive health and rights (SRHR). Ugandan adolescents, and in particular girls, are exposed to risks of early initiation of sexual intercourse, HIV/AIDS and STI infections, unintended pregnancies, and coercive sex. A number of factors contribute to this vulnerability, both at the individual level (e.g., lack of awareness, insufficient knowledge about SRHR, negative attitudes and norms and a low self-efficacy of (safe) sexual behaviours) and at the contextual level (e.g., socio-cultural norms towards gender issues, low socio-economic status, legal framework).

Comprehensive rights-based sex education (CRSE), including the promotion of consistent condom use, is an important intervention strategy in addressing sexual and reproductive health issues of adolescents and in preventing sexual health problems such as unplanned pregnancies, HIV/AIDS, and sexually transmitted infections (STIs). CRSE addresses these issues within a rights framework, focusing on human rights issues and power dynamics within (intimate) relationships, and aims at empowering young people, improving personal expression and self-respect, and increasing satisfaction, communication, safety and health.

CRSE is likely to be most effective when it is based upon theory- and evidence-based needs assessments and intervention strategies. Understanding the socio-cognitive determinants of safe sex behaviour helps to specify which behaviour and determinants should be addressed to obtain the desired health outcomes (i.e., delaying (first) sexual intercourse and using condoms when sexually active based on own well-informed decision making), to prioritize age-, gender- or other segments, and to select behaviour change methods that are tailored to the needs of the target population and fit the intervention context. Also, understanding the socio-cultural, economic and political context in which sexual behaviour takes place, is essential to connect SRHR to the local context in which they have to take form. Understanding these contextual factors helps to determine which multi-sectoral approach should be taken and which supporting environments should be promoted.

The current thesis describes the results of different studies conducted to increase our insight in socio-cognitive determinants of safe sex behaviour among Ugan- 
dan adolescents, to explore the views of Ugandan adolescents on SRHR in their own daily socio-cultural, economic and political context, and to assess the effectiveness and implementation context of the comprehensive rights-based sex education programme The World Starts With Me (WSWM) which has been implemented in Uganda at secondary school students since 2003.

Chapter 1 gives an introduction to the main topics relevant in this thesis. It discusses the sexual and reproductive health and behaviour of Ugandan adolescents, current knowledge of determinants of safe sexual behaviour and of contextual factors influencing sexual behaviour and risks. Also, the current knowledge on the effectiveness of school-based sex education programmes is discussed in the introduction. The introduction also gives an overview of the studies presented in this dissertation.

Chapter 2 describes a cross-sectional study examining predictors of the intention to use a condom and the intention to delay sexual intercourse among secondary school students (aged 12-20) in Uganda. A school-based sample was drawn from 48 secondary schools throughout Uganda. Participants $(N=1978)$ completed a survey in English measuring beliefs regarding pregnancy, STIs and HIV and AIDS, attitudes, social norms and self-efficacy towards condom use and abstinence/delay, intention to use a condom and intention to delay sexual intercourse. As secondary sexual abstinence is one of the recommended ways for preventing HIV, STDs and unplanned pregnancies among the sexually experienced, participants with and without previous sexual experience were compared. For adolescents without sexual experience (virgins), self-efficacy, perceived social norms and attitude towards condom use predicted the intention to use condoms. Among those with sexual experience (non-virgins), only perceived social norm was a significant predictor of the intention to use a condom. The intention to delay sexual intercourse was, however, predicted similarly for both groups, with attitudes, perceived social norm and self-efficacy being significant predictors. This study has established relevant predictors of intentions of safe sex among young Ugandans and has shown that the intention to use condoms is motivated by different factors depending on previous sexual experience. A segmented approach to intervention development and implementation is thus recommended. 
Chapter 3 presents the findings of a qualitative explorative study, comparing universal declared SRHR with the local realities of young people in Uganda. This is done by analysing statements of Ugandan adolescents extracted from Focus Group Discussions (FGD) relating to two sexual and reproductive health rights central in this research: (1) the right of young people to complete and accurate information and (2) the right to self-determination. Discrepancies between these universally formulated SRHR and the (political, economic and community) context young Ugandans live in were found. Consequently, it is argued how comprehensive rights-based sex education could take this local reality into account in order to make SRHR meaningful for Ugandan adolescents. For example, to make the right to sexual self-determination meaningful for young people, CSRE should be accompanied by a political lobby to ensure that this right is enshrined in the Ugandan law and that the defilement law is changed accordingly.

The final two studies focus on the implementation and effectiveness of WSWM. Chapter 4 reports the results of a process evaluation of WSWM. Drawing on quantitative and qualitative data provided by teachers, factors associated with dose delivered (number of lessons implemented) and fidelity of implementation (implementation according to the manual) were examined, as well as the main barriers and facilitators of implementation. Teachers' confidence in teaching WSWM was negatively associated with dose delivered. Confidence in educating and discussing sexuality issues in class was positively associated with fidelity of implementation, whereas the importance teachers attach to open sex education showed a negative association with fidelity. Main barriers for implementing WSWM were lack of time, unavailability of computers, lack of student manuals and lack of financial support and rewards. Other barriers for successful implementation were related to high turnover of staff, insufficient training and guidance. Teachers' beliefs/attitudes towards sexuality of adolescents, condom use and sex education were found to be important factors in implementing WSWM. A supportive school management, supportive colleagues and students as well as the availability of sufficient and good quality student- and teacher manuals, were identified as main facilitators of implementation.

Chapter 5 reports on the effects of WSWM on socio-cognitive determinants of safe sex behaviour (delay; condom use and non-coercive sex). A large scale survey 
was conducted both before and immediately after the intervention among students in intervention and comparison groups. A mixed model repeated measures analysis was performed to assess the effectiveness of the programme on the main socio-cognitive determinants of safe sex behaviour at post-test. A similar post-hoc comparison was made between schools based on completeness and fidelity of implementation of WSWM. Positive effects were found on beliefs regarding what could or could not prevent pregnancy, the perceived social norm towards delaying sexual intercourse, and the intention to delay sexual intercourse. Furthermore, significant positive effects were found on attitudes, self-efficacy and intention towards condom use and on self-efficacy in dealing with sexual violence (pressure and force for unwanted sex). A reversed effect of intervention was found on knowledge scores relating to non-causes of HIV (petting, fondling and deep kissing). A follow-up comparison between intervention schools based on completeness of the programme implementation revealed that almost all significant positive effects disappeared for those schools that only implemented up to 7 out of 14 lessons. Another follow-up analysis on the basis of implementation fidelity showed that schools with a "partial" fidelity score yielded more significant positive effects than schools with a "full" fidelity of implementation score. These results suggest that it is important to implement the programme completely and that the programme itself should be flexible enough for teachers to use and adapt it according to the specific context in which they have to implement the programme (i.e. adapting to accommodate specific questions and needs of the students and coping with the limited time and resources available), without having to skip lessons.

The study showed an intervention effect on a number of socio-cognitive determinants. However, the effectiveness of WSWM could be improved by giving more systematic attention to the context in which such a programme is to be implemented.

Finally, in Chapter 6, a summary and general discussion of the main research findings of the studies reported in this dissertation are given. This chapter also reflects on the methods used to conduct the research reported in this dissertation and provides recommendations for suggestions for future research. In addition, recommendations for comprehensive rights-based sex education programmes in a Sub-Saharan context are made. 


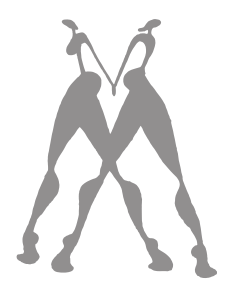

Samenvatting 
Hoewel over het algemeen jongeren in Sub-Saharisch Afrika de meest gezonde bevolkingsgroep vormen, zijn ze kwetsbaar als het gaat om hun Seksuele en Reproductieve Gezondheid en Rechten (SRGR). Oegandese adolescenten, vooral meisjes, hebben te maken met risico's van vroegtijdige start van seksuele gemeenschap, HIV/AIDS en seksueel overdraagbare aandoeningen (SOA), ongeplande zwangerschappen en gedwongen seks. Een aantal factoren draagt bij aan deze kwetsbaarheid, zowel op individueel niveau (bijvoorbeeld gebrek aan bewustwording en een tekort aan kennis over SRGR, negatieve normen en houding en een lage zelfeffectiviteit ten aanzien van veilig seksueel gedrag), alsook op omgevingsniveau (bijvoorbeeld sociaal-culturele normen ten aanzien van gender, lage sociaal economische status en een gebrek aan ondersteunende politiek-juridische kaders).

Seksuele voorlichting op scholen is een belangrijke interventiestrategie om seksuele en reproductieve gezondheid van jongeren te bevorderen en hun rechten op dit terrein te waarborgen. Seksuele voorlichting die gebaseerd is op basale grondrechten van de mens zoals vastgelegd in de Universele Verklaring van de Rechten van de Mens, richt zich vooral op de machtsdynamiek binnen (intieme) relaties tussen man en vrouw (jongen en meisje) en heeft tot doel jongeren te ondersteunen bij hun seksuele ontwikkeling en bij het maken van seksueel verantwoorde keuzen.

Seksuele voorlichting op scholen heeft de meeste kans van slagen wanneer deze gebaseerd is op een gedegen theoretische kader en gevoed wordt door een bewezen effectieve aanpak. Het kennen van de sociaal-cognitieve determinanten van veilig vrijen is richtinggevend bij het bepalen van welke specifieke gedragingen en welke determinanten van die gedragingen centraal moeten staan om het gewenste gedrag te bevorderen, in dit geval het uitstellen van (de eerste) geslachtsgemeenschap of, wanneer jongeren seksueel actief zijn, het consistent en correct gebruiken van een condoom. Op basis van een behoeftenonderzoek kunnen gedragsveranderingsmethodieken worden gekozen die zich specifiek richten op de behoeften van de doelgroep en passen bij de interventiecontext. Tot slot, het begrijpen van de sociaal-culturele, economische en politieke context waarin seksueel gedrag plaatsvindt is essentieel om te bereiken dat de SRGR van jongeren ook in hun dagelijkse level daadwerkelijk gestalte kan krijgen. 
Dit proefschrift beschrijft de resultaten van verschillende studies die zijn uitgevoerd om meer inzicht te krijgen in de sociaal-cognitieve factoren van veilig vrijen onder Oegandese jongeren en hun kijk op SRGR binnen hun dagelijkse sociaalculturele, economische en politieke context. Daarnaast beschrijft dit proefschrift de resultaten van een effect- en procesevaluatie van het seksueel voorlichtingsprogramma The World Starts With Me (WSWM), dat sinds 2003 in Oeganda op middelbare scholen wordt uitgevoerd.

Hoofdstuk 1 is een introductie op de belangrijkste thema's die centraal staan in dit proefschrift. Het bespreekt de seksuele en reproductieve gezondheidssituatie van Oegandese adolescenten en de huidige kennis over determinanten van veilig vrijen en over contextuele factoren die seksueel gedrag en risico's beïnvloeden en bepalen. Ook wordt de huidige kennis van de effectiviteit van seksuele voorlichting op scholen besproken. Deze introductie sluit af met een overzicht van de studies die in dit proefschrift worden gepresenteerd.

Hoofdstuk 2 beschrijft een determinantenstudie met betrekking tot (1) de intentie om seksuele gemeenschap uit te stellen tot later en (2) de intentie een condoom te gebruiken wanneer jongeren besluiten seks te hebben. De studie is uitgevoerd onder Oegandese middelbare scholieren in de leeftijd van 12 tot 20 jaar. Er is een selecte steekproef van 48 middelbare scholen verspreid over Oeganda getrokken. Leerlingen ( $N=1978)$ vulden een enquête in het Engels in over overtuigingen met betrekking tot zwangerschap, seksueel overdraagbare aandoeningen (SOA's) en HIV en AIDS, houding, sociale normen en eigen-effectiviteit ten aanzien van condoomgebruik en onthouding/uitstel van seks. In Oeganda komt "secondary delay" relatief vaak voor, dat wil zeggen dat een jongere na eerst seksueel actief te zijn geweest besluit zich voor onbepaalde tijd te onthouden van seks. "Secondary delay" wordt in Oeganda algemeen beschouwd als een aan te bevelen methode om ongewenste zwangerschappen en SOA en HIV infecties te voorkomen. In de studie zijn jongeren die nog maagd zijn vergeleken met jongeren die seksueel actief zijn. Voor jongeren die nog maagd waren bleken zelfeffectiviteit, waargenomen sociale normen en attitude ten aanzien van condoomgebruik significante voorspellers van de intentie tot condoomgebruik te zijn. Onder de seksueel actieve jongeren bleek alleen de waargenomen sociale 
norm een significante voorspeller van de intentie tot condoomgebruik. Voor beide groepen bleken de houding, de waargenomen sociale normen en de zelfeffectiviteit ten aanzien van de intentie om seksuele gemeenschap uit te stellen significant. Deze studie heeft relevante factoren geïdentificeerd voor het beïnvloeden van de intentie tot het uitstellen van seksuele gemeenschap en de intentie tot condoomgebruik en heeft aangetoond dat de inhoud van deze factoren verschilt afhankelijk van de seksuele ervaring van de respondenten. Op basis van deze resultaten is een gesegmenteerde benadering op basis van seksuele ervaring aanbevolen voor de ontwikkeling en uitvoering van toekomstige gezondheidsinterventies.

In Hoofdstuk 3 worden de resultaten gepresenteerd van een kwalitatieve exploratieve studie waarbij de universeel verklaarde SRGR vergeleken is met de lokale dagelijkse realiteit waarin Oegandese jongeren opgroeien. Deze vergelijking kwam tot stand door uitspraken van Oegandese jongeren te analyseren die zij deden tijdens Focus Groep Discussies met betrekking tot twee seksuele en reproductieve rechten die centraal stonden in de studie: (1) het recht van jongeren op complete en accurate informatie over hun SRGR en (2) het recht op seksuele zelfbeschikking. De studie vond een aantal verschillen tussen deze rechten en de (sociaal-politieke en economische) dagelijkse context van Oegandese jongeren. Op basis van de resultaten zijn er aanbevelingen gedaan over hoe seksuele voorlichting rekening kan houden met deze lokale realiteit, zodat SRGR voor Oegandese jongeren betekenisvol kunnen worden. Het recht op seksuele zelfbeschikking bijvoorbeeld is gebaat bij een politieke omgeving waarbij jongeren het recht hebben zelf te beslissen of ze seksueel actief zijn of niet. Dit betekent dat seksuele voorlichting die uitgaat van dit recht gepaard zou moeten gaan met een politieke lobby om het recht van jongeren op seksualiteit in de wet te waarborgen.

De laatste twee studies hebben betrekking op de implementatie en effectiviteit van WSWM. Hoofdstuk 4 rapporteert de resultaten van een procesevaluatie van WSWM. Op basis van kwantitatieve en kwalitatieve data van leraren zijn factoren vastgesteld die samenhangen met het aantal lessen dat is geïmplementeerd, de zogenaamde dosering en de nauwkeurigheid of getrouwheid van programma-implementatie, dat wil zeggen in hoeverre het programma volgens het programmahandboek is geïmplementeerd. 
Daarnaast zijn de belangrijkste barrières en faciliterende factoren die een succesvolle implementatie bevorderen onderzocht.

De mate waarin leraren zeker van zichzelf waren om WSWM te begeleiden/ onderwijzen correleerde negatief met het aantal lessen dat zij hadden verzorgd. Met andere woorden, de onzekerheid leidde tot een mindere mate van implementatie van het programma. Leraren die zeker waren in het onderwijzen en bediscussiëren van seksualiteit en seksuele onderwerpen in de klas hielden zich beter aan het volgen van de manual. Er werd een negatieve relatie gevonden tussen de mate waarin leraren open seksuele voorlichting belangrijk vonden en de mate waarin ze het programma volgens de handleiding implementeerden. Een reden dat leraren bij tijd en wijle afwijken van het handboek zou kunnen zijn dat zij de voorlichting beter wensten te laten aansluiten bij de behoeften van de leerlingen. De belangrijkste barrières voor de implementatie van WSWM waren gebrek aan tijd, gebrek aan computers, gebrek aan handboeken voor studenten en het gebrek aan financiële ondersteuning en vergoeding. Andere barrières voor een succesvolle implementatie bleken een hoge mate van personeelswisseling en onvoldoende training en ondersteuning van leraren. Ook bleken de overtuigingen en de houding van leraren ten aanzien van seksualiteit van jongeren, van condoomgebruik en van seksuele voorlichting belangrijke factoren te zijn bij de implementatie van WSWM. Een ondersteunend schoolmanagement, ondersteunende collega's en leerlingen, alsmede de beschikbaarheid van voldoende en kwalitatief hoogwaardige handboeken voor studenten en leraren, waren volgens de leraren de belangrijkste faciliterende factoren van implementatie.

Hoofdstuk 5 rapporteert de effecten van WSWM op de sociaal-cognitieve determinanten van veilig vrijgedrag. Een grootschalige survey werd uitgevoerd voorafgaand aan de start van de interventie en direct na de implementatie van het programma onder jongeren in de interventiegroep $(N=853)$ en jongeren in de vergelijkingsgroep $(N=1011)$. Om de effectiviteit van WSWM vast te stellen werd er een analyse uitgevoerd met behulp van een herhaalde-metingenanalyse (mixed model repeated measurement analysis). Significante positieve effecten werden gevonden voor overtuigingen hoe je ongewenste zwangerschap wel of niet zou kunnen voorkomen, voor de waargenomen sociale norm ten aanzien van het uitstellen van 
geslachtsgemeenschap, en voor de intentie seksuele gemeenschap uit te stellen. Daarnaast werden er positieve effecten gevonden voor de houding, de zelfeffectiviteit en de intentie ten aanzien van condoomgebruik en voor de zelfeffectiviteit van het omgaan met seksuele dwang (het vermijden van risicovolle situaties en het kunnen weigeren van ongewenste seks). Een omgekeerd interventie-effect werd gevonden voor kennis ten aanzien van factoren die geen HIV kunnen veroorzaken, zoals tongzoenen.

Vervolgens is er een vergelijking gemaakt in effectiviteit van WSWM tussen de scholen die 10 tot 14 lessen hadden geïmplementeerd en scholen die niet verder zijn gekomen dan les 7. Bijna alle eerder gevonden positieve effecten verdwenen voor die scholen die slechts tot les 7 waren gekomen. Een andere vergelijking werd gemaakt tussen scholen die het programma volgens het handboek hadden geïmplementeerd en scholen die dat deels volgens het handboek hadden gedaan. Hieruit bleek dat scholen die zich niet volledig aan het handboek hadden gehouden meer significante positieve effecten opleverden dan de scholen die zich volledig aan het handboek hadden gehouden. Deze resultaten suggereren dat het belangrijk is om het programma in zijn geheel te implementeren. Tegelijkertijd moet het programma flexibel genoeg zijn om door de leraren aangepast te kunnen worden om bijvoorbeeld beter aan te kunnen sluiten bij de behoeften van de jongeren waardoor de effectiviteit van het programma verbeterd wordt.

Hoofdstuk 6 bevat een samenvatting en een algemene discussie van de belangrijkste resultaten van de studies die in dit proefschrift centraal staan. Daarnaast wordt de onderzoeksmethodologie besproken en worden er suggesties voor vervolgonderzoek gedaan. Tot slot bevat dit hoofdstuk aanbevelingen voor seksuele voorlichtingsprogramma's in sub-Sahara Afrika. 


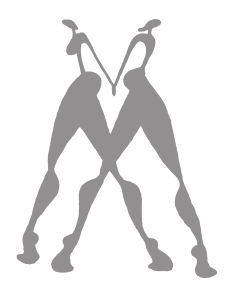

\section{Dankwoord/}

Acknowledgements 
Eind 2006 speelde ik voor het eerst met de gedachte een proefschrift te schrijven. Frits, mijn toenmalige leidinggevende, dacht dat ik het wel kon en stimuleerde mij een voorstel te maken. Dat deed ik en het werd goedgekeurd. Frits, bedankt voor je steun en betrokkenheid, en voor het feit dat je me het zetje in de rug gaf toen ik dat nodig had. Een lange zoektocht begon naar de juiste focus, een praktische toepassing, een promotor en co-promotoren die mij wilden begeleiden. Deze laatsten werden gevonden in Herman, Arjan en Rico. Herman was degene die mij vanaf het begin af aan meegaf dat ik mijn proefschrift moest zien als een eerste stap binnen de wetenschap, niet meer en niet minder. 'Niet moeilijker doen dan nodig, maak er geen levenswerk van', was zijn goede advies. Dat advies heb ik proberen op te volgen, ook nadat Herman veel te vroeg en plotseling overleed in 2009. Zonder Herman was dit proefschrift er niet gekomen.

Rob, jij werd mijn nieuwe promotor. Bedankt voor de tijd die je voor me vrijmaakte, de gedegen feedback die ik van je kreeg, de wondere wereld van de statistiek die je me hebt leren kennen en het vertrouwen dat je me gaf dat het allemaal goed zou komen. Arjan, naast je grote betrokkenheid bij het onderzoek had je ook altijd oog voor de persoon achter de onderzoeker. Bedankt voor je gastvrijheid en de gezellige avonden als ik in Maastricht was. Ik kon jou altijd bellen met een vraag en als ik het even niet meer zag zitten. Met je positieve benadering was ik aan het eind van zo'n gesprek weer vol goede moed en zag ik de volgende te nemen stap beter voor me. Je feedback was altijd goed, "to the point" en ik hoefde er nooit lang op te wachten. Rico, jij kunt als geen ander de vinger op de zere plek leggen waardoor ik weer verder kon als ik vastliep. Bedankt voor je inspiratie, vertrouwen en begeleiding in de kunst van het doen van kwalitatief onderzoek. Drie heren aan mijn zijde; zonder jullie, was het schrijven van dit proefschrift bij een intentie gebleven.

De focus en een praktische toepassing werden eind 2007 gevonden bij the World Population Foundation, waar ik samen met jou Joanne begin 2008 de WSWM evaluatie in vier landen ter hand nam. Een groot en veel te ambitieus onderzoeksproject, waarvan we nu achteraf zeggen "dat hadden we anders moeten doen". Ik heb er veel 
van geleerd. Ik heb onze samenwerking als positief en stimulerend ervaren en het was fijn om frustraties, zorgen, maar ook de hoogtepunten te kunnen delen. Ellen, jij hebt een belangrijke bijdrage geleverd aan de procesevaluatie, niet alleen in Oeganda, maar ook in de andere landen waar we het evaluatieonderzoek uitvoerden. Ontzettend bedankt daarvoor. Jo, Henk en Linette van WPF, bedankt voor het vertrouwen en de support die jullie mij hebben gegeven om dit onderzoek over The World Starts With Me in Oeganda uit te voeren.

Ans, het grootste deel van de periode dat ik aan mijn proefschrift werkte was jij mijn leidinggevende bij het Windesheim Honours College (WHC). Dank voor je betrokkenheid en steun. Ik heb dat heel erg gewaardeerd. Mijn collega's bij WHC, en in het bijzonder Edith, Elaine, Lineke en Tineke: heel erg veel dank voor jullie geduld en collegialiteit. Jullie hebben mij nooit het gevoel gegeven dat het werken aan mijn proefschrift jullie tot last was, terwijl ik weet dat dat soms wel het geval was. Windesheim wil ik bedanken dat ik dit proefschrift grotendeels in werktijd heb mogen schrijven. Ik hoop dat mijn promotie van toegevoegde waarde zal blijken voor de studenten van Windesheim Honours College aan wie ik les geef en waarvoor ik onderwijsprogramma's ontwikkel.

I would also like to thank the students and teachers of the secondary schools in Uganda who participated in the study. Without their effort to fill in questionnaires and to talk with me in Focus Group Discussions, there would not be a thesis. I can only hope that the results of my research give further input to the improvement of comprehensive sex education in Uganda. Special thanks to Allen Nansubuga from SchoolNet Uganda who was responsible for a big part of the practical organisation of the research in the field.

Ik heb veel hulp gehad van drie studenten die in het kader van hun afstudeeronderzoek belangrijke delen van het veldwerk hebben helpen uitvoeren. Billy, Vera en Marieke, heel erg veel dank voor jullie uitstekende werk. Ik vond het een leerzame en leuke ervaring om met jullie samen te werken. Mariëlla, jou wil ik bedanken voor al het 
regelwerk dat je voor me deed op de universiteit, zodat ik goed kon werken als ik in Maastricht was. Coen, bedankt voor je mooie omslagontwerp en André, bedankt voor de broodnodige punten op de "i's" van de Nederlandse samenvatting.

Mijn sociale leven heeft de afgelopen jaren op een laag pitje gestaan, maar echte vriendschap bleef overeind. En er was toch altijd wel tijd voor een filmpje, etentje of gezellig stapavondje, ook met mijn zussen en schoonfamilie. Mijn proefschrift kwam niet vaak ter sprake, heel verfrissend! Er zijn andere dingen in het leven die veel belangrijker zijn. Een speciaal dankwoord voor mijn lieve ouders die er altijd voor mij en mijn gezin zijn, zonder oordeel, met veel liefde; papa en mama, jullie zijn goud waard en ik ben diep dankbaar dat jullie mijn ouders zijn.

En dan, mijn gezin: Pieter, Joep, Lulu en Coen. Volgens mij vinden jullie het best jammer dat het proefschrift af is en ik niet af en toe naar Oeganda of Maastricht verdwijn. Lieve Pieter, je kent me als geen ander en bent al 30 jaar mijn persoonlijke "goeroe". Je hebt me altijd in alles wat ik doe de ruimte gegeven en gesteund. Je hebt een hekel aan dankwoorden, maar ik schrijf het voor 1 x zwart op wit: heel veel dank daarvoor. Lieve Joep, Lulu en Coen, jullie zijn mijn grootste inspiratiebron als het om loslaten, relativeren én genieten gaat. En dat zijn toch wel de belangrijkste lessen die ik de afgelopen jaren heb geleerd. Daar kan geen enkel proefschrift tegenop. 


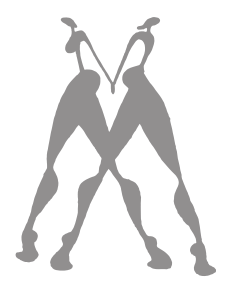

About the Author 
Liesbeth Rijsdijk was born on August 6th, 1963 in 's- Gravenhage, the Netherlands. She lived with her parents and sisters in Tanzania and Ghana and returned to the Netherlands when she was four. She completed secondary school in Nijmegen in 1981 (VWO at St. Canisius College) and studied Health Promotion at Rijksacademie Nieuw Rollecate (Bachelor degree in 1985) in Deventer. She continued her studies at the Catholic University in Nijmegen where she obtained her propaedeutic diploma in Cultural Anthropology in 1986, and her Masters in Communication Sciences in 1990.

In 1990, Liesbeth started her professional career as a communication staff member of the International University of Applied Sciences Larenstein in Velp, the Netherlands. In 1994, she moved with her husband Pieter and son Joep to Apia, Western Samoa, where she got a position as an Associate Expert in Communication at the UNESCO Regional Office for the Pacific States. She was responsible for writing project proposals for funding and for the planning, monitoring and evaluation of media development projects in the Pacific. In 1997, the family, added by daughter Lulu, moved to Almaty, Kazakhstan, where Liesbeth got a position at the UNESCO Regional Office for Central Asia. She coordinated the communication programme involving media development projects and was involved in HIV/AIDS prevention programmes in Central Asia.

Upon return to the Netherlands in 1999, Liesbeth took a position at the Dutch Council for Child Protection, first as a policy member in prevention (1999-2002) and later as the managing director of the Communications Department at the headquarters in Utrecht (2002-2003). In October 2003, Liesbeth started her career in higher education, as a lecturer in communication at Windesheim University of Applied Sciences in Zwolle. Currently, she is the coordinator year 3 and 4 of Windesheim Honours College (WHC), where she also teaches Social and Behavioural Change, Entertainment Education and Advanced Research. She is a member of the curriculum committee and involved in developing courses and projects for the WHC programme. She is currently also involved in the research programme on Social Innovation at Windesheim. In 2008, Liesbeth started her PhD research as an external candidate at Maastricht University, while working at WHC. 